\title{
Behavioral activation for depressed patients in Iran: Effectiveness, predictors and mediators in the context of a randomized trial
}

Citation for published version (APA):

Moradveisi, L. (2015). Behavioral activation for depressed patients in Iran: Effectiveness, predictors and mediators in the context of a randomized trial. [Doctoral Thesis, Maastricht University]. Datawyse / Universitaire Pers Maastricht. https://doi.org/10.26481/dis.20150108Im

Document status and date:

Published: 01/01/2015

DOI:

10.26481/dis.20150108Im

Document Version:

Publisher's PDF, also known as Version of record

Please check the document version of this publication:

- A submitted manuscript is the version of the article upon submission and before peer-review. There can be important differences between the submitted version and the official published version of record.

People interested in the research are advised to contact the author for the final version of the publication, or visit the DOI to the publisher's website.

- The final author version and the galley proof are versions of the publication after peer review.

- The final published version features the final layout of the paper including the volume, issue and page numbers.

Link to publication

\footnotetext{
General rights rights.

- You may freely distribute the URL identifying the publication in the public portal. please follow below link for the End User Agreement:

www.umlib.nl/taverne-license

Take down policy

If you believe that this document breaches copyright please contact us at:

repository@maastrichtuniversity.nl

providing details and we will investigate your claim.
}

Copyright and moral rights for the publications made accessible in the public portal are retained by the authors and/or other copyright owners and it is a condition of accessing publications that users recognise and abide by the legal requirements associated with these

- Users may download and print one copy of any publication from the public portal for the purpose of private study or research.

- You may not further distribute the material or use it for any profit-making activity or commercial gain

If the publication is distributed under the terms of Article 25fa of the Dutch Copyright Act, indicated by the "Taverne" license above, 


\section{Behavioural Activation for Depressed Patients in Iran}

Effectiveness, Predictors and Mediators in the context of a Randomized Trial

\section{Latif Moradveisi}




\section{Acknowledgment}

The studies in the present dissertation were supported by Maastricht University and Kurdistan University of Medical Sciences.

ISBN 9789461593948

CCopyright Latif Moradveisi, Maastricht 2015 


\title{
Behavioural Activation for Depressed Patients in Iran: \\ Effectiveness, Predictors and Mediators in the Context of a Randomized Trial
}

\author{
Dissertation \\ to obtain a degree of Doctor at Maastricht University, \\ on the authority of the rector magnificus, \\ Prof. Dr. L.L.G Soete \\ in accordance with the decision of the board of deans, \\ to be defended in public \\ on Thursday 8 January 2015, at 14:00 hours
}

by

Latif Moradveisi

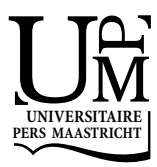




\section{Supervisors}

Prof. Dr. A. Arntz

Prof. Dr. M.J.H. Huibers

\section{Assessment Committee}

Prof. dr. P.E.H.M. Muris (chairman)

Prof. dr. F.Peeters

Prof. dr. A.T. Jansen

Prof. dr. C.L.H. Bockting (University of Groningen)

Prof. dr. W.J.M.J. Cuijpers (VU University) 


\section{Table of contents}

$\begin{array}{lll}\text { Chapter } 1 & \text { General introduction } & 7\end{array}$

$\begin{array}{lll}\text { Chapter } 2 & \text { Behavioural activation and antidepressant medication for } & 17\end{array}$ depression in Iran: a randomized trial

Chapter 3 The influence of comorbid personality disorder on the effects of behavioural activation vs. antidepressant medication for major depressive disorder: results from a randomized trial in Iran

Chapter 4 The influence of patients' preference/attitude towards psychotherapy and antidepressant medication on the treatment of major depressive disorder

Chapter 5 The influence of patients' attributions of the immediate effects of treatment of depression on long-term effectiveness of behavioural activation and antidepressant

Chapter 6 General discussion

Overview Valorization addendum

Summary

Acknowledgments

Curriculum Vitae 

Chapter 1

General Introduction 

Major depressive disorder (MDD) is a common mental health problem (American Psychiatric Association, 1994). Most clinicians have treated numerous clients suffering from MDD. Depression influences 18 million people in the United States alone (Schrof, 1999). It is estimated that between 3 and 20 percent of the adult population have met criteria for MDD at some point in their lives, with 20 to 50 percent of these people experiencing more than one episode. Life time prevalence rates among women are about twice as high as among men (see for a review Kuehner, 2003). No gender difference in rates of recurrence has been reported in adult samples (Kuehner, 2003), but the recurrence rate of depression is twice as high in girls compared to boys in late adolescent (Curry et al., 2010). In short, it can be concluded that high depression rates and recurrence rates among people from all ages can pose a significant social problem that should be taken seriously.

Much research and clinical expertise has been dedicated to try to understand and treat MDD. Effective psychological and pharmacological treatments for treating MDD are developed. Beck's cognitive approach $(1967,1979)$ is one of the most influential models of conceptualization and treatment of depression. In recent years, interest in behavioural approaches such as Behavioural Activation (BA) in the treatment of depression has been rapidly increasing. Clinical studies of BA have offered evidence that the early behavioural approach of Lewinsohn (1974) and colleagues (Lewinsohn et al., 1976) was on the correct track in treating depression. It is worth remembering that the findings of Jacobson and colleagues' component analysis study (1996) that BA did as well as cognitive therapy were replicated in Dimidjian and colleagues' treatment for depression study (2006). Both of the mentioned studies were conducted at Washington University where BA was developed. Until now, only one study outside the BA's developers site was published (Ekers et al., 2011). This study compared BA with treatment as usual in a routine clinical setting in England (BA delivered by nurse practitioners). BA in the study was superior to treatment as usual. The evidence base for the effectiveness of a treatment is increased if results are replicated in other settings, with new therapists and patients. BA seems to be a very effective treatment based on a rather simple model and using techniques that appeal as easy to learn to non-specialist mental health care providers. This makes BA an attractive candidate for implementation in usual health care, even in countries with limited resources. However, the evidence base for this is still limited and needs more empirical tests.

\section{Definition of Behavioural Activation}

The BA approach we used was based on two manuals (Martell et al., 2001, 2010). BA interventions are behaviourally based and specific cognitive interventions are prohibited. BA is an idiographic and functional approach. By means of functional analysis of 
behaviours therapists try to find with the patients the functions of their behaviours and the contingencies that may maintain the behaviours. The focus of BA model is on activation, and on the barriers to activation. BA does not include cognitive treatment; BA therapists help patients to break the avoidance patterns and to schedule activities that will support them to move toward their goals in life.

\section{Behavioural Activation}

As said, in BA, interventions are behaviourally based and specific cognitive interventions are prohibited. BA pays attention to the participant's behaviours and the environmental context in which the behaviours take place; acting according to goals, not to feelings; and using an activity chart to schedule people's activities and monitor the relationship between activity and mood. Identifying secondary problems such as avoidance patterns and depressive ruminations are important because they play a role in maintaining and exacerbating depression. Most depressed individuals withdraw from social activities, thereby minimizing distress in the short-term but creating longterm difficulties. BA tries to break down the pattern of avoidance and utilizes behavioural techniques to target depressive ruminations. BA therapists deal with ruminating as behaviour rather than exploring or challenging the contents of ruminative thoughts.

Beck and colleagues (1979) also used behavioural activation in the treatment manual for cognitive therapy for depressed patients. In the early stages of cognitive therapy for individuals who are more severely depressed, behavioural activation is used. For severely depressed individuals, behavioural activation can be used as the primary strategy more than cognitive intervention. Behavioural activation in cognitive therapy involves first teaching the patients to monitor their behaviours through an activity schedule. Patients should rate their mood during each hour on the activity schedule or provide an overall rating for the whole day. After several days of monitoring, the therapist and the patient evaluate the activity schedule and the patient is helped to draw conclusions about the relationship between the activity level and mood.

After the patient has learned to monitor activity, the therapist offers a list of activities to the patients that may provide a sense of either mastery or pleasure (or both). In cognitive therapy, these activity schedules and mastery/pleasure ratings are considered as homework. As patient's mood improves, standard cognitive interventions are applied and the patient is taught to use the dysfunctional thought record (Beck et al., 1979) to record automatic thoughts (Beck, 1976) and to explore and find alternative responses to the automatic thoughts.

The Behavioural activation goal in our study is activating patients, not changing or modifying cognitions. In this model, it is believed that a behavioural formulation is suf- 
ficient without offering underlying structures such as core beliefs or schemas. According to Ferster (1973), there is a strong theoretical rationale for increasing activities that will allow patients to break through a passive approach to life and help them to increase contact with positive, natural reinforcement. BA therapists try to help the patients to increase the opportunity for behaviours to be reinforced positively. However, BA therapists do not look for a full cause-and-effect relationship to explain how depression originated and is maintained in the patient's life. Most schools of treatment for psychological disorders follow the basic philosophy that they look for a working mechanism inside the depressed patient and try to influence that alleged mechanism to lessen the depression. Cognitive, psychodynamic, and biological therapists with very different theoretical orientations share this basic philosophy of mechanism and try to find the solution for solving psychological problems inside the individual (e.g, changing cognitions, unresolved conflicts or biological deficits). BA and other contextual therapists on the other hand look at the whole life of the person and the context in which the person lives (environment), try to reengage the person in the events of her or his life and pay less attention to what is going on inside the person (Martell et al., 2001).

The reasons for choosing BA and its comparison condition ADM as treatments of depression are as follows. The first one was the availability of a new psychological treatment (BA) for treating MDD with high effectiveness. This approach had not been tested in other countries than the United States and Great Britain, and only one study was published testing its effectiveness outside the site where BA was developed. This promising new approach inspired us to test its application in Iran. The second reason was the expectancy that the strategies and techniques in this approach could be delivered by non-expert professionals in clinical settings, and would therefore be easy to implement.

The most accessible and widely available treatment for psychological disorders throughout Iran (and perhaps the whole world) is medication treatment. Thus, in Iran the usual treatment for MDD in mental hospitals and private practice by psychiatrists is ADM. Therefore, we chose to compare BA to ADM.

A randomized control trial ( $R C T)$ is the most rigorous and important method of determining whether a cause-effect relation exist between treatment and outcome and also for evaluating cost-effectiveness of a treatment. Non-RCTs can find associations between an intervention and an outcome (Sibbald, B., \& Roland, M., 1998), but they cannot detect the probability that the association was caused by a third factor related to intervention and outcome. An RCT guaranties no systemic differences between factors associated with participants, specified or non-specified, that may influence outcome. Therefore, we chose the RCT as our method to test BA vs ADM for depression in an Iranian context to prevent the influence of such third factors in the treatment and outcome of the study. 
Many studies concluded that personality pathology comorbid with depression negatively affects the treatment of MDD (Hardy et al., 1995; Newton-Howes, Tyrer, \& Johnson, 2006; Sato, Sakado, Sato, \& Morikawa, 1994). However, two recent reviews reported that comorbidity of personality disorder with MDD does not have a negative influence on treatment outcome (Kool et al., 2005; Mulder, 2002). Until now, there has been a controversy among clinicians and researchers in this field over whether comorbidity of personality disorder with MDD has or does not have a negative influence on depression treatment. Therefore, we tested the influence of personality disorder comorbid with MDD in our participants on the outcome of treatment conditions.

Concerning the influence of patient preferences for psychological or medication conditions in treatment of MDD, the literature reports mixed results. Some studies did not find an association between preference and outcome of depression treatment (Bedi et al., 2000; Dunlop et al., 2012; Kwan, Dimijian, \& Rezvi, 2010), while others found an association between preference and outcome of depression treatment (Kocsis et al., 2009; Mergl et al., 2011; Patricia et al., 2005). To help to further clarify this issue, we tested patients' preference for psychological or medication treatments on the influence of treatment outcome.

The final question addressed in this dissertation is the influence of patients' attributions of the immediate effect of depression treatment on long-term effectiveness of BA and ADM. One important study by Basoglu et al. (1994) investigated attributions that patients with panic disorder and agoraphobia made for their improvement. At follow-up in week 43, those patients who at week 8 attributed their improvement to medication reported more severe problems and relapse in comparison to those patients who attributed their improvement to their own efforts. Another study by Biondi and Picardi, (2003) that investigated panic disorder with agoraphobia produced the same findings. It is hypothesized that similar attributional processes play a role in the differential long-term effects of CBT vs. ADM in depression treatment. So far, no previous study tested this hypothesis. In our study, we tested the influence of patients' attributions of the immediate effect of depression treatment on long-term effectiveness of $B A$ and $A D M$ and then investigated whether attributions also mediated the longterm difference between BA and ADM.

\section{Main aims of the dissertation}

The first aim of the present dissertation was to investigate whether behavioural activation would be a viable alternative for ADM for depressed people. We compared BA to ADM (Treatment As Usual in Iran) in terms of dropout rates, effectiveness in reducing 
depressive symptoms, response and remission rates, and relapse at approximately one year. The second aim was whether depressed participants with co-morbid PD differ in symptom reduction over time compared to those without comorbid PD, and whether $B A$ and $A D M$ differ in this respect. The third aim was to investigate whether depressed patients' preference for and attitudes towards psychological treatment and ADM influence symptom reduction in the course of one year and dropout from treatment. The final purpose was whether the attribution of treatment effects to the self predicts better long-term effects of treatment, even when controlled of the short-term effects of treatment; and whether attributions to medication would predict relatively worse long-term effects.

\section{Outline of the dissertation}

As this study was the first study in a non-Western country to compare BA and ADM, chapter 2 covers an evaluation of the effectiveness of BA and treatment as usual (ADM) for MDD in routine clinical practice in Iran. More specifically, the study reported in chapter 2 aimed to test BA versus ADM in terms of dropout rates, effectiveness in reducing depressive symptoms, response and remission rates, and relapse at approximately one year. We also assessed whether initial depression severity would moderate condition differences.

The findings of the study investigating effects of comorbid personality disorder (PD) are presented in chapter 3 . We investigated whether depressed participants with comorbid $\mathrm{PD}$ differ in symptom reduction over time compared to those without comorbid PD, and whether BA and ADM differ in this respect. We also compared participants with comorbid PD to those without PD in terms of dropout rates, and reduction of depressive symptoms during and after short-term treatments and at approximately one year. Furthermore, we examined the association of the number of PDtraits with dropout and outcome.

Chapter 4 addresses the influence of patients' preferences/attitudes towards psychological treatment or antidepressant medication. Our focus was on whether depressed patients' preference for and attitudes towards psychological treatment and ADM influence symptom reduction in the course of one year and dropout from treatment. If so, this would have important implications for optimal matching of treatments and patients.

Chapter 5 covers the results of attribution of treatment effects to the self and to medication. We studied whether attribution of treatment effects to the self predicts better long-term effects of treatment, even when controlled of the short-term effects of treatment and whether attributions mediated the long-term difference between BA 
and ADM. Similarly, we investigated whether attribution to medication predicts longterm effects and mediates the long-term differences between the two conditions.

Chapter 6 offers a general discussion and summary of the findings presented in chapters 2-5. The chapter commences with a summary and integration of the findings of the four studies. Next, a critical discussion is offered, including a discussion of the limitations of the studies, scientific, clinical and societal implications, and future prospects. The dissertation ends with a general summary. 


\section{References}

American Psychiatric Association (1994). Diagnostic and Statistical Manual of Mental Disorders (4 ${ }^{\text {th }}$ edn) (DSM-IV). Washington, DC. APA.

Ba, M., Marks, I. M., Kili, C., Brewin, C. R., \& Swinson, R. P. (1994). Alprazolam and exposure for panic disorder with agoraphobia. Attribution of improvement to medication predicts subsequent relapse. The British Journal of Psychiatry, 164(5), 652-659.

Beck, A. T. (1967). Depression: Clinical, experimental, and theoretical aspects. Philadelphia. University of Pennsylvania Press.

Beck, A., Rush, A., Shaw, B., \& Emery, G. (1979). Cognitive Therapy of Depression. New York, NY. Guilford Press. Social Psychology Bulletin, 28(2), 184.

Bedi, N., Lee, A., Harrison, G., Chilvers, C., Dewey, M., Fielding, K., Miller, P., Gretton, V., Williams, I.,Churchil, R., \& Duggan, C. (2000). Assessing effectiveness of treatment of depression in primary care partially randomised preference trial. The British Journal of Psychiatry, 177(4), 312-318.

Biondi, M., \& Picardi, A. (2003). Attribution of improvement to medication and increased risk of relapse of panic disorder with agoraphobia. Psychotherapy and Psychosomatics, 72 (2), 110-111.

Curry, J., Silva, S., Rohde, P., Ginsburg, G., Kratochvil, C., Simons, A., Kirchner, J., May, D., Kennard, B., Mayes, T., Feeny, N., Albano, A, M., Lavanier, S., Reinecke, M., Jacobs, R., Becker-Weidman, E., Weller, E., Emslie, G., Walkup, J., Kastelic, E., Burns, B., wells, K., \& March, J. (2011). Recovery and recurrence following treatment for adolescent major depression. Archives of General Psychiatry, 68(3), 263-269.

Dimidjian, S., Hollon, S. D., Dobson, K. S., Schmaling, K. B., Kohlenberg, R. J., Addis, M. E., Gallop,R., McGlinchey, J.B., Markley, D. K., Gollan, J.K., Atkins, D.C., Dunner. D. L., \& Jacobson, N. S. (2006). Randomized trial of behavioural activation, cognitive therapy, and antidepressant medication in the acute treatment of adults with major depression. Journal of Consulting and Clinical Psychology, 74(4), 658-70.

Dunlop, B. W., Kelley, M. E., Mletzko, T. C., Velasquez, C. M., Craighead, W. E., \& Mayberg, H. S. (2012). Depression beliefs, treatment preference, and outcomes in a randomized trial for major depressive disorder. Journal of Psychiatric Research, 46(3), 375-381.

Ekers, D., Richards, D., McMillan, D., Bland, J. M., \& Gilbody, S. (2011). Behavioural activation delivered by the non-specialist: phase II randomised controlled trial. The British Journal of Psychiatry, 198(1), 66-72.

Ferster, C. B. (1973). A functional analysis of depression. American Psychologist, 28(10), 857-870.

Hardy, G. E., Barkham, M., Shapiro, D. A., Stiles, W. B., Rees, A., \& Reynolds, S. (1995). Impact of Cluster C personality disorders on outcomes of contrasting brief psychotherapies for depression. Journal of Consulting and Clinical Psychology, 63(6), 997-1004.

Jacobson, N. S., Dobson, K. S., Truax, P. A., Addis, M. E., Koerner, K., Gollan, J. K., Gortner, E., \& Prince, S. E. (1996). A component analysis of cognitive-behavioural treatment for depression. Journal of Consulting and Clinical Psychology, 64(2), 295-304.

Kocsis, J. H., Leon, A. C., Markowitz, J. C., Manber, R., Arnow, B., Klein, D. N., \& Thase, M. E. (2009). Patient preference as a moderator of outcome for chronic forms of major depressive disorder treated with nefazodone, cognitive behavioural analysis system of psychotherapy, or their combination. Journal of Clinical Psychiatry, 70 (3), 354-361.

Kool, S., Schoevers, R., de Maat, S., Van, R., Molenaar, P., Vink, A., \& Dekker, J. (2005). Efficacy of pharmacotherapy in depressed patients with and without personality disorders: a systematic review and metaanalysis. Journal of Affective Disorders, 88(3), 269-278.

Kuehner, C. (2003). Gender differences in unipolar depression: an update of epidemiological findings and possible explanations. Acta Psychiatrica Scandinavica, 108(3), 163-174.

Kwan, B. M., Dimidjian, S., \& Rizvi, S. L. (2010). Treatment preference, engagement, and clinical improvement in pharmacotherapy versus psychotherapy for depression. Behaviour Research and Therapy, 48 (8), 799-804. 
Lewinsohn, P. M. (1974). A behavioural approach to depression. In R. M. Friedman \& M. M. Katz (Eds.), The psychology of depression: Contemporary theory and research (pp. 157-185). New York: Wiley.

Lewinsohn, P. M., Biglan, A., \& Zeiss, A. S. (1976). Behavioural treatment of depression. In P. O. Davidson (Ed.), The behavioural management of anxiety, depression and pain (pp. 91-146). New York: Brunner/Mazel.

Lin, P., Campbell, D. G., Chaney, E. F., Liu, C. F., Heagerty, P., Felker, B. L., \& Hedrick, S. C. (2005). The influence of patient preference on depression treatment in primary care. Annals of Behavioural Medicine, 30 (2), 164-173.

Martell, C. R., Addis, M. E., \& Jacobson, N. S. (2001). Depression in context: Strategies for guided action. New York. W.W. Norton \& Co.

Martell, C. R., Dimidjian, S., \& Herman-Dunn, R. (2010). Behavioural activation for depression: A clinician's guide. New York. Guilford Press.

Mergl, R., Henkel, V., Allgaier, A. K., Kramer, D., Hautzinger, M., Kohnen, R., Coyne, J \& Hegerl, U. (2010). Are treatment preferences relevant in response to serotonergic antidepressants and cognitive-behavioural therapy in depressed primary care patients? Results from a randomized controlled trial including a patients' choice arm. Psychotherapy and Psychosomatics, 80 (1), 39-47.

Mulder, R. T. (2002). Personality pathology and treatment outcome in major depression: a review. American Journal of Psychiatry, 159(3), 359-371.

Newton-Howes, G., Tyrer, P., \& Johnson, T. (2006). Personality disorder and the outcome of depression: meta-analysis of published studies. The British Journal of Psychiatry, 188(1), 13-20.

Sato, T., Sakado, K., Sato, S., \& Morikawa, T. (1994). Cluster A personality disorder: A marker of worse treatment outcome of major depression? Psychiatry Research, 53 (2), 153-159.

Schrof, J. M., \& Schultz, S. (1999). Melancholy Nation. US News and World Report, 57.

Sibbald, B., \& Roland, M. (1998). Understanding controlled trials. Why are randomised controlled trials important? British Medical Journal, 316 (7126), 201. 


\section{Chapter 2}

\section{Behavioural activation and antidepressant medication for treating depression in Iran: randomized trial ${ }^{1}$}

1 Published as: Moradveisi, L., Huibers, M. J., Renner, F., Arasteh, M., \& Arntz, A. (2013). Behavioural activation v. antidepressant medication for treating depression in Iran: randomised trial. The British Journal of Psychiatry, 202(3), 204-211. 


\section{Abstract}

\section{Background}

Behavioural activation (BA) might be a viable alternative to antidepressant medication (ADM) for major depressive disorder (MDD).

\section{Aims}

To compare the effectiveness of behavioural activation and treatment as usual (TAU, antidepressant medication) for major depressive disorder in routine clinical practice in Iran.

\section{Method}

Patients with major depressive disorder $(\mathrm{N}=100)$ were randomized to 16 sessions of behavioural activation ( $n=50$ ) or antidepressant medication $(n=50)$ (IRCT138807192573N1). The main outcome was depression, measured with the Beck Depression Inventory (BDI) and the Hamilton Rating Scale for Depression (HRSD), and assessed at $0,4,13$ and 49 weeks.

\section{Results}

Symptom reduction was stronger in behavioural activation group than in the TAU group on both the BDI and the HRSD at 13 and 49 weeks in multilevel analysis. Baseline depression severity was a moderator, with relatively better effects of behavioural activation who were more severely depressed. Also, there was better retention in the behavioural activation than in the TAU group.

\section{Conclusions}

Behavioural activation is a viable and effective treatment for people with major depressive disorder, especially for those who are more severely depressed, and it can successfully be disseminated into routine practice settings in a non-Western country such as Iran. 


\section{Introduction}

Major Depressive Disorder is a common mental health problem ${ }^{1}$ and there are many studies that have demonstrated the effectiveness of antidepressant medication in treating it. ${ }^{2,5}$ Thus, antidepressants have become the standard treatment for depression $^{6,7}$, despite their limitations such as problems with side-effects, refusal by patients, and considerable relapse after discontinuation. Psychological treatments might offer a viable alternative. ${ }^{8,10}$ In non-Western countries, the use of antidepressant medication is even more common, due to the limited availability of psychotherapy. This means there is a need for better dissemination of relatively simple but effective psychological treatments. Behavioural Activation is such a candidate, given its effectiveness and relatively simple protocol.

Behavioural activation is based on the behavioural component of cognitive behaviour therapy (CBT) for treating depression. ${ }^{11} \mathrm{~A}$ study by Jacobson et $a l^{12}$ found that BA was as effective as the full CBT-package for treating depression. In a subsequent trial by the same research group, Dimidjian et al. compared behavioural activation with antidepressant medication and $\mathrm{CBT} .{ }^{13}$ They found that behavioural activation was as effective as antidepressant medication, and even outperformed CBT, especially in individual who were more severely depressed. Moreover, participants originally treated with antidepressant medication and later a pill-placebo experienced more relapse at the 2-year follow-up than individuals treated with behavioural activation or CBT. ${ }^{8}$ Thus, for prevention of recurrence, behavioural activation and CBT were superior to medication discontinuation. Finally, more recently, two meta-analyses unanimously found that behavioural activation interventions are as effective as CBT. ${ }^{14,15}$

One study by Ekers et $\mathrm{al}^{16}$ compared behavioural activation (delivered by nurse practitioners) with treatment as usual (TAU) in a routine clinical setting. The behavioural activation was superior to TAU and the authors concluded that it might be easily delivered by mental health professionals.

The present study was set up to document the effectiveness of behavioural activation when implemented in clinical practice in Iran after a short period of training. We reasoned that there is a need for psychological treatment for depression in Iran as an alternative to antidepressant medication, which although readably available is not very popular due to its association with mental illness (creating stigma) and because of side effects. From the effective psychological treatments available, behavioural activation seemed the most easy to implement. Training and treatment were based on the published behavioural activation protocol ${ }^{17,18}$, and none of the developers of behavioural activation or specialists were involved.

Thus, the study's aim was to investigate whether a simple psychological treatment, behavioural activation, would be a viable alternative to antidepressant medica- 
tion for people with depression, when implemented in a non-Western country. We compared behavioural activation to antidepressant medication (TAU) in Iran including drop-out rates, effectiveness in reducing depressive symptoms, response and remission rates, and relapse at approximately 1 year. We also assessed whether initial depression severity would moderate condition differences.

\section{Method}

\section{Participants}

Participants included 100 people with depression between the ages of 18 to 70 years, selected from 174 referrals. Inclusion criteria were: a primary diagnosis of MDD according to the DSM-IV-TR ${ }^{19}$, confirmed by the Structured Clinical Interview for the DSM-IV-TR (SCID-CT) ${ }^{20}$; a score of $\geq 19$ on the Beck Depression Inventory (BDI-II) ${ }^{21}$ and $\geq 14$ on the 17-item Hamilton Rating Scale for Depression (HRSD); ${ }^{22}$ written consent to participate in the study. Exclusion criteria were: a life-time diagnosis of bipolar disorder or psychosis; organic brain syndrome; intellectual disability; substantial and imminent suicide risk; a current (within the past six months) diagnosis of alcohol or drug misuse or dependence, or a positive toxicology screen; a primary diagnosis other than major depressive disorder; unfavourable antidepressant medication response within the preceding year; unstable medical condition; medication use that would complicate antidepressant medication administration; known allergy to antidepressant medication/Sertraline; pregnancy or a plan to become pregnant; inability to read and understand the study's instruments.

Participants were recruited through the media and poster advertisements ( $n=45$; $45 \%)$, word of mouth $(n=8 ; 8 \%)$, and referral from other mental health clinics ( $n=28$; $28 \%$ ), and general practitioners ( $n=19 ; 19 \%)$. Participants diagnosed with major depressive disorder through telephone screening were referred to the Mental Health Clinic for further assessment. Psychiatrists confirmed diagnoses and checked the eligibility of participants who completed the assessment. When eligibility was confirmed, participants were randomized by an independent coordinator using a computergenerated list based on blocks of four, created by an independent statistician at Kurdistan University of Medical Science. Fifty participants were randomly assigned to each condition (IRCT138807192573N1). Baseline HRSD was used as severity-index. Participants were allocated to therapists and psychiatrists based on their availability.

The study was powered to detect a medium to large effect between conditions with $80 \%$ power and a 0.05 level of significance. To compensate for participants dropping-outs, the original $\mathrm{N}=80$ on which the power analysis was based was extended to $\mathrm{N}=100$. The study was approved by the local Medical Ethics Committee of Kurdistan 
University of Medical Science. Participants were treated at Ghods Psychiatric Hospital and the Mental Health Clinic in Sanandaj, Kurdistan Province. The study was conducted from November 2009 to September 2011.

\section{Therapists}

Behavioural activation was conducted by two counsellor psychologists and the first author (L.M); they had six years clinical experience on average. Training in behavioural activation was provided by L.M., a master-level psychologist, in $20 \mathrm{~h}$ over 2 weeks. Therapists participated in an on-site consultation meeting held almost twice a week, led by L.M. Four psychiatrists provided TAU (antidepressant medication); all were certified with an average of approximately five years of clinical experience. Training and supervision was provided by (M.A.).

\section{Treatments}

\section{Behavioural activation}

The behaviour activation model we used was based on the two behavioural activation manuals by Martell et al. ${ }^{17,18}$ Behavioural activation interventions are behavioural based and specific cognitive interventions are prohibited. The focus is on the participant's behaviours and the environmental context in which the behaviours take place; acting according to goals, not to feelings; and using an activity chart to schedule people's activities and follow the relationship between activity and mood. Identifying secondary problems such as avoidance patterns and depressive ruminations are important because they play a role in maintaining depression. Most depressed individuals withdraw from social activities, thereby minimizing distress in short-term but creating long-term difficulties. Behavioural activation tries to break down the pattern of avoidance and utilises behavioural techniques to target depressive ruminations. BA therapists deal with ruminating as a behaviour rather than engaging or challenging the contents of ruminative thoughts.

Participants received 16 sessions during 12 weeks (as opposed to the earlier trials by Jacobson and Dimidjian ${ }^{12,13}$ in which patients received 24 sessions in 4 months). For the first 4 weeks there were two sessions per week, and for the following 8 weeks there was one session per week.

\section{Treatment As Usual (antidepressant medication)}

For TAU, we chose Sertraline, a selective serotonin reuptake inhibitor (SSRI), the major reason being the availability of it in Iran. The participants in the TAU group were not offered any psychotherapeutic interventions by their psychiatrists but they established treatment rapport to support the continuation of treatment. For the first 4 weeks of 
the treatment, participants received one session per week and for the next 8 weeks they received one session every 2 weeks. For the first session, psychiatrists saw participants for $20 \mathrm{~min}$ and the following sessions lasted approximately $10 \mathrm{~min}$ to monitor pharmacotherapy and side-effects. The maximum dosage of Sertraline was $100 \mathrm{mg}$ per day. In week 1, participants in the TAU group received $25 \mathrm{mg} /$ daily of Sertraline, the dosage in week 2 increased to $50 \mathrm{mg}, 75 \mathrm{mg}$ in week 4, and $100 \mathrm{mg}$ in week 6 up to week 12. Psychiatrists could reduce the dosage temporarily in the case of side-effects and then increase the dosage to the previous level. The maximum dosage was $100 \mathrm{mg}$ because as a rule, higher dosages do not increase antidepressant efficacy, but may increase the risk of adverse effects. ${ }^{23}$ All decisions about the dosage were made by the supervising psychiatrist (M.A). After 12 weeks, it was up to participants whether they continued or stopped antidepressant medication. In case of continuation, participants had to pay for their medication.

\section{Measures}

Diagnostic measures (baseline)

We used SCID-I, ${ }^{20}$ which is a semi-structured clinical interview to evaluate DSM-IV-TR axis-I diagnoses. We used SCID-II ${ }^{24}$ for diagnosing personality disorders (effects are reported separately).

\section{Outcome measures}

The modified 17-item HRSD and the 21-item BDI-II), both assessing depressive symptoms, were outcome measures. The HRSD was taken by evaluators who were masked to group. Assessments were conducted at baseline, and at 4, 13 and 49 weeks. In accordance with the Dimidjian study ${ }^{13}$, each session was preceded by the HRSD (TAU group) and the BDI-II (Behavioural activation group), administered by assistants who were masked to group; for participants who dropped out of treatment we used these data as the last observation in the analysis (see statistical analysis).

\section{Baseline severity}

The baseline HRSD was used as the depression severity measure.

\section{Response, remission, and relapse criteria}

Response indicates substantial symptomatic improvement, whereas remission means that symptoms lie within the normal range. Response was defined as at least $50 \%$ reduction from baseline on both the HRSD and BDI-II. Remission was defined as scores of $\leq 7$ on the HRSD and $\leq 10$ on BDI. Relapse was defined as no longer meeting the remission criterion at 49 weeks in patients who remitted at 13 weeks. 


\section{Statistical Analysis}

Multilevel analysis was used to estimate change in depression severity over time. We applied intention-to-treat analysis, with the HRSD and BDI as dependent variables, by including all available scores. Visual inspection suggested linear and quadratic time effects; we therefore modelled time linearly and quadratically. We used an unstructured covariance structure for repeated measures, with time, time-squared and condition as fixed effects. We computed effect sizes for continuous outcomes (Cohen's $d$ and $r)^{2}$ from the multilevel estimates (Cohen's $d=$ (baseline mean- mean at time i) $/(v$ baseline variance) for within-condition change; $d=$ (difference between means of condition at time i)/ $\sqrt{ }$ (residual variance at time i) for differences between conditions; $r=v$ $(F /(F+d . f))$. For participants who dropped out of treatment, we used the last observation with the associated time, and estimated missing HRSD scores (for those in behavioural activation group) from changes on the BDI, and missing BDI scores (for those in the TAU) from changes on the HRSD, using regression derived equations (1 BDI unit=1.3 HRSD unit). All treatment drop-out took place before the mid-treatment assessment. We repeated the analyses without these estimates as a sensitivity analysis.

For the test of moderation by baseline symptom severity, we entered time, timesquared, the standardized baseline severity score and condition as covariates in the model. There was only one baseline assessment and therefore we included HRSD and BDI scores at weeks 4, 13 and 49 as dependent variables in the analyses. The baseline severity $X$ condition and the time $X$ baseline severity $X$ treatment condition interactions are of primary interest in this analysis. In all models, treatment condition was centred at $-1 / 2$ and $1 / 2$. Analyses were conducted using SPSS19 for windows.

\section{Results}

\section{Participant Enrolment}

Figure 1 shows the flow of participants. Of 174 participants originally recruited, 74 did not meet selection criteria: 20 did not meet selection criteria for major depressive disorder, 9 had too low severity on the HRSD or BDI-II, 37 had other primary diagnoses/problems (generalized anxiety disorder $(n=10)$, medical problems $(n=6)$, PTSD ( $n$ $=1)$, bipolar disorder $(n=5)$, substance dependence $(n=3), \operatorname{OCD}(n=8)$, positive alcohol screen $(n=3)$, opiate addiction more than four years $(n=1)$ ), antidepressant use unsuccessfully for more than 2 years $(n=5)$, and 3 were pregnant. The remaining 100 were randomised.

2 Cohen's $d=$ (Baseline mean - mean at time i) / (SQRT baseline variance); $r=$ SQRT $(F /(F+d f)$ ) 


\section{Baseline}

Table 1 presents baseline sample demographic and clinical characteristics. Treatment groups were not significantly different on any of the variables.

\section{Drop out}

Five participants (10\%) dropped out of behavioural activation, as opposed to 15 participants (30\%) from TAU group. In the behavioural activation group, two people were dissatisfied with behavioural activation and three had personal reasons (one due to participant's business; two moved to another city). In TAU group, 12 participants were dissatisfied with medication (3 due to medication side-effects), 2 distrusted privacy of participation, and 1 believed no one could solve their problem. The difference in dropout rate was significant, $\chi^{2}(1, N=100)=6.25, p=0.012, O R=3.86(95 \% \mathrm{Cl}[1.28$, 11.64]).

\section{Change in depression severity over time}

Table 2 and 3 summarizes the multilevel analyses results. In the primary analyses (Table 2), there were significant interactions between time and condition (HRSD $r=0.29$; $\mathrm{BDI} r=0.25$ ) and between time-squared and condition (HRSD $r=0.29 ; B D I r=0.22$ ). Figure 2 shows the stronger symptom reduction over time on the HRSD and BDI in BA at 13 weeks.

Within condition changes (all $p<0.001$; Cohen's d's with baseline SD) are presented in table 4. Response to behavioural activation differed from TAU at 13 weeks (mean HRSD-change difference $3.09,(95 \% \mathrm{Cl} 1.71 ; 4.47), d=0.88, p<0.001$; mean BDI-change difference $3.34(95 \% \mathrm{Cl} 1.63 ; 5.05), d=0.76, p<0.001)$ and at 49 weeks (mean HRSDchange difference $2.34(95 \% \mathrm{Cl} 0.84 ; 3.84), d=0.61, p<0.001$; mean BDI-change difference $3.67(95 \% \mathrm{Cl} 2.10 ; 5.23), \mathrm{d}=0.92, \mathrm{p}<0.001)$; statistics based on residual variances at 13 and 49 weeks respectively.

Sensitivity analyses yielded comparable results (Table 2 ). We also tested whether referral type influenced the results by adding referral (self-referral vs. professionalreferral) as covariate (Table DS1 and Figure DS1). The table reports results after deleting NS higher order effects involving referral. In short, referral did not change the condition by time (squared) effects, but professionally referred patients had a steeper decrease in depressive symptoms in the behavioural activation than self-referred patients, with no (HRSD) or the opposite effect (BDI) in the TAU group. 


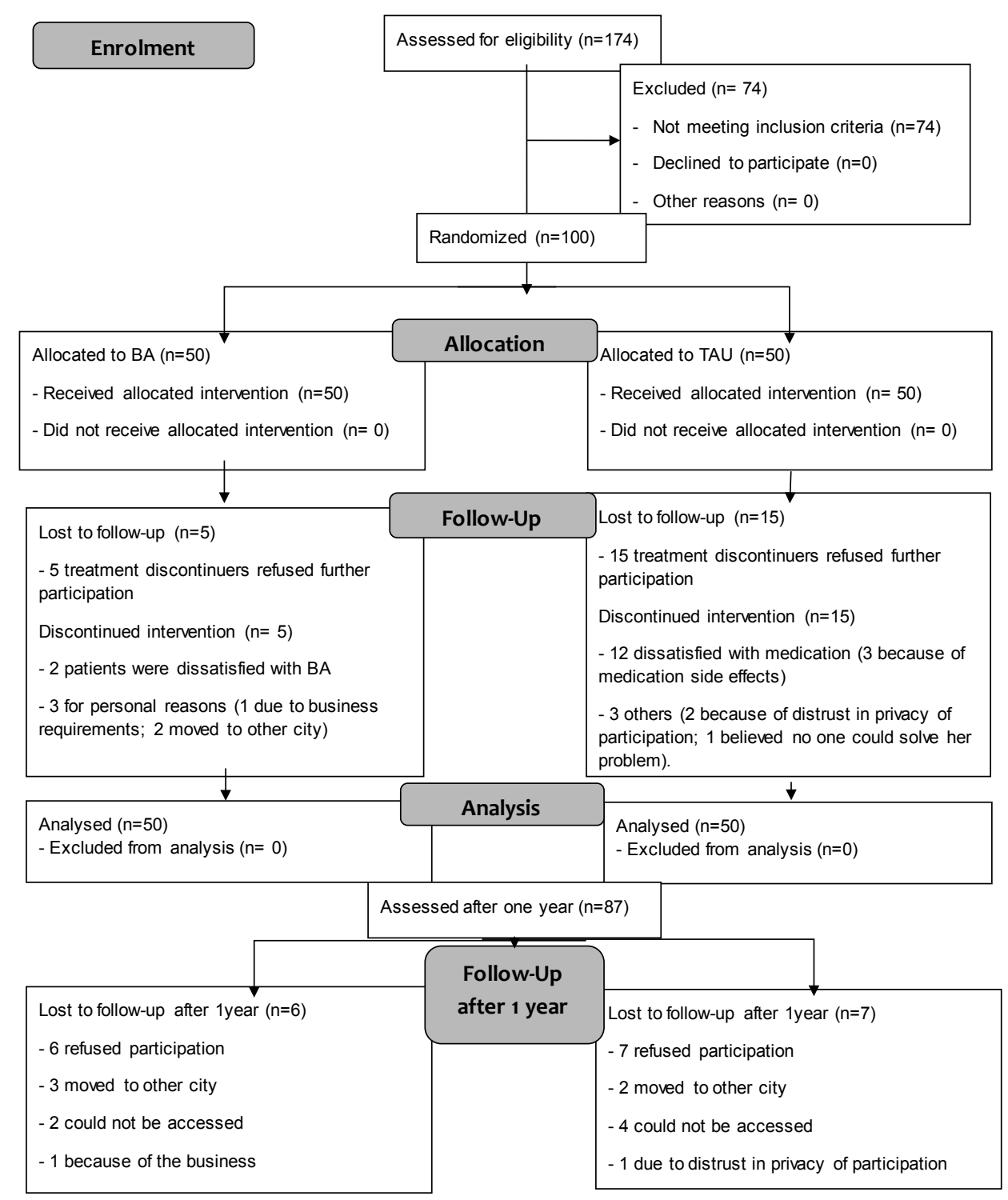

Figure1. Participant flow CONSORT 2010 Flow Diagram 
Table 1. Baseline Characteristics of Participants in two conditions

\begin{tabular}{|c|c|c|c|c|c|}
\hline & $\begin{array}{l}\text { Full sample } \\
\qquad(N=100)\end{array}$ & $\begin{array}{c}\text { Medication } \\
\text { Treatment } \\
\text { (50) }\end{array}$ & $\begin{array}{c}\text { Behavioural } \\
\text { Activation } \\
\text { (50) }\end{array}$ & $\begin{array}{l}\text { Test statistic } \\
\chi 2 \text { (df) t (d.f) } U\end{array}$ & $\begin{array}{c}\mathrm{P} \\
\text { (2-tailed) }\end{array}$ \\
\hline \multicolumn{6}{|l|}{ Baseline characteristics } \\
\hline Gender: $\mathrm{n}$ (female) & $85(85 \cdot 0)$ & $40(80 \cdot 0)$ & $45(90 \cdot 0)$ & $\chi^{2}(1)=1.96$ & $0 \cdot 16$ \\
\hline Age (years): M(SD) & $31.37(8.97)$ & $32 \cdot 62(10 \cdot 17)$ & $30 \cdot 12(7 \cdot 47)$ & $t(98)=1.4$ & $0 \cdot 16$ \\
\hline Currently married or cohabiting: $\mathrm{n}(\%)$ & $48(48 \cdot 0)$ & $25(50 \cdot 0)$ & $23(46 \cdot 0)$ & $\chi 2(1)=0.04$ & $0 \cdot 84$ \\
\hline College graduate: $\mathrm{n}(\%)$ & $40(40 \cdot 0)$ & $19(38 \cdot 0)$ & $21(42 \cdot 0)$ & $\chi^{2}(1)=0.37$ & 0.54 \\
\hline College student: $\mathrm{n}(\%)$ & $23(23 \cdot 0)$ & $10(20 \cdot 0)$ & $13(26 \cdot 0)$ & $x^{2}(1)=2 \cdot 68$ & $0 \cdot 10$ \\
\hline Employed outside home: n (\%) & $35(35 \cdot 0)$ & $19(38 \cdot 0)$ & $16(32 \cdot 0)$ & $\chi^{2}(1)=0.38$ & $0 \cdot 58$ \\
\hline Current episode length (months): $M(S D)$ & $5 \cdot 87(2 \cdot 14)$ & $5.69(1.97)$ & $6.06(2 \cdot 31)$ & $t(98)=1.01$ & $0 \cdot 31$ \\
\hline \multicolumn{6}{|l|}{ Severity } \\
\hline HRSD Overall M(SD) & $21 \cdot 37(5 \cdot 32)$ & $21 \cdot 62(5 \cdot 42)$ & $21 \cdot 12(5 \cdot 26)$ & $t(98)=-0 \cdot 47$ & 0.64 \\
\hline Number of prior episode: M(SD) & $1.03(0.80)$ & $1.00(0.72)$ & $1.06(0.88)$ & $U=1222 \cdot 5$ & 0.63 \\
\hline Recurrent depression: $\mathrm{n}(\%)$ & $73(73 \cdot 0)$ & $38(76 \cdot 0)$ & $35(70 \cdot 0)$ & $\chi^{2}(1)=0.45$ & 0.49 \\
\hline Pre psychiatric hospitalization: $\mathrm{n}(\%)$ & $2(2 \cdot 0)$ & 0 & $2(4 \cdot 0)$ & Fisher Exact Test & $0 \cdot 49^{\mathrm{a}}$ \\
\hline Any current Axis I diagnosis: $\mathrm{n}(\%)$ & $11(11.0)$ & $4(8 \cdot 0)$ & $7(14.00)$ & Fisher Exact Test & $0 \cdot 52^{\mathrm{a}}$ \\
\hline Personality disorders: $\mathrm{n}(\%)$ & $20(20.0)$ & $12(24 \cdot 0)$ & $8(16.0)$ & $\chi 2(1)=0.54$ & 0.46 \\
\hline Any current anxiety diagnosis: $\mathrm{n}(\%)$ & $11(11 \cdot 0)$ & $4(8 \cdot 0)$ & $7(14.0)$ & Fisher Exact Test & $0.52^{a}$ \\
\hline
\end{tabular}

HRSD, Hamilton Rating Scale for Depression.

a.Fisher Excat test.

\begin{tabular}{|c|c|c|c|c|c|c|c|c|c|c|c|c|}
\hline & \multicolumn{6}{|c|}{ Baseline to Week 13} & \multicolumn{6}{|c|}{ Baseline to Week 49} \\
\hline & \multicolumn{3}{|l|}{ HRSD } & \multicolumn{3}{|l|}{ BDI } & \multicolumn{3}{|l|}{ HRSD } & \multicolumn{3}{|l|}{ BDI } \\
\hline & $\mathrm{m}$ & SD & d & $\mathbf{m}$ & SD & d & $\mathbf{m}$ & SD & d & m & SD & d \\
\hline Behavioural activation & -17.31 & 3.52 & 3.24 & -22.28 & 4.51 & 3.51 & -13.58 & 3.83 & 2.54 & -18.79 & 3.99 & 2.96 \\
\hline Treatment as usual & -14.22 & 5.32 & 2.66 & -18.94 & 4.37 & 2.99 & -11.25 & 3.83 & 2.11 & -15.12 & 3.99 & 2.39 \\
\hline
\end{tabular}

HRSD, Hamilton Rating scale or depression; BDI, beck depression inventory. 
Table 2. Results of mixed regression analyses of outcome analysis

\begin{tabular}{|c|c|c|c|c|c|c|}
\hline $\begin{array}{l}\text { Hamilton Rating Scale for } \\
\text { Depression }\end{array}$ & B & $95 \% \mathrm{Cl}(\mathrm{B})$ & $\mathrm{F}$ & d.f. & $r^{a}$ & $\mathrm{p}$ \\
\hline \multicolumn{7}{|l|}{ Primary analysis } \\
\hline Intercept & 21.39 & $20.34 ; 22.44$ & 1630.67 & 98.26 & 0.97 & $<0.001$ \\
\hline Time & -1.56 & $-1.67 ;-1.46$ & 885.78 & 87.95 & 0.95 & $<0.001$ \\
\hline Time-Squared & 0.03 & $0.02 ; 0.03$ & 797.22 & 83.20 & 0.95 & $<0.001$ \\
\hline Condition & -0.72 & $-2.82 ; 1.38$ & 0.46 & 98.26 & 0.06 & 0.499 \\
\hline Time $x$ Condition & -0.31 & $-0.51 ;-0.10$ & 8.56 & 87.95 & 0.29 & 0.004 \\
\hline Time-Squared $x$ Condition & 0.00 & $0.00 ; 0.00$ & 7.83 & 83.20 & 0.29 & 0.006 \\
\hline \multicolumn{7}{|l|}{ Beck Depression inventory } \\
\hline Intercept & 27.87 & $26.64 ; 29.10$ & 2028.61 & 98.17 & 0.97 & $<0.001$ \\
\hline Time & -2.03 & $-2.16 ;-1.91$ & 1000.78 & 91.56 & 0.95 & $<0.001$ \\
\hline Time-Squared & 0.03 & $0.03 ; 0.03$ & 907.91 & 88.02 & 0.95 & $<0.001$ \\
\hline Condition & -1.95 & $-4.40 ; 0.50$ & 2.48 & 98.17 & 0.15 & 0.118 \\
\hline Time $x$ Condition & -0.32 & $-0.57 ; 0.06$ & 6.31 & 91.56 & 0.25 & 0.014 \\
\hline Time-Squared x Condition & 0.00 & $0.00 ; 0.00$ & 4.90 & 88.02 & 0.22 & 0.029 \\
\hline \multicolumn{7}{|l|}{ Sensitivity analyses outcome } \\
\hline Intercept & 21.46 & $20.41 ; 22.52$ & 1620.34 & 98.47 & 0.97 & $<0.001$ \\
\hline Time & -1.56 & $-1.66 ;-1.46$ & 926.95 & 92.05 & 0.95 & $<0.001$ \\
\hline Time-Squared & 0.02 & $0.02 ; 0.03$ & 843.77 & 89.70 & 0.95 & $<0.001$ \\
\hline Condition & -0.72 & $-2.83 ; 1.40$ & 0.45 & 98.47 & 0.06 & 0.503 \\
\hline Time $x$ Condition & -0.29 & $-0.49 ;-0.08$ & 7.76 & 92.05 & 0.27 & 0.006 \\
\hline Time-Squared $x$ Condition & 0.00 & $0.00 ; 0.01$ & 6.97 & 89.70 & 0.26 & 0.010 \\
\hline \multicolumn{7}{|l|}{ Beck Depression Inventory } \\
\hline Intercept & 27.67 & $26.45 ; 28.90$ & 2012.54 & 98.21 & 0.97 & $<0.001$ \\
\hline Time & -2.03 & $-2.15 ; 1.90$ & 990.07 & 90.91 & 0.95 & $<0.001$ \\
\hline Time-Squared & 0.03 & $0.03 ; 0.04$ & 897.95 & 87.16 & 0.95 & $<0.001$ \\
\hline Condition & -1.80 & $-4.24 ; 0.66$ & 2.11 & 98.21 & 0.14 & 0.150 \\
\hline Time $x$ Condition & -0.31 & $-0.67 ; 0.06$ & 5.88 & 90.91 & 0.24 & 0.017 \\
\hline Time-Squared $x$ Condition & 0.00 & $0.00 ; 0.01$ & 4.31 & 87.16 & 0.21 & 0.041 \\
\hline
\end{tabular}


Table 3. Results of moderation analysis, testing whether baseline severity (assessed with the Hamilton Rating Scale for Depression) moderates condition effects on outcome

\begin{tabular}{|c|c|c|c|c|c|c|}
\hline $\begin{array}{l}\text { Hamilton Rating scale for } \\
\text { Depression }\end{array}$ & B & $95 \% \mathrm{Cl}(\mathrm{B})$ & $\mathrm{F}$ & d.f. & $r^{a}$ & $\mathrm{p}$ \\
\hline \multicolumn{7}{|l|}{ Moderation } \\
\hline Intercept & 21.42 & $20.39 ; 22.45$ & 1701.45 & 85.90 & 0.97 & $<0.001$ \\
\hline Time & -1.56 & $-1.69 ;-1.44$ & 641.20 & 71.65 & 0.94 & $<0.001$ \\
\hline Time-Squared & 0.03 & $0.02 ; 0.03$ & 619.70 & 74.44 & 0.94 & $<0.001$ \\
\hline Condition & -0.14 & $-2.21 ; 1.92$ & 0.01 & 85.80 & 0.01 & 0.889 \\
\hline Baseline Severity & 4.62 & $3.55 ; 5.70$ & 73.32 & 87.70 & 0.67 & $<0.001$ \\
\hline Time $x$ Condition & -0.36 & $-0.60 ;-0.10$ & 8.31 & 71.21 & 0.32 & $<0.005$ \\
\hline Time-Squared $x$ Condition & 0.00 & $0.00 ; 0.01$ & 8.18 & 74.04 & 0.31 & 0.006 \\
\hline Time x Baseline severity & -0.30 & $-0.43 ;-0.17$ & 2131 & 74.91 & 0.47 & $<0.001$ \\
\hline Time-Squared x Baseline severity & 0.00 & $0.00 ; 0.00$ & 17.86 & 76.62 & 0.43 & $<0.001$ \\
\hline Condition x Baseline severity & -2.57 & $-4.04 ;-1.10$ & 12.11 & 77.32 & 0.36 & $<0.001$ \\
\hline \multicolumn{7}{|l|}{ Beck Depression Inventory } \\
\hline Intercept & 26.33 & $24.55 ; 28.10$ & 867.20 & 95.97 & 0.94 & $<0.001$ \\
\hline Time & -1.88 & $-2.08 ;-1.68$ & 360.04 & 93.80 & 0.89 & $<0.001$ \\
\hline Time-Squared & 0.03 & $0.03 ; 0.03$ & 361.43 & 19.01 & 0.97 & $<0.001$ \\
\hline Condition & -8.62 & $-12.17 ;-5.07$ & 23.23 & 95.90 & 0.44 & $<0.001$ \\
\hline Baseline Severity & 3.37 & $1.52 ; 5.20$ & 13.14 & 96.93 & 0.34 & $<0.001$ \\
\hline Time $x$ Condition & 0.36 & $-0.03 ; 0.75$ & 3.26 & 93.47 & 0.18 & 0.074 \\
\hline Time-Squared $x$ Condition & -0.01 & $-0.01 ; 0.00$ & 3.02 & 92.07 & 0.17 & 0.086 \\
\hline Time x Baseline severity & -0.17 & $-0.37 ; 0.03$ & 2.65 & 97.28 & 0.16 & 0.107 \\
\hline Time-Squared x Baseline severity & 0.00 & $-0.00 ; 0.00$ & 2.23 & 95.03 & 0.15 & 0.139 \\
\hline Condition x Baseline severity & -2.20 & $-3.40 ;-1.00$ & 13.25 & 92.85 & 0.35 & $<0.001$ \\
\hline
\end{tabular}

${ }^{1}$ Effect size $r=V(F /(F+d f))$

\section{Moderation by baseline severity}

The three-way interactions between time (respectively time-squared), condition and baseline severity were not significant; linear time-effect: $F(1,75.85)=1.49, p=0.17$ for the HRSD, and $F(1,97.20)=1.03, p=0.31$ for the BDI; quadratic time-effect: $F(1,75.85)$ $=1.49, p=0.23$ for the HRSD and $F(1,94.80)=0.96, p=0.33$ for the BDI (results not shown in table). After removing the three-way interactions from the model, there were significant interactions between treatment condition and baseline severity (Table 3 ) indicating that baseline severity moderated treatment outcome at 4, 13 and 49 
weeks. As is shown in Figure 3, participants with higher baseline severity had relatively lower HRSD and BDI scores in the behavioural activation group than in the TAU group.

\section{Remission and response}

Among study completers, remission and response rates for the behavioural activation group at 13 weeks were 41 out of 45 (91.1\%) and 44 out of 45 (97.8\%) participants. For the TAU group, these rates were 24 out of 35 (68.6\%) and 33 out of $35(94.3 \%)$. Behavioural activation differed significantly from TAU in remission rate; $\chi^{2}(1, N=80)=6.93$, $\mathrm{p}<0.01, \mathrm{OR}=4.69\left(95 \% \mathrm{Cl}[1.35,16.40)\right.$; but not in response rate; $\chi^{2}(1, \mathrm{~N}=80)=0.67$, $\mathrm{p}=0.42, \mathrm{OR}=2.66(95 \% \mathrm{Cl}[0.23,30.67])$.

\section{Remission, response and relapse at 49 weeks}

A total of 87 participants were available for assessment at 49 weeks. Remission and response rates for the behavioural activation were 29 out of $44(65.9 \%)$ and 39 out of 44 (88.6\%) participants; and for the TAU group, 12 out of $43(27.9 \%)$ and 20 out of 43 (46.5\%). Behavioural activation differed significantly from TAU in remission rate, $\chi^{2}(1$, $\mathrm{N}=87)=12.60, \mathrm{p}<0.001, \mathrm{OR}=4.99(95 \% \mathrm{Cl}[2.01,12.44])$; and in response rate, $\chi^{2}(1, \mathrm{~N}$ $=87)=17.69, \mathrm{p}<0.001, \mathrm{OR}=8.97,(95 \% \mathrm{Cl}[2.96,27.14])$. From those that remitted at 13 weeks, 10 out of 36 ( $27.8 \%$ behavioural activation group) and 12 out of 20 (60.0\% TAU group) relapsed at 49 weeks. This difference was also significant, $\chi^{2}(1, N=56)=$ $5.60, p=0.018, \mathrm{OR}=3.90(95 \% \mathrm{Cl}[1.23,12.37])$. At 49 weeks, 3 out of $44(6.8 \%)$ in the behavioural activation group and 11 out of 43 (25.6\%) in the TAU group used ADM, $\chi^{2}(1, N=87)=5.67, p=0.017$. 

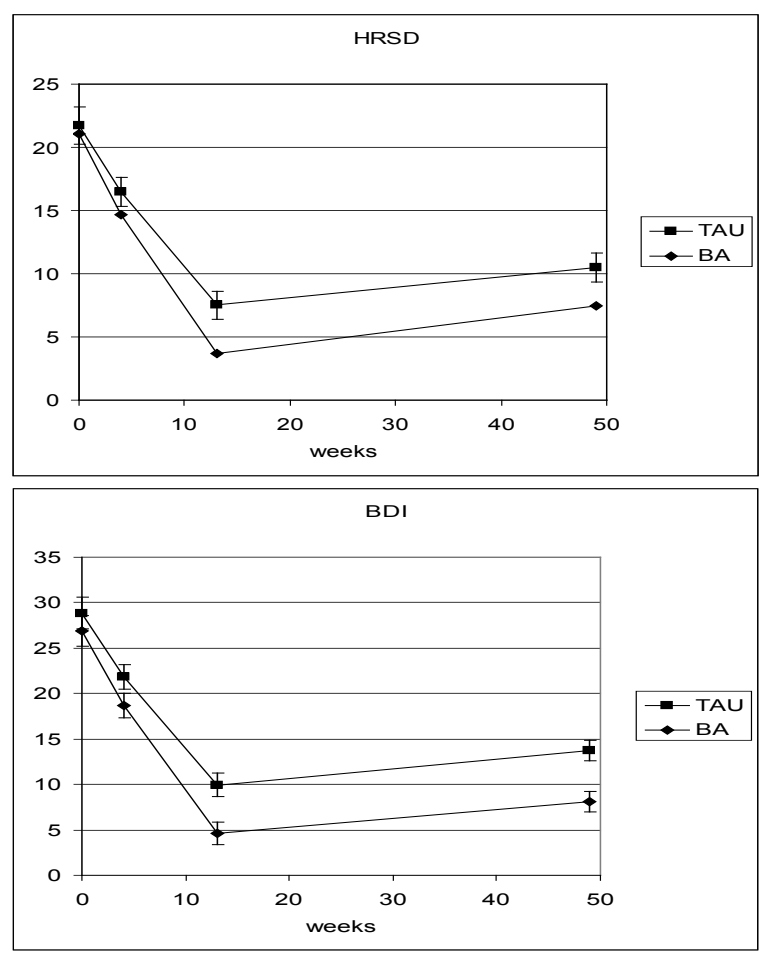

Figure 2. Mixed regression-based estimated means and $95 \% \mathrm{Cl}$ of Hamilton Rating Scale for Depression (HRSD) and Beck Depression Inventory (BDI) at baseline, 4, 13 and 49 weeks for Behavioural Activation (BA) and Treatment as usual (TAU).
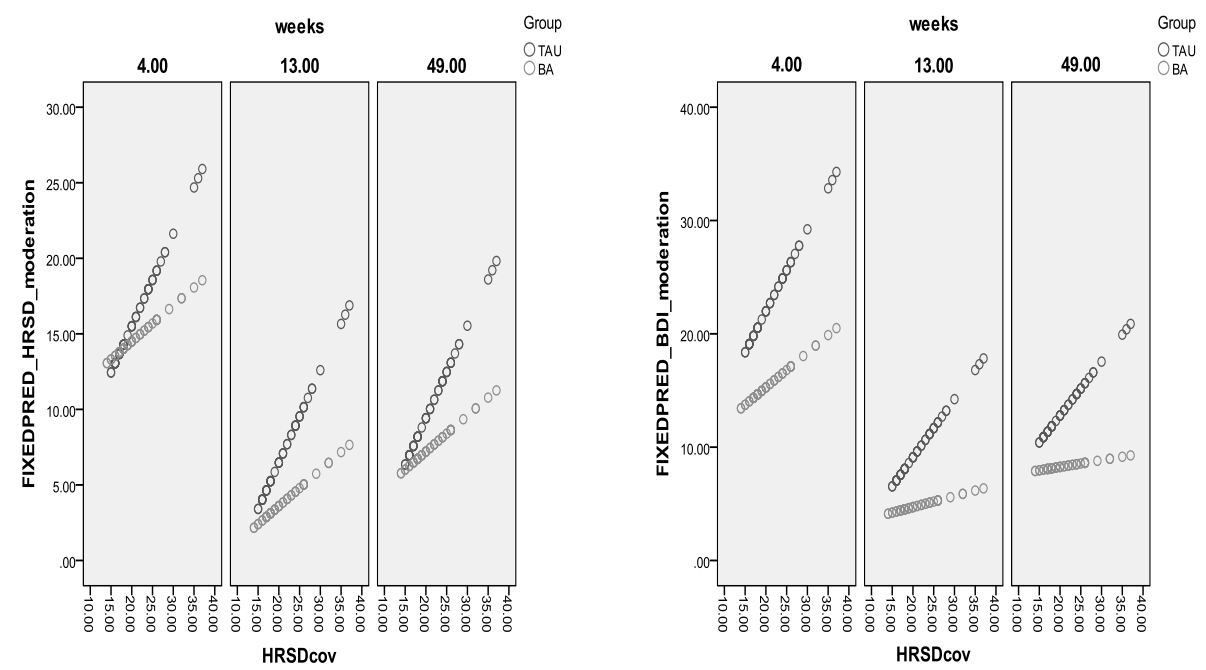

Figure 3: Moderation of condition effects by baseline severity (Hamilton Rating Scale for Depression score at baseline) at 4, 13 and 49 weeks assessments on the (a) HRSD and (b) Beck Depression Inventory: fixed predicted scores from mixed regression analyses.

Individuals in the behavioural activation (BA) group had on average lower HRSD and BDI scores, but the higher the baseline severity, the stronger the difference between Behavioural activation and Treatment as usual (TAU). HRSDcov, HRSD score at baseline, representing baseline severity. 
Table DS1. Results of mixed regression analyses of outcome controlled by referral on BDI and HDRS

\begin{tabular}{|c|c|c|c|c|c|c|}
\hline \multicolumn{7}{|l|}{ Primary analyses outcome } \\
\hline HRSD & B & $95 \% \mathrm{Cl}(\mathrm{B})$ & $\mathrm{F}$ & df & $r^{1}$ & $\mathrm{p}$ \\
\hline Intercept & 21.36 & $20.31 ; 22.42$ & 1614.85 & 98.19 & 0.97 & $<0.001$ \\
\hline Time & -1.56 & $-1.66 ;-1.45$ & 875.45 & 85.99 & 0.95 & $<0.001$ \\
\hline Time-Squared & 0.03 & $0.02 ; 0.03$ & 788.08 & 81.79 & 0.95 & $<0.001$ \\
\hline Condition & -0.73 & $-2.84 ; 1.37$ & 0.48 & 98.19 & 0.06 & 0.491 \\
\hline Referral & -0.86 & $-2.47 ; 0.75$ & 1.12 & 82.52 & 0.11 & 0.293 \\
\hline Time $x$ Condition & -0.32 & $-0.53 ;-0.11$ & 8.98 & 85.99 & 0.30 & 0.004 \\
\hline Time-Squared x Condition & 0.01 & $0.00 ; 0.01$ & 8.44 & 81.79 & 0.30 & 0.005 \\
\hline Referral x Condition & -2.16 & $-5.38 ; 1.07$ & 1.77 & 82.52 & 0.14 & 0.187 \\
\hline Referral x Time & 0.04 & $-0.00 ; 0.07$ & 3.93 & 83.72 & 0.21 & 0.051 \\
\hline Referral x Condition x Time & 0.11 & $0.03 ; 0.18$ & 8.54 & 83.72 & 0.30 & 0.004 \\
\hline \multicolumn{7}{|l|}{ BDI } \\
\hline Intercept & 27.77 & $26.55 ; 28.98$ & 2062.60 & 97.61 & 0.97 & $<0.001$ \\
\hline Time & -2.03 & $-2.16 ;-1.90$ & 1006.16 & 90.04 & 0.95 & $<0.001$ \\
\hline Time-Squared & 0.03 & $0.03 ; 0.04$ & 901.27 & 86.14 & 0.95 & $<0.001$ \\
\hline Condition & -2.01 & $-4.43 ; 0.42$ & 2.69 & 97.61 & 0.07 & 0.104 \\
\hline Referral & -.73 & $-2.67 ; 1.21$ & 0.56 & 91.31 & 0.07 & 0.455 \\
\hline Time $x$ Condition & -0.32 & $-0.58 ;-0.07$ & 6.48 & 90.04 & 0.25 & 0.013 \\
\hline Time-Squared x Condition & 0.06 & $0.00 ; 0.01$ & 5.28 & 86.14 & 0.24 & 0.024 \\
\hline Referral x Condition & -4.05 & $-7.93 ;-0.16$ & 4.29 & 91.31 & 0.21 & 0.041 \\
\hline Referral x Time & 0.03 & $-0.02 ; 0.08$ & 1.74 & 86.35 & 0.14 & 0.191 \\
\hline Referral x Condition x Time & 0.14 & $0.05 ; 0.23$ & 9.48 & 86.35 & 0.31 & 0.003 \\
\hline \multicolumn{7}{|l|}{ Sensitivity analyses outcome } \\
\hline \multicolumn{7}{|l|}{ HRSD } \\
\hline Intercept & 21.43 & $20.37 ; 22.49$ & 1605.72 & 98.30 & 0.97 & $<0.001$ \\
\hline Time & -1.56 & $-1.66 ;-1.46$ & 928.18 & 91.01 & 0.95 & $<0.001$ \\
\hline Time-Squared & 0.02 & $0.02 ; 0.03$ & 841.43 & 88.68 & 0.95 & $<0.001$ \\
\hline Condition & -0.75 & $-2.87 ; 1.38$ & 0.49 & 98.30 & 0.07 & 0.487 \\
\hline Referral & -0.67 & $-2.31 ; 0.96$ & 0.67 & 80.29 & 0.09 & 0.416 \\
\hline Time $x$ Condition & -0.29 & $-0.50 ;-0.09$ & 8.20 & 91.01 & 0.28 & 0.005 \\
\hline Time-Squared $x$ Condition & 0.01 & $0.00 ; 0.01$ & 7.61 & 88.68 & 0.28 & 0.007 \\
\hline Referral x Condition & -1.73 & $-5.00 ; 1.54$ & 1.11 & 82.90 & 0.11 & 0.296 \\
\hline Referral x Time & 0.03 & $-0.00 ; 0.07$ & 3.32 & 82.90 & 0.19 & 0.072 \\
\hline Referral x Condition $x$ Time & 0.10 & $0.03 ; 0.18$ & 7.56 & 8290 & 0.28 & 0.007 \\
\hline \multicolumn{7}{|l|}{ BDI } \\
\hline Intercept & 27.57 & $26.36 ; 28.78$ & 2047.75 & 97.51 & 0.97 & $<0.001$ \\
\hline Time & -2.03 & $-2.15 ;-1.90$ & 994.28 & 89.46 & 0.95 & $<0.001$ \\
\hline Time-Squared & .03 & $0.03 ; 0.04$ & 890.89 & 85.38 & 0.95 & $<0.001$ \\
\hline Condition & -1.84 & $-4.28 ; 0.58$ & 2.28 & 97.51 & 0.08 & 0.134 \\
\hline Referral & -0.77 & $-2.71 ; 1.16$ & 0.63 & 91.88 & 0.08 & 0.430 \\
\hline Time $x$ Condition & -0.32 & $-0.57 ;-0.63$ & 6.13 & 89.46 & 0.25 & 0.015 \\
\hline Time-Squared x Condition & 0.01 & $0.00 ; 0.01$ & 4.71 & 85.38 & 0.22 & 0.033 \\
\hline Referral x Condition & -3.99 & $-7.85 ;-0.11$ & 4.17 & 91.88 & 0.20 & 0.044 \\
\hline Referral x Time & 0.03 & $-0.02 ; 0.08$ & 1.74 & 86.52 & 0.29 & 0.191 \\
\hline Referral x Condition $x$ Time & 0.14 & $0.05 ; 0.23$ & 8.10 & 86.52 & 0.29 & 0.004 \\
\hline
\end{tabular}

${ }^{1}$ Effect size $r=V(F /(F+d f))$ 

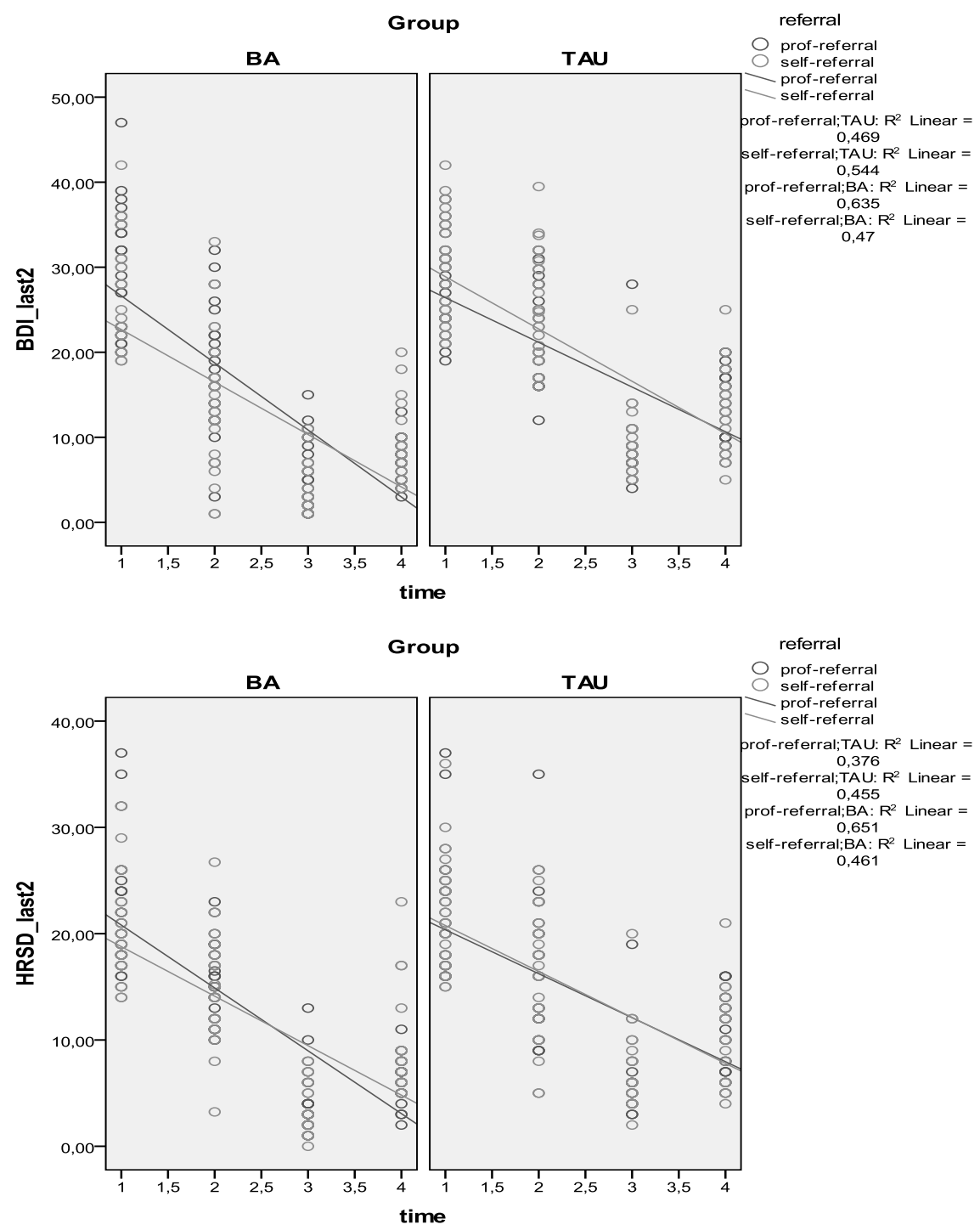

Figure DS1. Mixed regression-based estimated means BDI and HRSD at baseline, mid-treatment, posttreatment and 1 year follow-up for those participants who recruited by self-referral and referral by other professionals.

\section{Discussion}

The findings of this study indicate that behavioural activation is superior to antidepressant medication in terms of effectiveness, especially in those with severe depression, 
and the prevention of relapse. The lower drop out in the behavioural activation group suggests that behavioural activation was better tolerated than medication. As it was also more effective, behavioural activation might offer a viable alternative to medication, especially for those who prefer non-pharmacological treatment. The results replicate and extend findings of three earlier trials ${ }^{12,13,16}$ and emphasise the value of simple behavioural strategies in the treatment of depression.

Until now, behavioural activation has been tested by the developers ${ }^{12,13}$ and by only one independent study ${ }^{16}$. In our study, behavioural activation therapists were not trained and supervised by behavioural activation experts but by a non-expert using the published protocol, which is encouraging regarding the feasibility of its dissemination around the globe. Behavioural activation interventions are relatively simple and easy to understand for depressed participants, and do not require difficult or complex skills from participants and therapists. ${ }^{25}$ It could therefore be considered as a first choice treatment, with potentially good cost-effectiveness.

In the Dimidjian et al's study ${ }^{13}$ behavioural activation was conducted over 24 sessions over a 4- month period, as opposed to the 16 sessions in our study. Remission and response rates were higher in our study (remission and response rates in the behavioural activation group of $91.1 \%$, and $97.8 \%$ respectively) compared with the rates in the high severity group in the Dimidjian et al study ${ }^{13}$ (remission and response rates in the behavioural activation group of $52 \%-56 \%$ and $60 \%-76 \%$ respectively). Reasons for the striking effectiveness of behavioural activation in our study might be that behavioural activation fits particularly well with the Iranian culture. Although avoidance and rumination are typical responses observed in all depressed participants, they might be even more typical in the Iranian context. The behavioural activation therapists had the impression that behavioural activation strategies that tackle rumination led to a strong reduction in depressive symptoms. In Iran, psychological treatment seems more acceptable than pharmacological treatment, because seeing a psychologist is more accepted (as the reason is that one merely has "life problems"), whereas pharmacological treatment is associated with having "mental disease" which has a heavy cultural stigma, especially for men.

Several studies have reported substantial relapse after discontinuation of antidepressant medication. ${ }^{10,26,27}$ From a behavioural activation perspective, a likely reason is that people who are treated with antidepressants and then relapse did not change their coping skills. Patterns of avoidance, environmental punishment, lack of reinforcement, and depressive rumination might still exist, although their effect on mood might have been temporarily reduced through the use of antidepressants. In contrast, behavioural activation equips individuals with healthy behavioural skills and thus the probability of relapse is reduced. 
The difference in effectiveness between behavioural activation and antidepressant medication also points to differential pathways of change. Behavioural activation and antidepressants are obviously likely to work through different mechanisms, but this study provides further evidence that activation is needed crucial element that leads to improvement in psychotherapy for depression. The original study by Jacobson et $\mathrm{al}^{12}$ was set up to identify the active components of CBT, and found that behavioural activation was at least as effective as the complete package of CBT. Dimidjian et $a l^{13}$ replicated this finding, and found behavioural activation to be even more effective than CBT in severe depression. Although behavioural activation in our study is not compared with $\mathrm{CBT}$, the findings underline that simple activation strategies in psychotherapy are essential. It should be noted, however, that this study provides merely indirect evidence for a causal link between activation and recovery in depression and that experimental studies are needed to reveal the working mechanisms of behavioural activation.

\section{Limitations}

A number of limitations should be mentioned. First, the fact that therapists were not trained by BA experts might have led to suboptimal application of the behavioural activation techniques. Furthermore, participants had to pay for antidepressant medication after 3 months, which might have contributed to discontinuation. However, these two limitations can also be considered as strengths from the point of view of effectiveness research, which addresses how the two approaches compare in routine practice settings. A third limitation is the high proportion of participants recruited by advertising and word of mouth. It is unclear to what degree the sample is different from regular clinical samples in Iran. Fourth, the rate of attrition in the antidepressant medication group was relatively high and this could have influenced the results. Fifth, we did not change the prescribed drug for the patients, Sertraline, in case of non-response. However, this was the same for behavioural activation. Sixth, independent assessments of treatment integrity and reliability checks of the HRSD interviews were not done because of financial constraints. Seventh, the sample may have been biased in that the study especially attracted participants preferring psychological treatment, which is not widely available in Iran. Eighth, the absence of a non-treatment or placebo condition is another limitation. Ninth, we did not control for the amount of attention participants received from their therapists. The weaker effects of antidepressant medication might be partially explained by this. Tenth, the majority of our sample was female, and although this reflects clinical practice in Iran, further studies are needed into non-Western male samples. 


\section{Future research}

Our finding that behavioural activation was superior to antidepressant medication, and even more so in the more severely depressed subgroup should be replicated by other groups and in other settings. Subsequent trials in which the effectiveness and costeffectiveness of behavioural activation, antidepressant medication and other psychological treatments such as cognitive therapy are investigated are indicated.

Another issue pertains to mechanisms of change that are accountable for the superior effects of behavioural activation. Understanding the (differential) causal pathways that lead to recovery in behavioural activation and antidepressant medication might illuminate important insights that help to improve treatment strategies in depression, and future research is warranted here.

\section{Implications of this study}

The findings of our study suggest that behavioural activation is a simple and effective intervention for depression that can be easily disseminated to routine practice settings, similar to what has been demonstrated in Western countries. ${ }^{16}$ Especially the fact that behavioural activation was delivered effectively by therapists with a minimum of training and supervision is very promising, taken together with the superior effects in the subgroup of participants with more severe depression, it speaks for timely dissemination to other routine practice settings as well. Moreover, behavioural activation might be a very cost-effective intervention. Although our study did not include a formal economic evaluation, we calculated that the total direct treatment costs for behavioural activation participants amounted to $€ 128$ per patient, while the total direct treatment costs for ADM patients were $€ 198$ per patient on average, depending on the number of follow-up consultations. It has even been suggested that behavioural activation can be provided by health care professionals who had no previous experience with providing psychotherapy ${ }^{16}$, which further increases possibilities for its implementation. 


\section{References}

1 American psychiatric Association. Diagnostic and statistical manual of mental disorders. $4^{\text {th }}$ ed. Washington, DC: APA, 1994.

2 Blacker D. Maintenance treatment of major depression: A review of the literature. Harvard Rev of Psychiat 1996; 4: 19.

3 Fein S, Paz V, Rao N, \& Lagrassa J. The combination of lithium carbonate and an MAO in refractory depression. Am J Psychiatry 1988; 145: 249-50.

4 Hirschfeld RMA, \& Schatzberg AF. Long-term management of depression. Am J Medicine 1994; $97: 338$.

5 Schatzberg AF. Treatment of severe depression with the selective serotonin reuptake inhibitors. Depression 1996; 4: 182-9.

6 American Psychiatric Association. Practice guidelines for the treatment of patients with major depressive disorder (revision). Am J Psychiatry 2000; 157: 1-45.

7 Olfson M, Marcus SC, Druss B, \& Pincus HA. National trends in the use of outpatient psychotherapy. Am J Psychiatry 2002; 159: 1914-20.

8 Dobson KS, Hollon SD, Dimidjian S, et al. Randomized trial of behavioral activation, cognitive therapy, and antidepressant medication in the prevention of relapse and recurrence in major depression. J Consult Clin Psych 2008; 76: 468- 77.

9 Hollon SD, \& Shelton RC. Treatment guidelines for major depressive disorder. Behav Ther 2001; 32: 235-58.

10 Gloaguen V, Cottraux J, Cucherat M, \& Blackburn IM. A meta-analysis of the effects of cognitive therapy in depressed patients. J Affect Disorders 1998; 49: 59-61.

11 Beck AT, Rush AJ, Shaw BF, \& Emery G. Cognitive therapy of depression. Guilford Press, 1979.

12 Jacobson NS, Dobson KS, Truax PA, et al. A component analysis of cognitive- behavioral treatment for depression. J Consult Clin Psych 1996; 64: 295-304.

13 Dimidjian S, Hollon SD, Dobson KS, et al. Randomized trial of behavioral activation, cognitive therapy, antidepressant medication in the acute treatment of adults with major depression. J Consult Clin Psych 2006; 74: 658-70.

14 Cuijpers P, Van Straten A, \& Warmerdam L. Behavioral activation treatment of depression: A metaanalysis. Clin Psychol Rev 2007; 27: 318-26.

15 Ekers D, Richards D, \& Gilbody S. A meta-analysis of randomized trials of behavioral treatment of depression. Psychol Med 2008; 38: 611-23.

16 Ekers D, Richards D, McMillan D, Bland JM, and Gilbody S. Behavioral activation delivered by the nonspecialist: phase II randomized controlled trial. Br J Psychiatry 2011; 198: 66-72.

17 Martell CR, Dimidjian S, \& Herman-Dunn R. Behavioural activation for depression: A clinician's guide. New York: The Guilford Press, 2010.

18 Martell CR, Addis ME, \&Jacobson NS. Depression in context: strategies for guided action. New York: Norton Press, 2001.

19 American Psychiatric Association. Diagnostic and statistical manual of mental disorders (DSM-IV-TR.). Washington, DC: APA, 2000.

20 First MB, Williams, JB, Spitzer RL, \& Gibbon M: Structured Clinical Interview for DSM-IV- TR Axis I Disorders, Clinical Trials Version (SCID-CT). New York: Biometrics Research, New York State Psychiatric Institute, 2007.

21 Beck AT, Steer RA, \& Brown GK. Manual for the BDI-II. San Antonio, TX: Psychological Corporation,1996.

22 Hamilton M. A rating scale for depression. J Neurol Neurosur Ps 1960; 23: 56-61.

23 Sadock BJ, \& Sadock VA. Kaplan and Sadock's Synopsis of Psychiatry: Behavioral Sciences/Clinical Psychiatry. 10th Edition. Philadelphia: Lippincott Williams \& Wilkins, 2007. 
24 First MB, Spitzer RL, Gibbons M, Williams JB, \& Benjamin L. User's guide for the Structured Clinical Interview for DSM-IV Axis II Personality Disorders (SCID-II). New York: New York State Psychiatric Institute, Biometrics Research Department, 1996.

25 Lejuez CW, Hopko DR, LePage JP, Hopko SD, \& McNeil DW. A brief behavioral activation treatment for depression. Cogn Behav Pract 2001; 8: 164-75.

26 Hollon SD, DeRubeis RJ, Shelton RC, et al. Prevention of relapse following cognitive therapy vs. medications in moderate to severe depression. Arch Gen Psychiat 2005; 62: 417-22.

27 Evans MD, Hollon SD, DeRubeis RJ, Piasecki JM, Grove WM, Garvey MJ, et al. Differential relapse following cognitive therapy and pharmacotherapy for depression. Arch Gen Psychiat 1992; 49: 802-8. 



\section{Chapter 3}

\section{The influence of comorbid personality disorder on}

the effects of behavioural activation vs. antidepressant medication for major depressive disorder: results from a randomized trial in $\operatorname{Iran}^{3}$

3 Published as: Moradveisi, L., Huibers, M. J., Renner, F., Arasteh, M., \& Arntz, A. (2013). The influence of comorbid personality disorder on the effects of behavioural activation vs. antidepressant medication for major depressive disorder: Results from a randomized trial in Iran. Behaviour Research and Therapy, 51(8), 499-506. 


\section{Abstract}

There is a disagreement about the impact of personality disorder (PD) on treatment outcome for patients with major depressive disorder (MDD). 100 out-patients with MDD were randomized to 16 sessions of behavioural activation (BA) ( $n=50)$ or antidepressant medication (ADM) $(n=50)$ in Iran. Main outcome was depression severity, measured with the Beck Depression Inventory (BDI-II) and the Hamilton Rating Scale for Depression (HRSD), and assessed at 0, 4, 13 and 49 weeks. Participants with comorbid PDs had higher scores on BDI and HRSD at baseline and throughout the study than participants without comorbid PD. Participants in both treatment groups responded equally to the short-term treatment and this trend continued through one year of follow-up. Overall, BA was better in reducing symptoms in patients but this effect was not influenced by comorbid PD. Similar effects were found for a dimensional PD-measure. Only cluster-C PD-traits turned out to be associated with overall depression severity. Cluster-A PD-traits predicted poorer long-term treatment response to $A D M$ and $B A$, but only on the BDI, not on the HRSD. No effects of cluster-B PD-traits were found. However, PD was associated with higher dropout. The general conclusion is that comorbid PD pathology, especially from cluster- $C$, is associated with higher depression severity, but not with less response to treatment. Comorbid PD did predict increased chance of dropout. 


\section{Introduction}

Many clinicians and researchers share the view that co-morbidity of personality disorder (PD) interferes with the treatment of depression (Shea, Widiger, \& Klein 1992). Several studies indeed reported that comorbid personality pathology negatively influences treatment of major depressive disorder (MDD) (Hardy, Barkham, Shapiro, Rees, Stiles \& Reynolds, 1995; Sato et al., 1994; Newton-Howes et al., 2006). However, recent reviews have challenged this notion (Mulder, 2002; Kool et al., 2005). One review reported that co-morbidity of personality pathology does not have a negative effect on the treatment results for MDD and concluded that those studies that used structural clinical interviews and randomized designs (so that treatment allocation was unbiased) found the least evidence that personality pathology adversely influences treatment outcome (Mulder, 2002). Another meta-analysis on the effects of comorbid PD on pharmacological treatment of MDD included six randomized controlled trials. This study reported little effect of PD on response to treatment (Kool et al., 2005).

Effects of comorbid PDs might depend on treatment modality. For instance, (Tyrer, Seivewright, Ferguson, Murphy \& Johnson, 1993) reported that depressed participants with PD responded better to medication than to psychotherapy. Another recent study found that ADM was more effective than cognitive therapy in reducing depressive symptoms in patients with co-morbid personality pathology, while the reversed difference was found for patients without PD (Fournier, 2008). The PD effect seemed to be caused particularly by cluster-B PD-pathology.

Behavioural activation (BA) is a relatively new treatment model for patients with depression. As far as we know, no study to date investigated the effects of comorbid PD on treatment effects of BA in comparison to ADM for participants with MDD. The data presented in this paper are drawn from a randomized controlled trial comparing BA and Sertraline for patients with MDD (Moradveisi, Huibers, Renner, Arasteh \& Arntz, 2013). Our focus is on whether depressed participants with co-morbid PD differ in symptom reduction over time compared to those without comorbid PD, and whether BA and Sertraline differ in this respect. We compared participants with co-morbid PD to those without PD in terms of drop-out rates, and reduction of depressive symptoms during and after short-term treatments and at approximately one year. Given the dimensional nature of PDs, we also explored the association of the number of PD-traits with dropout and outcome. As Fournier et al (2008) found a specific effect for cluster-B PD-pathology, we also explored whether cluster A, B, or C PD-traits moderated outcome. 


\section{Method}

Main treatment outcome results and the sample characteristics of the study have been reported elsewhere (Moradveisi et al., 2013). Participants were 100 depressed patients from Sanandaj, Iran, between the ages of 18 to 60 years (mean 31.37, SD 8.97), 85 women, with a primary diagnosis of MDD according to the Diagnostic and Statistical Manual of Mental Disorders DSM-IV-TR (American Psychiatric Association, 2000) confirmed by the Structured Clinical Interview for the DSM-IV-TR Axis-I Disorders Clinical Trials Version (SCID-CT) First, Williams, Spitzer \& Gibbon (2007); and a score of $\geq 19$ on the Beck Depression Inventory, second edition (BDI-II) Beck, Steer \& Brown (1996) and $\geq 14$ on the 17-item Hamilton Rating Scale for Depression (HRSD) Hamilton (1960). The Structured Clinical Interview for DSM-IV Axis II PDs (SCID-II, First, Spitzer, Gibbons, Williams \& Benjamin, 1996) was used at baseline to diagnose PDs. Among all participants, 20 were diagnosed to have at least one comorbid PD. The following PDs were diagnosed: 6 Avoidant; 6 Dependent; 2 Borderline; 2 Paranoid, and 4 Obsessivecompulsive. None of the PDs was an exclusion criterion. Eight out of 50 participants randomized to $B A$ and 12 out of 50 to treatment as usual (ADM) conditions had a comorbid PD. ${ }^{4}$ The study was approved by the local Committee of Medical Ethics, Second Session. All participants signed written informed consent to participate in the study.

\section{Treatment}

One hundred participants were randomly assigned to receive BA $(n=50)$ or Sertraline $(n=50)$. Participants in the BA condition received sixteen 50 -min sessions over 12 weeks, for the first 4 weeks twice a week, and for the next 8 weeks once a week. In TAU participants were seen for the first 4 weeks of the treatment once a week and for the next 8 weeks once every two weeks. Psychiatrists saw each participant 20 min in the first session and in the subsequent sessions for approximately 10 min to monitor pharmacotherapy and side effects of the medication. BA and ADM were delivered in the same way to PD and non-PD comorbid patients, as the therapists and patients were blind for the results of the SCID-II.

\section{Outcome measures}

Depression severity was assessed with the modified 17-item version of the HRSD (Hamilton, 1960) and the BDI-II (Beck et al., 1996). Both measures were administered at

1 In the first draft of our study, there were three conditions, antidepressant medication, behavioural activation, and pill placebo; but the local Committee of Medical Ethics rejected the placebo condition. The study therefore had only two active conditions. 
baseline, 4, 13, and 48 weeks of treatment. HRSD assessments were done by evaluators blind to treatment conditions. Independent assessors took HRSD for TAU patients and BDI for BA patients, before every session and supplied therapists with the results.

\section{Statistical analyses}

The effect of PD on dropout rates was tested by means of a Chi-square test, whereas the combined effects of PD, condition, and their interaction were tested with logistic regression. Multilevel analysis was used to estimate effects of PD on change in depression severity over time. We applied intention-to-treat analysis, with the HRSD and BDI as dependent variables, by including all available scores. Visual inspection suggested linear and quadratic time effects; we therefore modelled time linearly and quadratically. We used multilevel analyses with an unstructured covariance structure for repeated measures, with time, time-squared, condition, time by condition, time-squared by condition, and PD as fixed effects. We also tested time (-squared) $\times$ PD, PD $\times$ condition, and time (-squared) $x$ PD $\times$ condition interactions. The PD $\times$ time (-squared) and the main PD effects, and their interactions with condition are of primary interest in this analysis. Unstructured covariance structure for repeated measures does not allow for random slopes (as this is already represented in the unstructured covariance structure for repeated measures) and looking into the effects of PDs on slopes take depression severity at baseline into account. In all models, treatment condition was centred at $-1 / 2$ and $1 / 2$. Non-significant interactions were removed stepwise from the model starting with the highest order interactions. Similar analyses were done with the standardized sum of PD-traits, total or by cluster, as predictor, instead of the dichotomous presence vs absence of PD variable. We computed effect sizes $(r)^{5}$ for continuous outcomes from the multilevel estimates. For treatment dropouts who refused further assessments, we used the last observation with the associated time, and estimated missing HRSD scores (for BA-dropouts) from changes on the BDI, and missing BDI scores (for TAU-dropouts) from changes on the HRSD, using regression derived equations (1 BDI unit=1.3 HRSD unit). All treatment drop-out took place before the mid-treatment assessment. Analyses were conducted using SPSS19.

$5 r=V(F /(F+d f))$ 


\section{Results}

\section{Dropout}

The overall rate of participant's dropout of the treatment was presented in the main publication (Moradveisi et al., 2013). Twenty participants dropped out of treatment, 8 out of 20 (40\%) had PD, compared to 12 out of 80 (15\%) completers. The condition by PD interaction was NS (OR $=0.82[0.07 ; 9.30] ; p=0.87)$. After deleting the interaction the main effects of condition (OR $=3.70[1.17 ; 11.70]$, Wald $(1)=4.98, p=0.026)$ and $\mathrm{PD}(\mathrm{OR}=0.20$ [0.07; 0.63], Wald $(1)=7.63, \mathrm{p}=0.006)$ were significant, with lower dropout in BA and in participants without PD. Thus, there were more dropouts in participants with PD than in those without PD.

\section{Drop-out with the PD-traits sum-scores}

The interaction between condition and the PD-traits sum-scores was not significant, $\mathrm{OR}=1.06[0.91 ; 1.24] ; \mathrm{p}=0.47)$. After removing the interaction the main effects of condition $(O R=3.78[1.23 ; 11.96]$, Wald $(1)=5.36, p=0.021)$ and PD-sum-scores $(O R=$ 1.08 [1.00; 1.15], Wald $(1)=4.28, p=0.039$ ) were significant. Thus, patients with higher PD sum-scores were more likely to drop out than were patients with lower PD sumscores.

\section{Effects of PD on depression severity}

Table 1 presents results of the multilevel analyses. The three-way PD $x$ time $x$ condition and PD $x$ time-squared $x$ condition interactions were not significant for the BDI, F (1, $141.41)=1.30, p=0.28$, and $F(1,98.02)=2.21, p=0.14$. The NS three-way interactions were removed from the model. The two-way interaction between PD and condition was not significant for the BDI, $F(1,101.23)=1.32, p=0.25$. The two-way interactions between $\mathrm{PD}$ and time and $\mathrm{PD}$ and time-squared were (marginally) significant for the $B D I, F(1,102.65)=3.25, p=0.074$, and $F(1,98.92)=4.25, p=0.042$. In addition to significant condition by time effects, the PD main effect was significant, reflecting an overall higher BDI score for patients with comorbid PD over all assessments ( $p=0.02)$. As can be seen from figure 1 , more depressive symptom reduction in participants without PD than in those with PD was observed at mid-treatment and post treatment, but at 48-week follow-up this effect disappeared. After removing the PD by time and PD by time-squared interactions from the model, there was a main effect of PD: F (1, $101.53)=30.84, p<0.001$ for the BDI (Table 1), indicating higher depression levels throughout the study in participants with PD. 


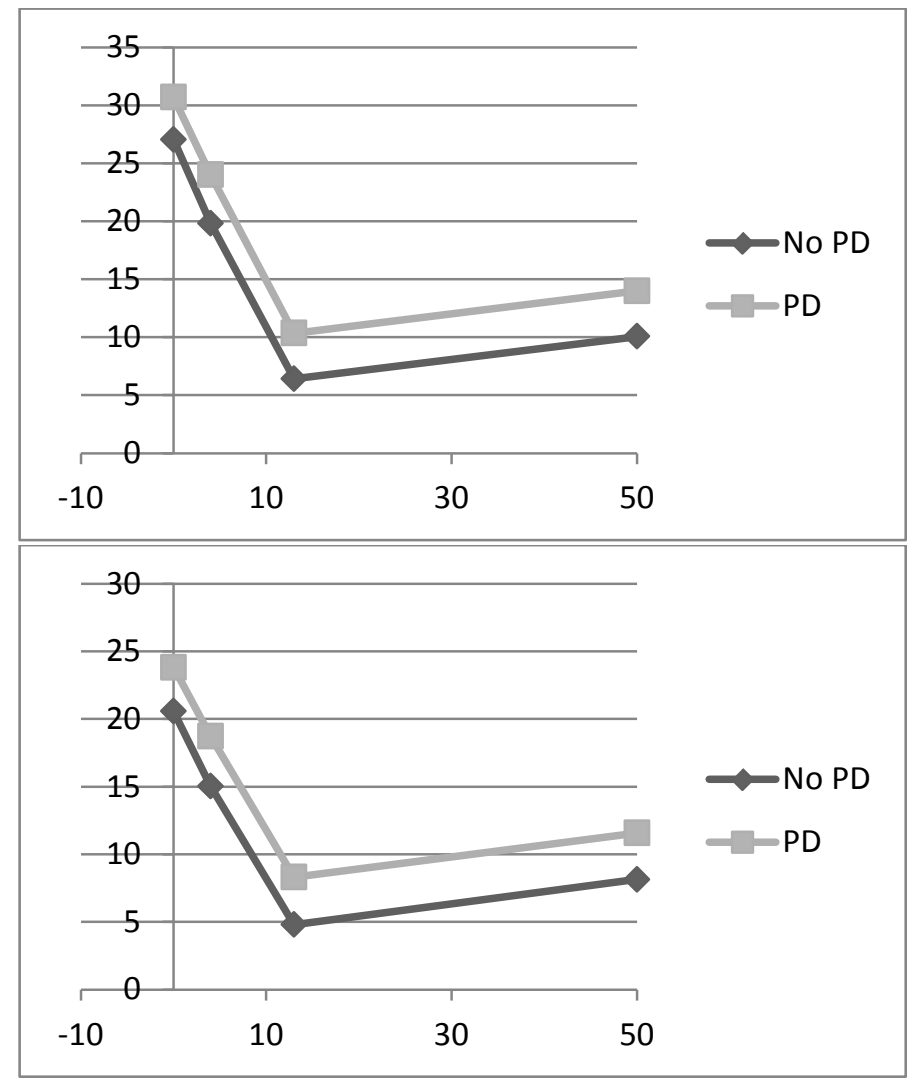

Figure 1. Mixed regression-based estimated means BDI(upper panel) and HRSD (lower panel) at baseline, mid-treatment, post-treatment and 1 year follow-up for those participants with and without PD, with PD by time and PD by squared time interaction in the model.

For the HRSD, the PD $x$ time $x$ condition and PD $x$ time-squared $x$ condition three-way interactions were not significant, $F(1,98.30)=1.48, p=0.27$, and $F(1,94.43)=1.86, p$ $=0.17$. The NS three-way interactions were removed from the model. The two-way interaction between PD and condition was not significant for the $\operatorname{HRSD}, F(1,95.19)=$ 1.03, $p=0.31$ and therefore removed. There were no two-way interactions between PD and time, and time-square, $F(1,100.11)=0.87, p=0.35$; and $F(1,96.46)=1.39, p$ $=0.24$. After deleting these interactions, there was a main effect of PD: $F(1,95.95)=$ $30.10, p<0.001$, indicating higher depression levels throughout the study in participants with PD (Figure 2). 


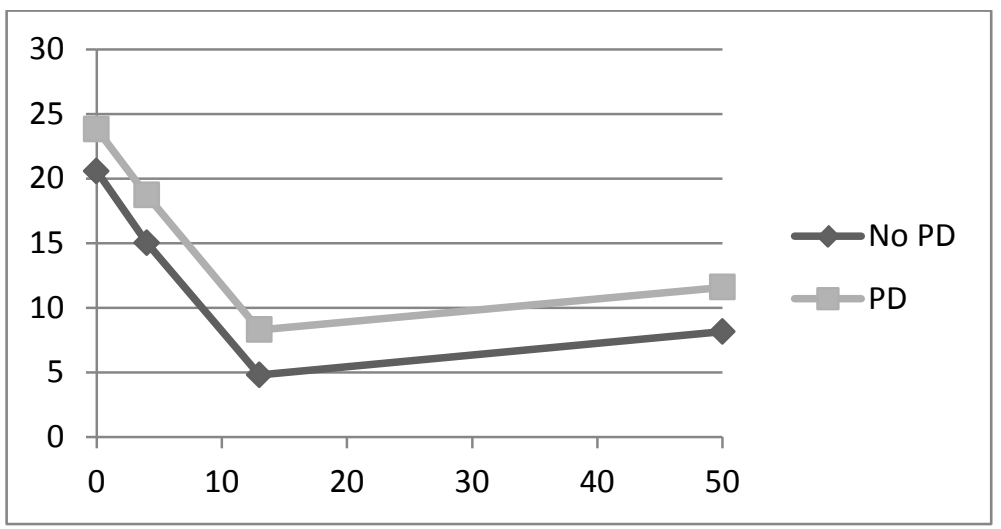

Figure 2. Mixed regression-based estimated means BDI and HRSD at baseline, midtreatment, post-treatment and 1 year follow-up without PD by time interaction.

\section{Effects of PD-trait sum-scores on depression severity}

We also tested for moderation by the standardized total sum-scores on the SCID-II as a measure of PD severity. The total sum-scores $x$ time $x$ condition and total sum-scores $x$ time-squared $x$ condition three-way interactions were not significant for the BDI, $F(1$, $78.04)=0.04, p=0.85$, and $F(1,77.64)=0.19, p=0.66$. The NS three-way interactions were removed from the model. The sum-scores $x$ condition two-way interaction was not significant for the $B D I, F(1,90.35)=2.24, p=0.13$. Also, the two-way interactions between sum-scores of the SCID-II and time and sum-scores and time-squared were not significant, $F(1,95.31)=0.01, p=0.91$, and $F(1,91.09)=0.09, p=0.76$. After removing these interactions from the model, there was a main effect of the total SCID-II sum-scores: $F(1,91.15)=8.15, p=0.005, r=.22$, indicating a higher depression level throughout the study in participants with a higher total score on the SCID-II.

For the HRSD, the sum-scores $x$ time $x$ condition and sum-scores $x$ time-squared $x$ condition three-way interactions were not significant, $F(1,70.37)=0.02, p=0.89$, and $F$ $(1,69.89)=0.18, p=0.67$. The NS three-way interactions were removed from the model. The two-way interaction between sum-scores and condition was not significant for the HRSD, $F(1,88.19)=2.45, p=0.12$. Also, there were no two-way interactions between sum-scores and time, and time-squared, $F(1,95.31)=0.01, p=0.91$, and $F(1$, $91.08)=0.08, p=0.76$. After deleting these interactions, there was a main effect of total sum-scores: $F(1,88.32)=9.38, p=0.003, r=.25$, indicating a higher depression level throughout the study in participants with a high total score on the SCID-II. 
Table1. Prediction of depressive symptoms by PD over time

\begin{tabular}{|c|c|c|c|c|c|c|}
\hline & $B$ & $95 \% \mathrm{Cl}(\mathrm{B})$ & $\mathrm{F}$ & $\mathrm{df}$ & $r^{1}$ & $p$ \\
\hline \multicolumn{7}{|c|}{ BDI with time $x$ PD interaction } \\
\hline Intercept & 27.18 & $25.84 ; 28.53$ & 1607.09 & 97.06 & 0.97 & $<0.001$ \\
\hline Condition & -1.13 & $-3.62 ; 1.37$ & 0.80 & 106.36 & 0.08 & 0.374 \\
\hline PD & 3.33 & $0.31 ; 6.35$ & 4.79 & 98.66 & 0.21 & 0.031 \\
\hline Time & -2.06 & $-2.20 ;-1.93$ & 871.10 & 88.73 & 0.95 & $<0.001$ \\
\hline Time-Squared & 0.04 & $0.03 ; 0.04$ & 821.90 & 85.91 & 0.95 & $<0.001$ \\
\hline Time $x$ Condition & -0.32 & $-0.58 ;-0.07$ & 6.45 & 91.51 & 0.25 & 0.013 \\
\hline Time-Squared x Condition & 0.01 & $0.00 ; 0.01$ & 5.20 & 88.51 & 0.23 & 0.025 \\
\hline Time $x$ PD & 0.31 & $-0.03 ; 0.65$ & 3.25 & 102.65 & 0.17 & 0.074 \\
\hline Time-Squared x PD & -0.01 & $-0.01 ;-0.00$ & 4.25 & 98.92 & 0.20 & 0.042 \\
\hline Condition x PD & -1.88 & $5.14 ; 1.37$ & 1.32 & 101.23 & 0.11 & 0.253 \\
\hline \multicolumn{7}{|c|}{ BDI without time $\times$ PD interaction } \\
\hline Intercept & 27.05 & $28.51 ; 28.29$ & 1875.91 & 107.70 & 0.97 & $<0.001$ \\
\hline Condition & -1.26 & $-3.65 ; 1.14$ & 1.08 & 98.51 & 0.10 & 0.301 \\
\hline PD & 4.43 & $2.85 ; 6.01$ & 30.84 & 101.503 & 0.48 & $<0.001$ \\
\hline Time & -2.03 & $-2.15 ;-1.90$ & 1004.01 & 92.86 & 0.95 & $<0.001$ \\
\hline Time-Squared & 0.03 & $0.03 ; 0.04$ & 917.46 & 89.65 & 0.95 & $<0.001$ \\
\hline Time $x$ Condition & -0.34 & $-0.60 ;-0.09$ & 7.17 & 92.85 & 0.26 & 0.009 \\
\hline Time-Squared $x$ Condition & 0.01 & $0.00 ; 0.01$ & 5.10 & 89.78 & 0.23 & 0.016 \\
\hline \multicolumn{7}{|c|}{ HRSD with time $x$ PD interaction } \\
\hline Intercept & 20.60 & $19.49 ; 21.73$ & 1324.07 & 97.00 & 0.96 & $<0.001$ \\
\hline Condition & -0.12 & $-2.22 ; 1.97$ & 0.01 & 106.97 & 0 & 0.910 \\
\hline PD & 3.67 & $1.14 ; 6.19$ & 8.31 & 98.72 & 0.27 & 0.005 \\
\hline Time & -1.57 & $-1.68 ;-1.46$ & 755.64 & 86.72 & 0.94 & $<0.001$ \\
\hline Time-Squared & 0.03 & $0.02 ; 0.03$ & 699.56 & 82.65 & 0.94 & $<0.001$ \\
\hline Time $x$ Condition & -0.31 & $-0.52 ;-0.10$ & 8.91 & 89.36 & 0.30 & 0.004 \\
\hline Time-Squared $x$ Condition & 0.01 & $0.00 ; 0.01$ & 8.28 & 85.28 & 0.29 & 0.005 \\
\hline Time $x$ PD & 0.13 & $-0.15 ; 0.40$ & 0.88 & 100.11 & 0.09 & 0.352 \\
\hline Time-Squared x PD & -0.00 & $-0.01 ; 0.00$ & 1.39 & 96.46 & 0.11 & 0.242 \\
\hline Condition x PD & -1.51 & $-.4 .45 ; 1.44$ & 1.03 & 95.19 & 0.10 & 0.313 \\
\hline \multicolumn{7}{|c|}{ HRSD without time $x$ PD interaction } \\
\hline Intercept & 20.57 & $19.53 ; 21.61$ & 1530.39 & 108.58 & 0.96 & $<0.001$ \\
\hline Condition & -0.41 & $-2.41 ; 1.60$ & 0.16 & 98.78 & 0.04 & 0.689 \\
\hline PD & 4.03 & $2.59 ; 5.47$ & 30.10 & 95.95 & 0.48 & $<0.001$ \\
\hline Time & -1.55 & $-1.65 ; 1.45$ & 898.10 & 90.80 & 0.95 & $<0.001$ \\
\hline Time-Squared & 0.03 & $0.02 ; 0.03$ & 811.90 & 86.90 & 0.95 & $<0.001$ \\
\hline Time $x$ Condition & -0.31 & $-0.51 ;-0.10$ & 8.89 & 90.79 & 0.29 & 0.004 \\
\hline Time-Squared x Condition & 0.01 & $0.00 ; 0.01$ & 8.38 & 87.01 & 0.28 & 0.005 \\
\hline
\end{tabular}

${ }^{1}$ Effect size $r=V(F /(F+d f))$ 


\section{Effects of cluster-A PD-traits on depression severity}

Table 2 presents the results of the mixed regression of the full model and the final model of cluster-A PD-traits for HRSD and BDI, respectively.

BDI: Three-way Condition $\times$ Time (Squared) $x$ cluster-A PD-traits interactions were not significant for the BDI (Table 2). After deleting of NS three-way interactions, there was a significant interaction between Time and cluster-A PD-traits, $F(1,94.57)=4.49$, $p=0.037$, indicating that both treatments are increasingly less effective over time for those with high cluster-A PD-trait scores. This holds for both BA and ADM, and is especially clear at 1 year follow-up (Figure 3 ). Cluster-A PD-traits did not predict overall higher BDI scores.

HRSD. Three-way Condition $\times$ Time (Squared) $x$ cluster-A PD-traits interactions were not significant for the HRSD (Table 2). Also, the two-way Condition $x$ cluster-A PD-traits and Time (Squared) $x$ cluster-A PD-traits interactions were not significant for the HRSD. Cluster-A PD-traits did not predict overall higher HRSD scores.

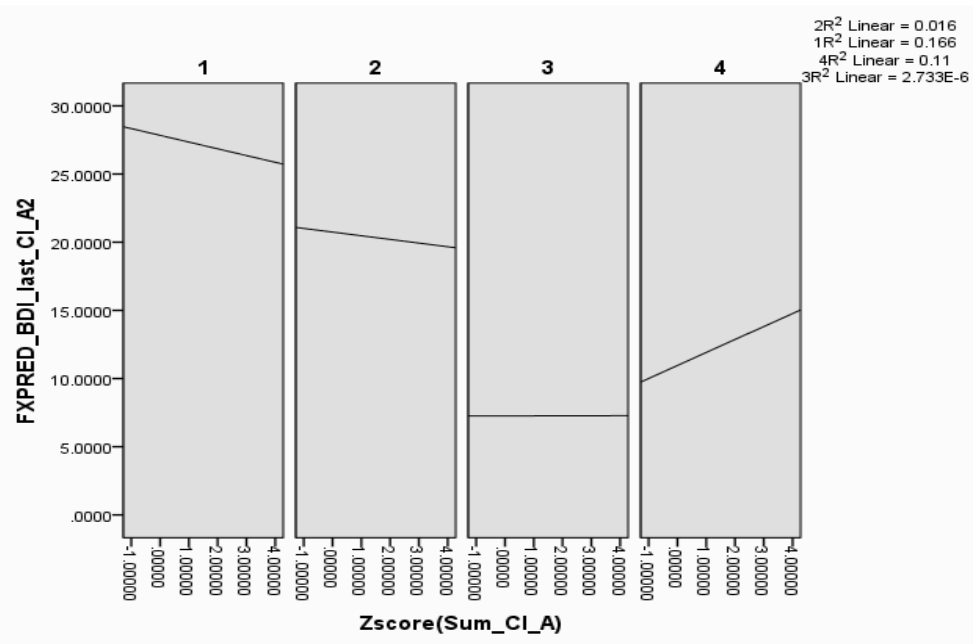

Figure 3. Mixed regression-based estimated slopes of cluster-A PD traits (standardized; $x$-axis) with BDI ( $y$-axis) at baseline, mid-treatment, post-treatment and 1 year followup with cluster $A$ traits by time interaction. 
Table 2. Prediction of depressive symptoms by cluster-A PD-traits over time

\begin{tabular}{|c|c|c|c|c|c|c|}
\hline & B & $95 \% \mathrm{Cl}(\mathrm{B})$ & $\mathrm{F}$ & df & $r^{1}$ & $\mathrm{p}$ \\
\hline \multicolumn{7}{|c|}{ BDI with time $x$-cluster-A traits interaction } \\
\hline Intercept & 28.00 & $26.78 ; 29.24$ & 2032.58 & 96.08 & 0.97 & $<0.001$ \\
\hline Condition & -1.75 & $-4.22 ; 0.71$ & 1.99 & 96.08 & 0.14 & 0.162 \\
\hline cluster-A traits & -0.16 & $-1.41 ; 1.09$ & 0.07 & 96.34 & 0.02 & 0.798 \\
\hline Time & -2.04 & $-2.17 ;-1.91$ & 964.58 & 90.02 & 0.95 & $<0.001$ \\
\hline Time-Squared & 0.03 & $0.03 ; 0.04$ & 871.68 & 86.92 & 0.95 & $<0.001$ \\
\hline Time $x$ Condition & -0.34 & $-0.60 ;-0.07$ & 6.71 & 90.02 & 0.26 & 0.011 \\
\hline Time-Squared $x$ Condition & 0.01 & $0.01 ; 0.01$ & 5.40 & 86.92 & 0.24 & 0.023 \\
\hline Condition $\mathrm{x}$ cluster-A traits & 1.70 & $-0.80 ; 4.21$ & 1.82 & 96.34 & 0.13 & 0.180 \\
\hline Time $\mathrm{x}$ cluster-A traits & -0.02 & $-0.16 ; 0.12$ & 0.08 & 94.10 & 0.02 & 0.784 \\
\hline Time-Squared $x$ cluster-A traits & 0.002 & $-0.001 ; 0.003$ & 0.37 & 91.87 & 0.06 & 0.545 \\
\hline Condition $\mathrm{x}$ Time $\mathrm{x}$ cluster-A traits & -0.07 & $-0.34 ; 0.21$ & 0.24 & 94.10 & 0.05 & 0.625 \\
\hline $\begin{array}{l}\text { Condition } \mathrm{x} \text { Time }- \text { Squared } \mathrm{x} \text { cluster- } \mathrm{A} \\
\text { traits }\end{array}$ & 0.001 & $-0.004 ; 0.01$ & 0.08 & 91.87 & 0.02 & 0.774 \\
\hline \multicolumn{7}{|l|}{ BDI without time $x$ cluster-A interaction } \\
\hline Intercept & 27.83 & $26.60 ; 29.07$ & 2006.70 & 97.37 & 0.97 & $<0.001$ \\
\hline Condition & -2.21 & $-4.69 ; 0.26$ & 3.15 & 97.80 & 0.17 & 0.079 \\
\hline cluster-A traits & -0.60 & $0.03 ; 0.04$ & 1.43 & 87.27 & 0.12 & 0.235 \\
\hline Time & -2.03 & $-2.16 ;-1.90$ & 984.22 & 90.17 & 0.95 & $<0.001$ \\
\hline Time-Squared & 0.03 & $-1.62 ; 0.40$ & 897.07 & 87.27 & 0.95 & $<0.001$ \\
\hline Time $x$ Condition & -0.31 & $-0.56 ;-0.05$ & 5.65 & 90.18 & 0.24 & 0.020 \\
\hline Time-Squared x Condition & 0.004 & $0.002 ; 0.01$ & 4.63 & 87.20 & 0.22 & 0.034 \\
\hline Time $\mathrm{x}$ cluster- $\mathrm{A}$ traits & 0.03 & $0.001 ; 0.05$ & 4.49 & 94.57 & 0.21 & 0.037 \\
\hline \multicolumn{7}{|c|}{ HRSD with time $x$ cluster-A traits interaction } \\
\hline Intercept & 21.4 & $20.39 ; 22.50$ & 1624.61 & 95.77 & 0.97 & $<0.001$ \\
\hline Condition & -0.73 & $-2.84 ; 1.38$ & 0.47 & 95.77 & 0.06 & 0.493 \\
\hline cluster-A traits & -0.03 & $-1.11 ; 1.04$ & 0.004 & 96.28 & 0 & 0.950 \\
\hline Time & -1.56 & $-1.67 ;-1.45$ & 864.53 & 87.24 & 0.95 & $<0.001$ \\
\hline Time-Squared & 0.03 & $0.02 ; 0.03$ & 777.51 & 82.75 & 0.95 & $<0.001$ \\
\hline Time $x$ Condition & -0.31 & $-0.52 ;-0.10$ & 8.60 & 87.25 & 0.29 & 0.004 \\
\hline Time-Squared $x$ Condition & 0.01 & $-.002 ; 0.01$ & 7.98 & 82.75 & 0.29 & 0.006 \\
\hline Condition $\mathrm{x}$ cluster-A traits & 1.21 & $-0.94 ; 0.3 .35$ & 1.25 & 96.28 & 0.11 & 0.266 \\
\hline Time $x$ cluster-A traits & -0.3 & $-0.14 ; 0.08$ & 0.28 & 91.10 & 0.05 & 0.599 \\
\hline Time-Squared $x$ cluster- $A$ traits & 0.002 & $-0.001 ; 0.002$ & 0.58 & 88.10 & 0.08 & 0.449 \\
\hline Condition $\mathrm{x}$ Time $\mathrm{x}$ cluster-A traits & -0.05 & $-0.27 ; 0.17$ & 0.20 & 91.10 & 0.04 & 0.654 \\
\hline $\begin{array}{l}\text { Condition } \mathrm{x} \text { Time }- \text { Squared } \mathrm{x} \text { cluster-A } \\
\text { traits }\end{array}$ & 0.002 & $-0.004 ; 0.004$ & 0.04 & 88.10 & 0.02 & 0.847 \\
\hline
\end{tabular}




\begin{tabular}{lclllll}
\hline & $\mathrm{B}$ & $95 \% \mathrm{Cl}(\mathrm{B})$ & $\mathrm{F}$ & $\mathrm{df}$ & $\mathrm{r}^{1}$ & $\mathrm{p}$ \\
\hline HRSD without time x cluster-A traits interaction & & & & & \\
Intercept & 21.39 & $20.33 ; 22.44$ & 1624.31 & 98.10 & 0.97 & $<0.001$ \\
Condition & -0.73 & $-2.84 ; 1.39$ & 0.47 & 98.55 & 0.06 & 0.496 \\
cluster-A traits & -0.04 & $-0.69 ; 0.62$ & 0.01 & 90.95 & 0.01 & 0.910 \\
Time & -1.55 & $-1.66 ;-1.45$ & 885.24 & 87.89 & 0.95 & $<0.001$ \\
Time-Squared & 0.03 & $0.02 ; 0.03$ & 796.65 & 83.14 & 0.95 & $<0.001$ \\
Time x Condition & -0.31 & $-0.52 ;-0.10$ & 8.56 & 87.88 & 0.29 & 0.004 \\
Time-Squared x Condition & 0.01 & $0.002 ; 0.01$ & 7.83 & 83.11 & 0.29 & 0.006 \\
\hline
\end{tabular}

${ }^{1}$ Effect size $r=V(F /(F+d f))$

\section{Effects of Cluster-B PD-traits on depression severity}

$B D I$ and HRSD. Cluster-B PD-traits did not moderate treatment or time effects on $B D I$ and HRSD, neither did these traits predict overall higher depression scores (Table 3).

\section{Effects of Cluster-C PD-traits on depression severity}

$B D I$. Table 4 presents the results. After deleting the three-way interactions, the two-way Condition x cluster-C PD-traits interaction was significant, $F(1,91.80)=4.95$, $p=0.028$, indicating a differential association between cluster-C PD-traits and BDI in the two treatment conditions. As this effect was already present at baseline, we refrain from interpreting it. The main effect of cluster-C PD-traits on the BDI was significant, $F$ $(1,91.80)=4.35, p=0.040$, indicating higher BDI-scores for those with more cluster-C PD-traits.

HRSD. The three-way Condition $x$ Time (Squared) $x$ cluster-C PD-traits interactions were not significant for the HRSD (Table 4). After removing the three-way interactions, the two-way Condition $x$ cluster-C PD-traits and Time $x$ cluster-C PD-traits interactions were significant, $F(1,88.82)=6.36, p=0.013$ and $F(1,87.23)=p=0.037$. As the Condition $x$ cluster-C PD-traits interaction was already present at baseline, we refrain from interpreting it. The Time by Cluster-C PD-traits interaction reflects a weakening of the association between Cluster-C PD-traits and HRSD over time. The main effect of cluster-C PD-traits on the HRSD was significant, $F(1,91.52)=14.90, p=0.001$, indicating that cluster-C PD-traits were associated with overall higher HRSD scores. 
Table 3. Prediction of depressive symptoms by cluster-B PD-traits over time

\begin{tabular}{|c|c|c|c|c|c|c|}
\hline & B & $95 \% \mathrm{Cl}(\mathrm{B})$ & $\mathrm{F}$ & $\mathrm{df}$ & $r^{1}$ & $\mathrm{p}$ \\
\hline \multicolumn{7}{|l|}{ BDI with time $x$ cluster-B traits interaction } \\
\hline Intercept & 27.91 & $26.65 ; 29.16$ & 1957.37 & 96.15 & 0.97 & $<0.001$ \\
\hline Condition & -1.93 & $-4.43 ; 0.58$ & 2.34 & 96.15 & 0.15 & 0.130 \\
\hline cluster-B traits & 0.04 & $-1.29 ; 1.38$ & 0.004 & 95.94 & 0 & 0.949 \\
\hline Time & -2.03 & $-2.16 ;-1.90$ & 991.02 & 89.07 & 0.95 & $<0.001$ \\
\hline Time-Squared & 0.03 & $0.03 ; 0.04$ & 904.58 & 85.51 & 0.95 & $<0.001$ \\
\hline Time $x$ Condition & -0.31 & $-0.56 ;-0.05$ & 5.65 & 89.07 & 0.24 & 0.020 \\
\hline Time-Squared $x$ Condition & 0.004 & $0.002 ; 0.01$ & 4.33 & 85.51 & 0.21 & 0.040 \\
\hline Condition $\mathrm{x}$ cluster- $\mathrm{B}$ traits & 0.54 & $-2.14 ; 3.21$ & 0.16 & 95.94 & 0.04 & 0.691 \\
\hline Time $x$ cluster- $B$ traits & 0.09 & $-0.05 ; 0.22$ & 1.66 & 86.57 & 0.13 & 0.201 \\
\hline Time-Squared $x$ cluster- $B$ traits & -0.002 & $-0.004 ; 0.002$ & 2.14 & 84.15 & 0.15 & 0.147 \\
\hline Condition $\mathrm{x}$ Time $\mathrm{x}$ cluster- $\mathrm{B}$ traits & 0.02 & $-0.25 ; 0.29$ & 0.03 & 86.57 & 0.01 & 0.867 \\
\hline Condition $x$ Time - Squared $x$ cluster- $B$ traits & -0.002 & $-0.01 ; 0.004$ & 0.03 & 84.15 & 0.01 & 0.867 \\
\hline \multicolumn{7}{|l|}{ BDI without time $x$ cluster-B traits interaction } \\
\hline Intercept & 27.87 & $26.64 ; 29.10$ & 2017.52 & 97.92 & 0.97 & $<0.001$ \\
\hline Condition & -1.86 & $-4.33 ; 0.61$ & 2.24 & 98.71 & 0.14 & 0.137 \\
\hline cluster-B traits & 0.28 & $-0.44 ; 0.10$ & 0.59 & 94.48 & 0.07 & 0.444 \\
\hline Time & -2.03 & $-2.16 ;-1.91$ & 1004.11 & 91.74 & 0.95 & $<0.001$ \\
\hline Time-Squared & 0.03 & $0.03 ; 0.04$ & 910.67 & 88.23 & 0.95 & $<0.001$ \\
\hline Time $x$ Condition & -0.32 & $-0.58 ;-0.07$ & 6.37 & 91.74 & 0.05 & 0.013 \\
\hline Time-Squared x Condition & 0.01 & $0.002 ; 0.01$ & 4.94 & 88.22 & 0.23 & 0.029 \\
\hline \multicolumn{7}{|l|}{ HRSD with time $x$ cluster-B traits interaction } \\
\hline Intercept & 21.42 & $20.35 ; 22.49$ & 1582.24 & 96.22 & 0.97 & $<0.001$ \\
\hline Condition & -0.81 & $-2.95 ; 1.32$ & 0.57 & 96.22 & 0.07 & 0.452 \\
\hline cluster-B traits & -0.36 & $-1.50 ; 0.78$ & 0.39 & 95.98 & 0.06 & 0.534 \\
\hline Time & -1.56 & $-1.66 ;-1.45$ & 870.82 & 84.86 & 0.95 & $<0.001$ \\
\hline Time-Squared & 0.03 & $0.02 ; 0.03$ & 781.91 & 80.24 & 0.95 & $<0.001$ \\
\hline Time $x$ Condition & -0.29 & $-0.50 ;-0.08$ & 7.66 & 84.86 & 0.28 & 0.007 \\
\hline Time-Squared $x$ Condition & 0.01 & $0.002 ; 0.01$ & 7.04 & 80.24 & 0.28 & 0.010 \\
\hline Condition $\mathrm{x}$ cluster- $\mathrm{B}$ traits & 0.46 & $-1.82 ; 2.74$ & 0.16 & 95.98 & 0.04 & 0.688 \\
\hline Time $\mathrm{x}$ cluster- $\mathrm{B}$ traits & 0.07 & $-0.04 ; 0.18$ & 1.62 & 82.60 & 0.13 & 0.206 \\
\hline Time-Squared $x$ cluster- $B$ traits & -0.002 & $-0.002 ; 0.004$ & 1.39 & 78.97 & 0.02 & 0.241 \\
\hline Condition $\mathrm{x}$ Time $\mathrm{x}$ cluster- $\mathrm{B}$ traits & 0.02 & $-0.20 ; 0.24$ & 0.05 & 82.60 & 0.01 & 0.833 \\
\hline Condition $\mathrm{x}$ Time - Squared $\mathrm{x}$ cluster- $\mathrm{B}$ traits & -0.002 & $-0.004 ; 0.002$ & 0.03 & 78.97 & 0.01 & 0.870 \\
\hline
\end{tabular}




\begin{tabular}{lcccccc}
\hline & $\mathrm{B}$ & $95 \% \mathrm{Cl}(\mathrm{B})$ & $\mathrm{F}$ & $\mathrm{df}$ & $\mathrm{r}^{1}$ & $\mathrm{p}$ \\
\hline HRSD without time x cluster-B traits interaction & & & & & \\
Intercept & 21.39 & $20.33 ; 22.24$ & 16.17 & 97.39 & 0.37 & $<0.001$ \\
Condition & -0.68 & $-2.80 ; 1.4$ & 0.41 & 98.23 & 0.06 & 0.523 \\
cluster-B traits & 0.13 & $-0.52 ; 0.78$ & 0.16 & 88.03 & 0.04 & 0.687 \\
Time & -1.56 & $-1.66 ;-1.45$ & 886.75 & 88.02 & 0.95 & $<0.001$ \\
Time-Squared & 0.03 & $0.02 ; 0.03$ & 798.13 & 83.29 & 0.95 & $<0.001$ \\
Time x Condition & -0.31 & $-0.52 ;-0.10$ & 8.61 & 88.02 & 0.29 & 0.004 \\
Time-Squared x Condition & 0.01 & $0.002 ; 0.01$ & 7.87 & 83.28 & 0.29 & 0.006 \\
\hline
\end{tabular}

${ }^{1}$ Effect size $r=V(F /(F+d f)$

Table 4. Prediction of depressive symptoms by cluster-C PD-traits over time

\begin{tabular}{|c|c|c|c|c|c|c|}
\hline & $B$ & $95 \% \mathrm{Cl}(\mathrm{B})$ & $\mathrm{F}$ & df & $r^{1}$ & $p$ \\
\hline \multicolumn{7}{|l|}{ BDI with time $x$ cluster-C traits interaction } \\
\hline Intercept & 27.87 & $26.69 ; 29.06$ & 2187.75 & 96.34 & 0.97 & $<0.001$ \\
\hline Condition & -2.07 & $-4.43 ; 0.30$ & 3.01 & 96.34 & 0.17 & 0.086 \\
\hline Time & -2.03 & $-2.16 ;-1.90$ & 988.67 & 90.08 & 0.95 & $<0.001$ \\
\hline Time-Squared & 0.03 & $0.03 ; 0.04$ & 897.00 & 86.33 & 0.95 & $<0.001$ \\
\hline Time $x$ Condition & -0.33 & $-0.58 ;-0.07$ & 6.50 & 90.08 & 0.25 & 0.012 \\
\hline Time-Squared x Condition & 0.01 & $0.004 ; 0.01$ & 5.21 & 86.33 & 0.23 & 0.025 \\
\hline cluster-C traits & 0.75 & $-0.47 ; 1.98$ & 1.48 & 96.69 & 0.12 & 0.226 \\
\hline Condition $\mathrm{x}$ cluster- $\mathrm{C}$ traits & -3.13 & $-5.58 ;-0.67$ & 6.40 & 96.69 & 0.24 & 0.013 \\
\hline Time $x$ cluster- $C$ traits & 0.05 & $-0.09 ; 0.19$ & 0.54 & 93.78 & 0.07 & 0.464 \\
\hline Time-Squared $\mathrm{x}$ cluster- $\mathrm{C}$ traits & -0.002 & $-0.002 ; 0.002$ & 0.93 & 89.29 & 0.01 & 0.338 \\
\hline Condition $\mathrm{x}$ Time $\mathrm{x}$ cluster-C traits & 0.26 & $-0.01 ; 0.53$ & 3.57 & 93.78 & 0.19 & 0.062 \\
\hline Condition $\mathrm{x}$ Time - Squared $\mathrm{x}$ cluster-C traits & -0.004 & $-0.01 ; 0.002$ & 3.60 & 89.29 & 0.19 & 0.061 \\
\hline \multicolumn{7}{|l|}{ BDI without time $x$ cluster-C traits interaction } \\
\hline Intercept & 27.87 & $26.69 ; 29.05$ & 2183.03 & 96.99 & 0.97 & $<0.001$ \\
\hline Condition & -2.02 & $-4.39 ; 0.35$ & 2.87 & 96.99 & 0.16 & 0.094 \\
\hline Time & -2.03 & $-2.15 ;-1.90$ & 992.33 & 91.36 & 0.95 & $<0.001$ \\
\hline Time-Squared & 0.03 & $0.03 ; 0.04$ & 901.03 & 87.95 & 0.95 & $<0.001$ \\
\hline Time $x$ Condition & 0.34 & $-0.59 ;-0.08$ & 6.90 & 91.36 & 0.26 & 0.010 \\
\hline Time-Squared $x$ Condition & -0.01 & $0.004 ; 0.01$ & 5.64 & 87.95 & 0.24 & 0.020 \\
\hline cluster-C traits & 0.73 & $0.03 ; 1.43$ & 4.35 & 91.80 & 0.21 & 0.040 \\
\hline Condition $\mathrm{x}$ cluster- $\mathrm{C}$ traits & -1.56 & $-2.95 ; 0.17$ & 4.95 & 91.80 & 0.22 & 0.028 \\
\hline \multicolumn{7}{|l|}{ HRSD with time $x$ cluster-C traits interaction } \\
\hline Intercept & 21.41 & $20.43 ; 22.39$ & 1879.74 & 96.35 & 0.97 & $<0.001$ \\
\hline Condition & -0.74 & $-2.70 ; 1.22$ & 0.56 & 96.35 & 0.05 & 0.457 \\
\hline Time & -1.55 & $-1.66 ;-1.45$ & 876.10 & 88.18 & 0.95 & $<0.001$ \\
\hline
\end{tabular}




\begin{tabular}{lllllll}
\hline & $\mathrm{B}$ & $95 \% \mathrm{Cl}(\mathrm{B})$ & $\mathrm{F}$ & $\mathrm{df}$ & $\mathrm{r}^{1}$ & $\mathrm{p}$ \\
\hline Time-Squared & 0.03 & $0.02 ; 0.03$ & 785.19 & 83.52 & 0.95 & $<0.001$ \\
Time x Condition & -0.32 & $-0.53 ;-0.11$ & 9.18 & 88.18 & 0.30 & 0.003 \\
Time-Squared x Condition & 0.01 & $0.00 ; 0.01$ & 8.58 & 83.52 & 0.30 & 0.004 \\
cluster-C traits & 1.28 & $0.26 ; 2.29$ & 6.22 & 96.66 & 0.24 & 0.014 \\
Condition x cluster-C traits & -2.64 & $-4.68 ;-0.61$ & 6.65 & 96.66 & 0.25 & 0.011 \\
Time x cluster-C traits & 0.004 & $-0.11 ; 0.11$ & 0.01 & 91.81 & 0.01 & 0.933 \\
Time-Squared x cluster-C traits & -0.004 & $-0.002 ; 0.002$ & 0.18 & 86.76 & 0.04 & 0.658 \\
Condition x Time x cluster-C traits & 0.17 & $-0.05 ; 0.39$ & 2.32 & 91.81 & 0.15 & 0.139 \\
Condition x Time -Squared x cluster-C traits & -0.002 & $-0.01 ; 0.002$ & 2.22 & 86.76 & 0.15 & 0.140 \\
HRSD without time x cluster-C trait interaction & & & & & & \\
Intercept & 21.40 & $20.42 ; 22.38$ & 1877.63 & 97.04 & 0.97 & $<0.001$ \\
Condition & -0.75 & $-2.71 ; 1.21$ & 0.58 & 97.04 & 0.07 & 0.449 \\
Time & -1.55 & $-1.65 ;-1.45$ & 879.89 & 88.80 & 0.95 & $<0.001$ \\
Time-Squared & 0.03 & $0.02 ; 0.03$ & 790.51 & 84.54 & 0.95 & $<0.001$ \\
Time x Condition & -0.32 & $-0.53 ;-0.11$ & 9.53 & 88.80 & 0.31 & 0.003 \\
Time-Squared x Condition & 0.01 & $0.002 ; 0.01$ & 8.99 & 84.57 & 0.30 & 0.004 \\
cluster-C traits & 1.49 & $0.72 ; 2.26$ & 14.90 & 91.52 & 0.37 & $<0.001$ \\
Condition x cluster-C traits & -1.57 & $-2.81 ;-0.33$ & 6.36 & 88.82 & 0.25 & 0.013 \\
Time x cluster-C traits & -0.02 & $-0.04 ;-0.002$ & 4.51 & 87.23 & 0.22 & 0.037 \\
\hline
\end{tabular}

${ }^{1}$ Effect size $r=V(F /(F+d f)$

\section{Discussion}

The results of this study indicate that participants with comorbid PDs had higher scores on BDI and HRSD at baseline and throughout the study than participants without comorbid PD. Both groups responded equally well to the short term treatments in the acute phase, and this parallel development over time was still apparent at one year follow-up. The absence of PD $x$ condition and PD $x$ time $x$ condition interactions indicates that PD did not moderate the difference between the treatment conditions. Thus, BA was overall better in reducing symptoms in patients but this effect was not influenced by comorbid PD. For the BDI we found equivocal evidence that PD was associated with a somewhat less strong immediate response to treatment, but this effect disappeared at one year follow-up. The statistical evidence for this effect was weak, could not be detected in the HRSD, and most of the effects were explained by parallel development in the two groups. We repeated the analyses for PD-trait sum score and the findings were the same: PD-traits were associated with higher depressive symptom scores from baseline on throughout the study, but not with a reduced treatment effect. However, an important effect of PD (both in terms of diagnosis and trait sum 
scores) was found in dropout rates, which were higher in those with comorbid PD (and with higher PD trait sum scores), independent of treatment condition.

Given the fact that Fournier et al. (2008) found that especially Cluster-B PDpathology was responsible for the moderation of treatment effects, we explored the effects of the three cluster scores. We did not find evidence for moderating effects of cluster scores on treatment differences. However, we found that cluster-C PD-traits were associated with generally higher levels of depression over the trial, whereas cluster-A and $B$ traits did not have this association. Moreover, for the HRSD this association became weaker over time, suggesting that over time the predictive power of cluster- $C$ PD-traits reduces. Lastly, we found evidence that cluster-A PD-traits were associated with a poorer treatment response over time, for both BA and ADM, but only for the BDI. Given the fact that this was not found on the HRSD, this result should be interpreted with caution.

The findings of this study are consistent with Mulder (2002), Kool and et al (2005), and De Bolle et al (2010), in that general personality pathology does not have an effect on treatment outcome and is not an obstacle to good treatment response. In other words, it seems that well-designed studies with structural clinical interviews and with good statistical analyses do not support the hypothesis of effects of PD on treatment outcome in patients with MDD. Our findings are in contrast to Newton-Howes's review (2006). An important methodological issue is whether baseline MDD severity is taken into account or not (Dreessen \& Arntz, 1998). In the Newton-Howes's meta-analysis baseline severity was not taken into account, so it cannot be excluded that the PD effects on depression scores found at follow-up in fact reflect differences already present at baseline (Dreessen \& Arntz, 1998).

In the meta-analysis by Kool et al, (2005) only two studies reported drop-out rates. Other meta-analyses did not report drop-out rates. No study so far found statistically significant differences in drop-out rates between patients with and without PDs. Sullivan's (Sullivan, Joyce \& Mulder, 1994) study reported 15\% dropout in the group without PD, and 15\% for those with PD. Dropout rates in Kool, Dekker, Duijsens, De Jonghe \& Puite (2003) study was $21.7 \%$ in the non-PD group and $22.4 \%$ in the PD group. Fournier et al (2008) found no overall difference in drop out between people with and without PD. In the antidepressant group the drop-out rate was $12 \%$ for people with PD and $21 \%$ for those without PD, and in the cognitive therapy group $12 \%$ for the people without PD and $22 \%$ for those with PD. Thus, the difference was not significant. In our study we found 8 out of 20 dropouts (40\%) had PD, compared to 12 out of 80 (15\%) completers, with no interaction with treatment condition.

Fournier et al, (2008) findings indicated that cognitive therapy did not do well in people with $\mathrm{PD}$, but in our study BA was quite effective in treating people with $\mathrm{PD}$ and had less drop out than ADM. This raises the possibility that BA should be preferred 
above CT in both patients with and without comorbid PD, at least for the acute treatment phase. It should be noted however that apart from the different psychological treatments (CT vs BA), there were other differences between the studies. Whereas Fournier et al. used DSM-III-R PD criteria; we used DSM-IV-TR PD criteria. Moreover, cultural differences might have played a role. Note that Fournier et al found that the $P D \times$ treatment condition effect was driven by Cluster-B PD criteria. We did not find such an effect of cluster-B PD psychopathology. In fact none of the PDpsychopathology indicators moderated condition differences on treatment outcome in our study.

Depressed participants with personality pathology bring more problems in addition to depression into therapy and these problems need more efforts by therapists in dealing with the problems, thereby exerting more stress on therapists (Dreessen \& Arntz, 1999). This might be a reason for therapists feeling that depressed patients with co-morbid personality pathology respond less to treatment. Another reason for the belief that PD is associated with less response might be the higher levels of depression at the end of treatment - which are in fact not an indication of less response, but of a generally higher level of depression, already present at baseline. Still another reason might be that therapists might attribute lack of treatment response to alleged PD pathology in the patient (Kool et al., 2003). At least one indication of increased problems in treating patients with comorbid PD is their higher dropout rate observed in the current study.

\section{Limitations}

A number of limitations should be considered for the data presented in this publication. First, the categorical model of PD is subject to controversies, and dimensional models are proposed as better representing personality pathology (De Bolle et al., 2010). However, we investigated the effects of dimensional measures of PD pathology and could not demonstrate any consistent moderation effects either. The only interactions with time we observed (with cluster-A and cluster- $\mathrm{C}$ trait scores) were restricted to one outcome measure, and the lack of replication on the other measure obviously limits the meaning of these findings, which may have been accidental. Second, the sample size was not large enough to investigate individual PDs. However, we were able to investigate effects of cluster scores. Third, due to ethical regulations we had to skip the originally planned pill-placebo condition, which would have been helpful to separate specific from non-specific effects. Fourth, the treatments were brief with regard to the durations suggested for people with depression with co-morbid personality pathology (Fournier et al., 2008). MDD treatment might need more time to reach similar endpoints in patients with comorbid PD compared to patients without this comorbidi- 
ty. Alternatively, approaches that focus more on issues related to the comorbid PD might be needed for this.

\section{Future Research}

This is the first trial comparing BA to ADM in depressed participants that assessed effects of co-morbid PD on treatment retention and response. Future studies with larger samples are needed to investigate the effects of specific PDs on effects of BA, or other psychological treatments such as cognitive therapy, and ADM.

\section{Clinical implications}

Our conclusion is that depressed participants with co-morbid PD responded to BA and ADM parallel to those without PD. The only indication of an exception to this general effect was the long-term effect of cluster-A PD-traits on the BDI, suggesting a weaker response in those with elevated cluster-A traits. However, given the fact that a similar effect was not found on the HRSD it seems too early to draw clinical conclusions from this finding, which might have been accidental. Thus, depressed participants with PD can be treated by both BA and ADM treatment although BA is more effective. At the start of the treatment, people with comorbid PD had a higher score on BDI and HRSD than those without personality pathology, and they maintained relatively higher scores over the short-term and at 1 year follow-up. This effect was especially driven by cluster-C PD-traits. To further decrease depression levels in patients with comorbid PD, longer treatment might be necessary. Comorbid PD does not seem to be an exclusion criterion for BA or ADM, although there is an increased risk of dropout from treatment. 


\section{References}

American Psychiatric Association (2000). Diagnostic and statistical manual of mental disorders (DSM-IV-TR.). Washington, DC: Author.

Beck, A.T., Steer, R.A., \& Brown, G.K. (1996). Manual for the BDI-II. San Antonio, TX: Psychological Corporation.

De Bolle, M., De Fruyt, F., C. Quilty, L., Rolland, J.P., Decuyper, M., Bagby, R.M., et al. (2010). Does personality disorder co-morbidity impact treatment outcome forpatients with major depression? A multi-level analysis. Journal of Personality Disorders, 25 (1), 15.

Dreessen, L., \& Arntz, A. (1999). Personality Disorders have no excessively negative impact on therapistrated therapy process in the cognitive and behavioral treatment of Axis I Anxiety Disorders. Clinical Psychology \& Psychotherapy, 6, 384-394.

Dreessen, L., \& Arntz, A. (1998). The impact of personality disorders on treatment outcome of anxiety disorders: Best-evidence synthesis. Behaviour Research and Therapy, 36 (5), 483-504.-129.

First, M.B., Williams, J.B., Spitzer, R.L., \& Gibbon, M. (2007). Structured Clinical Interview for DSM-IV- TR Axis I Disorders, Clinical Trials Version (SCID-CT). New York: Biometrics Research, New York State Psychiatric Institute.

First, M.B., Spitzer, R.L., Gibbons, M., Williams, J.B., \& Benjamin, L. (1996). User's guide for the Structured Clinical Interview for DSM-IV Axis II Personality Disorders (SCID-II). New York: New York State Psychiatric Institute, Biometrics Research Department.

Fournier, J.C., DeRubeis, R.J., Shelton, R.C., Gallop, R., Amsterdam, J.D., \& Hollon, S.D. (2008). Antidepressants medications $\mathrm{v}$. cognitive therapy in people with depression with or without personality disorder. British Journal of Psychiatry, 192, 124.

Hamilton, M. (1960). A rating scale for depression. Journal of Neurology Neurosurgery and Psychiatry, 23, 56-61.

Hardy, G.E., Barkham, M., Shapiro, D.A., Rees, A., Stiles, W.B., \& Reynolds, S. (1995). Impact of cluster-c personality disorders on outcomes of contrasting brief psychotherapies for depression. Journal of Consulting and Clinical Psychology, 63 (6), 997-1004.

Kool, S., Dekker, J., Duijsens, I.J., De Jonghe, F., \& Puite, B. (2003). Efficacy of combined therapy and pharmacotherapy for depressed patients with or without personality disorders. Harvard Review of Psychiatry, $11(3), 133-141$.

Kool, S., Schoevers, R., De Maat, S., Van, R., Molenaar, P., Vink, A., et al. (2005). Efficacy of pharmacotherapy in depressed patients with and without personality disorders: A systematic review and meta-analysis. Journal of Affective Disorders, 88, 269-79.

Moradveisi, L., Huibers, M., Renner, F., Arasteh, M., \& Arntz, A. (2013). Behavioural activation v. Antidepressant Medication for depression in Iran: a Randomized Trial. British Journal of psychiatry, 202 (3) 204211.

Mulder, R.T (2002). Personality pathology and treatment outcome in major depression: a review. American Journal of Psychiatry, 159, 359-371. Newton-Howes, G., Tyrer, P., \& Johnson, T. (2006). Personality disorder and the outcome of depression: meta-analysis of published studies. British Journal of Psychiatry, $188,13-20$.

Sato, T., Sakado, K., Sato, S., \& Morikawa, T. (1994). Cluster a personality disorder- A marker of worse treatment outcome of major depression. Psychiatric Research, 53 (2), 153-159.

Shea, M.T., Widiger, T.A., \& Klein, M.H. (1992). Comorbidity of personality disorder and depression implications for treatment. Journal of Consulting and Clinical Psychology, 60 (6), 857-868.

Sullivan, P.F., Joyce, P.R., \& Mulder, R.T. (1994). Borderline personality disorder in major depression. Journal of Nervous and Mental Disease, 182 (9), 508-516. 
Tyrer, P., Seivewright, N., Ferguson, B., Murphy, S., \& Johnson, A.L. The Nottingham Study of Neurotic Disorder: effect of personality status on response to drug treatment, cognitive therapy and self-help over two years. British Journal of Psychiatry, 162, 219-225. 


\section{Chapter 4}

\section{The influence of patients' preference/attitude towards psychotherapy and antidepressant medication on the treatment of major depressive disorder $^{6}$}

6 Published as: Moradveisi, L., Huibers, M., Renner, F., \& Arntz, A. (2014). The influence of patients' preference/attitude towards psychotherapy and antidepressant medication on the treatment of major depressive disorder. Journal of Behaviour Therapy and Experimental Psychiatry, 45(1), 170-177. 


\section{Abstract}

Background and Objectives: Preferences and attitudes that patients hold towards the treatment they receive are important, as these can influence treatment outcome. In depression research, the influence of patients' preference/attitudes on outcome and dropout has mainly been studied for antidepressant medication, and less for psychological treatments. We investigated the effects of patients' preference and attitudes towards psychological treatment and antidepressant medication on treatment outcome and dropout, and tested specificity of effects.

Methods: Data are based on a randomized trial testing the effectiveness of behavioural activation (BA) vs antidepressant medication (ADM) for major depression (MDD) in Iran. Patients with MDD $(N=100)$ were randomized to $B A(N=50)$ or $A D M(N=50)$. Patients' preference/attitudes towards psychotherapy and ADM were assessed at baseline and associated with dropout and treatment outcome using logistic regression and multilevel analysis.

Results: High scores on psychotherapy preference/attitude and low scores on ADM preference/attitude predicted dropout in ADM, while no association between dropout and preference/attitude was found in BA. Psychotherapy preference/attitude moderated the differential effect of BA and ADM on one outcome measure, although the association disappeared after one year.

Limitations: Because in Iran most patients have only access to ADM, offering a psychological treatment for depression could attract especially those patients that prefer this newly available treatment.

Conclusions: patients' preferences and attitudes towards depression treatments influence dropout from $A D M$, and moderate the short-term difference in effectiveness between BA and ADM. The fact that dropout from BA was not affected by preference/attitude speaks for its acceptability among patients. 


\section{Introduction}

Depressed patients generally come to treatment with a preference for psychological or medication treatment depending on what they think is effective for them (Khalsa, McCarthy, Sharpless, Barrett, \& Barber, 2011). Patients with major depressive disorder (MDD) in primary care often receive antidepressant medication (ADM), and not psychological treatment, because of the unavailability of psychotherapies (Van Schaik et al., 2004). There is a lack of specialist mental health care for depression in rural areas, compared to urban areas (Lambart, Agger, \& Hartley, 1999), and especially the availability of psychotherapy is low in rural areas (Fortney, Harman, Xu, \& Dong, 2009). There are also vast differences between countries, with Western countries having much more psychological treatments available than non-Western countries. The Median rate of psychologist per 100,000 population working in the mental health sector by WHO region is 0.04 for Africa, 1.29 for the Americans, 0.48 for the eastern Mediterranean, 2.58 for Europe, 0.03 for South East Asia, and 0.00 for the Western Pacific (WHO-Mental Health Atlas, 2011). In Iran, for instance, the usual treatment for depression is ADM, and psychological treatments are difficult to get. In rural areas, but even in most urban areas in Iran the supply of psychological treatment is very limited (WHO-AIMS Report, 2006). Sanandaj for instance, where the present study was conducted, has a population of more than 500.000, but there are only five psychologists available for mental health care. If factors like preference for psychological treatment and negative attitudes towards ADM influence the acceptability and effectiveness of $A D M$, the limited availability of psychological treatment in many regions around the world is problematic as this will lead to suboptimal health care.

Previous research on the influence of patient preference has however yielded mixed results. A first issue is whether preference influences the take up, adherence and completion of a treatment. A meta-analysis by Van Schaik et al (2004) reported that patients with a strong preference for psychological treatment are probably disinclined to be randomized in clinical trials where they might receive antidepressant medication. One study reported dropout and non-compliance in primary care to be related to being given non-preferred depression treatment (Schulberg, Magruder, \& Gegruy, 1996). A randomized controlled trial (Raue, schulberg, Heo, Klimstra, \& Bruce, 2009) that studied influences of preference of depressed patients for interpersonal psychotherapy and ADM reported that preference was related to treatment initiation and 12weeks adherence rate. Thus, these studies indeed indicate that treatment preference influences take up, adherence, and completion of treatment.

A second issue is the degree to which outcomes of treatment are influenced by (dis) concordance of preference and the offered treatment. Seven studies found no association between preference and outcome of depression treatment (Raue et al., 
2009; Bedi et al., 2000; Ward et al., 2000; Van et al.,2009; Dunlop et al., 2012; Kwan et al., 2010; Laykin et al., 2007). Two of these used a partially randomized patientpreference design (Bedi et al., 2000; Ward et al., 2000) i.e. patients who did not accept randomization were offered the preferred treatment. Neither of these studies reported significant differences in outcome between those who were randomized to psychotherapy and those who chose it, and preference for psychotherapy was not related to higher recovery rates at follow-up. Another study compared patient preference with random allocation in short-term psychodynamic supportive psychotherapy with indicated addition of pharmacotherapy for depression and did not find preference to influence outcome (Van et al., 2009).

Four studies reported evidence for influences of preference on outcome (Patricia et al., 2005; Steidtmann et al., 2012; Kocsis et al., 2009; Mergl et al., 2011). The results of a trial (Patricia et al., 2005) that investigated patients' preference for counselling or antidepressant medication indicated that those who received their preferred treatment had better treatment outcome. Steidtmann et al (2012) conducted a large trial with a two-phase design; in phase I, all depressed participants were offered ADM, while in Phase II non-remitters were randomized to either cognitive-behavioural system of psychotherapy (CBASP) plus ADM, brief supportive psychotherapy plus ADM, or ADM only. In phase I, participants without any preference had a higher rate of symptom reduction than those with any preference, and those who preferred combined treatment showed less attrition than those who preferred medication. In phase II, treatment preference was not related to attrition or reduction of symptoms. Kocsis et al (2009) compared the effectiveness of nefazodone, CBASP, or combination therapy in patients with chronic MDD. They found that patients who received their treatment of choice had a higher remission rate and lower depression scores than those who received the non-preferred reatment. Mergl et al (2011) investigated influences of treatment preference on effects of Sertraline and group-CBT for depression in depressed primary care patients, and found that those receiving their preferred treatment responded significantly better than those who did not receive their preferred therapy.

Renewed interest in behavioural strategies has led to the development of behavioural activation (BA) as a relatively new treatment for patients with MDD (Jacobson et al., 1996). Earlier studies have shown that BA is an effective intervention for depression that might even be more effective than cognitive therapy in severely depressed patients (Dimidjian et al., 2006). To date, no study investigated the association of treatment preference with the effects of $B A$ in comparison to ADM for patients with MDD. 


\subsection{Aims of the study}

The data presented in this paper are drawn from a randomized controlled trial comparing BA and Sertraline for patients with MDD, in which BA proved to be superior to ADM (Moradveisi et al., 2013). The focus of this paper is on whether depressed patients' preference for and attitudes towards psychological treatment and ADM influence symptom reduction in the course of one year and dropout from treatment.

Studies into preference effects typically assess preference by a single question (e.g., Dunlop et al., 2012; Kocsis et al., 2009; Kwan et al., 2010; Leykin et al., 2007; Mergl et al., 2011; Steidtmann et al., 2012). We wanted to improve on that by using a questionnaire with multiple items assessing preferences for and attitudes towards ADM and psychotherapy. With this, we could assess basic psychometric properties, for instance whether preferences for and attitudes towards BA and ADM are onedimensional or multidimensional, and how reliable these assessments are - issues that cannot be addressed when a single question is used. We expected that preference for and attitudes towards BA and ADM would not load on a single dimension, as we expected that at least some people have relatively negative attitudes to both, others positive attitudes to both, and some people have no clearcut preference, whereas others do. Using dimensional variables and a multiple regression approach, it is possible to represent the probably multidimensional nature of treatment preferences and attitudes in the statistical analyses.

\section{Method}

\subsection{Study design}

A randomized controlled trial (RCT) was conducted comparing BA and ADM (Sertraline) as treatment for MDD. There were two primary outcome measures: the Beck Depression Inventory (BDI) and the Hamilton Rating Scale for Depression (HRSD), assessed at 0 (baseline), 4, 13 and 49 weeks. At baseline, a preference/attitude questionnaire was also completed. Main treatment outcome findings and the sample characteristics of the study have been reported elsewhere (Moradveisi et al., 2013). The study was registered in the International Clinical Trial register, IRCT138807192573N1.

\subsection{Participants and setting}

Participants were 100 depressed patients from Sanandaj, Iran, between the ages of 18 to 60 years (mean 31.37, SD 8.97), 85 women, with a primary diagnosis of MDD according to the Diagnostic and Statistical Manual of Mental Disorders DSM-IV-TR (Amer- 
ican Psychiatric Association, 2000) confirmed by the Structured Clinical Interview for the DSM-IV-TR Axis-I Disorders Clinical Trials Version (SCID-CT) (First, Williams, spritzer, \& Gibbon, 2007). Participants had to have a score of $\geq 19$ on the Beck Depression Inventory, second edition (BDI-II) (Beck steer, \& Brown, 1996) and a score of $\geq 14$ on the 17-item Hamilton Rating Scale for Depression (HRSD) (Hamilton, 1960). Participants completed a preference/attitude questionnaire at baseline. The study was approved by the local Committee of Medical Ethics, Second Session of Kurdistan University of Medical Sciences. All participants signed written informed consent to participate in the study.

\subsection{Treatment Behavioural activation and antidepressant medication}

One hundred participants were randomly assigned to receive behavioural activation (BA, $n=50)$ or Sertraline $(n=50)$. Participants in the BA condition received sixteen 50 min sessions over 12 weeks, for the first 4 weeks twice a week, and for the next 8 weeks once a week. In the treatment as usual (TAU) condition, participants were seen for the first 4 weeks of the treatment once a week and for the next 8 weeks once every two weeks. Psychiatrists saw each participant $20 \mathrm{~min}$ in the first session and in the subsequent sessions for approximately $10 \mathrm{~min}$ to monitor pharmacotherapy and side effects of the medication.

\subsection{Measures and assessments}

\subsubsection{Primary outcome}

Depression severity was assessed with the modified 17-item version of the HRSD (Hamilton, 1960) and the BDI-II (Beck et al., 1996). Both measures were administered at baseline, 4, 13, and 49 weeks of treatment. HRSD assessments were done by evaluators blind to treatment conditions. In addition to these assessments, independent assessors, not blind for the condition, took the HRSD for ADM patients before every session and supplied therapists with the results, whereas BA patients completed the BDI-II before every session and the results were supplied to their therapists. These additional assessments where only used in the analysis as last observations in case of early dropout.

\subsubsection{Construction of the preference/attitude questionnaire}

The preference-attitude questionnaire was constructed by two authors (L.M and A.A). It had 15 items, organized in two sets: (1) psychotherapy preference/attitudes (items $1,2,7,9,11,13$ ); (2) ADM preference/attitudes (items 3, 4, 5, 6, 8, 10, 12, 14, 15). The items were:

1. I prefer psychotherapy above antidepressant medication in treating depression; 
2. Psychotherapy is an effective way to treat depression;

3. I avoid taking antidepressant medications due to the side effects;

4. Depression usually improves by antidepressant medication;

5. Depression is always caused by problems in people's lives, thus antidepressant medication cannot help to improve depression;

6. Antidepressant medications are addictive;

7. Depression is a physiological problem and psychotherapy is not capable of treating that;

8. Antidepressant medication is an effective way to treat depression;

9. Psychotherapy can help people to solve problems in their lives, therefore I prefer it;

10. When I was depressed in the past, antidepressants helped to improve my depression;

11. People with depression find it difficult to talk; therefore, psychotherapy cannot help to improve depression;

12. Depressed people are avoiding their daily routines and relationships with friends, therefore antidepressant cannot help to improve depression;

13. Depression is caused by low self-esteem and faulty thoughts, therefore psychotherapy can improve it;

14. I am more comfortable with taking antidepressant medication than psychological treatment;

15. Most depressed people respond better to antidepressant medications than psychological treatment.

Items were scored on 9-point Likert scales $(0=$ not at all; $8=$ very much so). Principal component analysis supported the structure of two scales: the scree-plot had an elbow at two components. The two components explained $49.53 \%$ of the variance. After oblimin rotation, the two components were clearly related to two sets described above: preference and positive attitudes to either ADM, or psychological treatment. Reliability analyses of the scales formed on the basis of these components (with reversed scorings of items $3,5,6,7,11$ ) indicated too low contributions of items 12 and 13. After deleting these items the subscales had acceptable internal consistencies (both $\alpha=.83$ ). Mean (standard deviation) was 5.90 (1.71) for psychotherapy preference/attitudes and 2.69 (1.51) for ADM preference/attitudes, respectively. The two scales correlated $-.413(p<.001)$ with each other.

\subsection{Statistical analysis}

Preference/attitude scores were centred by transformation into z-scores. The effects of preference/attitude, condition, and their interaction on treatment dropout were 
tested with logistic regression. Multilevel analysis was used to estimate influences of preference/attitude on change in depression severity over time, alone and in interaction with condition. As time was best fitted using a polynomial growth curve, we used time and time-squared in all analyses, as reported earlier (Moradveisi et al., 2013). We applied intention-to-treat analysis, with the HRSD and BDI as dependent variables, by including all available scores. We used multilevel analyses with an unstructured covariance structure for repeated measures, with time, time-squared, condition, time by condition, time-squared by condition, and preference/attitude, and the interactions between preference/attitude, time(-squared) and condition as fixed effects. In all models, treatment condition was centred at $-1 / 2$ and $1 / 2$. Non-significant interactions were removed stepwise from the model starting with the highest order interactions. We computed effect sizes $r(=V(F / F+d f))$ for continuous outcomes from the multilevel estimates. One extreme score on the ADM preference/attitude scale was pulled into $+2 \mathrm{SD}$, to prevent the case becoming a leverage point.

For treatment dropouts who refused further assessments, we used the last observation with the associated time, and estimated missing HRSD scores (for BA-dropouts) from changes on the BDI, and missing BDI scores (for TAU-dropouts) from changes on the HRSD, using regression derived equations (1 BDI unit=1.3 HRSD unit). All treatment drop-out took place before the mid-treatment assessment. Analyses were conducted using SPSS19.

\section{Results}

\section{Dropout}

The overall rate of participant's dropout was detailed in the original publication (Moradveisi et al., 2013). 20 participants dropped out of treatment, 5 in BA and 15 in the ADM condition. The two preference/attitudes scales were first analysed separately. As to psychotherapy preference/attitude, the condition by psychotherapy preference/attitude interaction was significant $(O R=0.21[0.05 ; 0.87] ; p=0.031)$, the main effect of psychotherapy preference/attitude was significant $(O R=5.01[1.86 ; 13.50]$; $p$ $=0.001)$ and the condition effect was not significant ( $O R=0.31[0.09 ; 1.09] ; p=0.060)$. As to ADM preference/attitude, the condition by ADM preference/attitude interaction was also significant $(O R=9.85[1.91 ; 50.75] ; p=0.006)$, the main effect of ADM preference/attitude was significant $(O R=0.11[0.03 ; 0.38] ; p=0.001)$ and the condition was significant $(O R=0.21[0.06 ; 0.78] ; p=0.019)$. As figure 1 illustrates, both high psychotherapy preference/attitude and low ADM preference/attitude were associated with higher dropout from ADM, while dropout from BA was not associated with preference/attitudes. When both preference/attitude scales were put in the analyses, the 
condition by psychotherapy preference/attitude interaction was no longer significant ( $p=0.18)$. After stepwise removing non-significant predictors, the model contained the condition, ADM preference/attitude, and their interaction.

In conclusion, the results indicate that a high preference for and positive attitude towards psychotherapy was associated with a higher chance to drop out from ADM, as was a low preference for and negative attitude towards ADM. The ADM preference/attitude score appeared to be the most important predictor of dropout from ADM. In contrast, both preference/attitude scales did not predict dropout from BA.
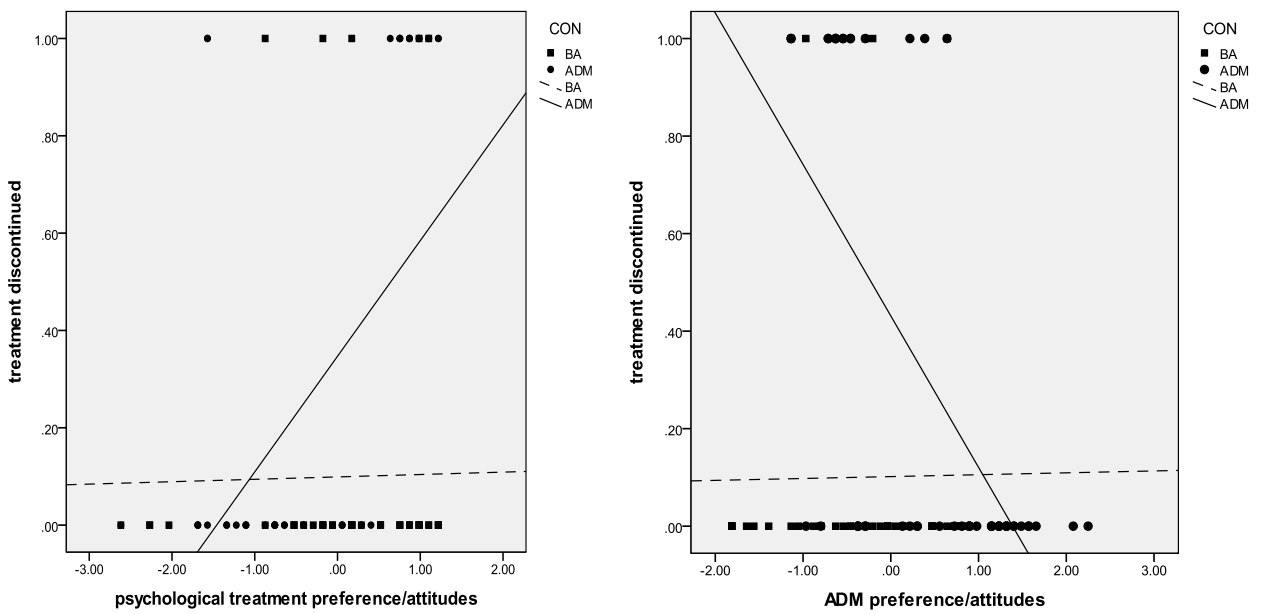

Figure 1. Illustration of the effects of treatment preference/attitude on chance of dropout by condition. Xaxis: z-score of psychotherapy preference/attitude (left panel), respectively z-score of ADM preference/attitude (right panel). Y-axis: chance of dropping out from treatment. Left panel: the regression lines depict the association between psychotherapy preference/attitudes and chance of dropout from ADM and $B A$ treatments separately. There is a positive association for ADM, but not for BA, meaning that chance of dropout from ADM is higher when psychotherapy preference/attitude is higher, whereas there is no effect of this preference on chance to dropout from BA. Right panel: the regression lines depict the association between ADM preference/attitudes and chance of dropout from ADM and BA treatments separately. There is a negative association for ADM, but not for $B A$, meaning that chance of dropout from ADM is higher when ADM preference/attitude is lower, whereas there is no effect of this preference on chance to dropout from BA.

Abbreviations: $\mathrm{BDI}=$ Beck Depression Inventory; HRSD = Hamilton Ratings Scale for Depression; $A D M=$ antidepressant medication (Sertraline); BA = behavioural Activation.

\section{Effects of preference/attitude on BDI and HRSD}

Table 1 presents the results of the mixed regression of the full model, including all predictor variables and higher order interactions, for both HRSD and BDI. Table 2 gives an overview of the results after deletion of non-significant higher order interactions involving the preference/attitude scales. 
Table 1. Prediction of depressive symptoms by preference over time: mixed regression full model results.

\begin{tabular}{|c|c|c|c|c|c|c|}
\hline$\overline{\mathrm{BDI}}$ & B & $95 \% \mathrm{Cl}(\mathrm{B})$ & $\mathrm{F}$ & $\mathrm{df}$ & $r^{1}$ & $p$ \\
\hline Intercept & 27.74 & $26.45 ; 29.02$ & 1831.99 & 103.04 & 0.97 & $<0.001$ \\
\hline Condition & -2.57 & $-5.16 ; 0.03$ & 3.85 & 105.18 & 0.18 & 0.052 \\
\hline Preference psychotherapy & 0.45 & $-0.65 ; 1.55$ & 0.66 & 95.96 & 0.08 & 0.417 \\
\hline Preference ADM & -0.60 & $-1.66 ; 0.45$ & 1.30 & 88.86 & 0.12 & 0.257 \\
\hline Time & -1.98 & $-2.12 ;-1.84$ & 838.17 & 92.51 & 0.94 & $<0.001$ \\
\hline Time-Squared & 0.03 & $0.03 ; 0.04$ & 732.25 & 87.09 & 0.94 & $<0.001$ \\
\hline Time $x$ Condition & -0.36 & $-0.62 ;-0.10$ & 7.71 & 90.66 & 0.27 & 0.007 \\
\hline Time-Squared $x$ Condition & 0.01 & $0.00 ; 0.01$ & 6.45 & 88.12 & 0.26 & 0.013 \\
\hline Condition $\mathrm{x}$ Preference psychotherapy & 0.06 & $-2.55 ; 2.66$ & 0.00 & 103.31 & 0 & 0.966 \\
\hline Condition $\mathrm{x}$ Preference ADM & 0.39 & $-1.26 ; 2.04$ & 0.21 & 83.66 & 0.05 & 0.643 \\
\hline Time x Preference psychotherapy & -0.00 & $-0.03 ; 0.02$ & 0.05 & 89.80 & 0.02 & 0.827 \\
\hline Time-squared $x$ Preference psychotherapy & 0.00 & $-0.00 ; 0.00$ & 0.353 & 87.79 & 0.06 & 0.554 \\
\hline Time $x$ Preference ADM & 0.00 & $-0.00 ; 0.00$ & 0.78 & 76.06 & 0.10 & 0.379 \\
\hline Time-squared x Preference ADM & 0.00 & $-0.00 ; 0.00$ & 0.571 & 77.91 & 0.08 & 0.452 \\
\hline Time $\mathrm{x}$ Condition $\mathrm{x}$ Preference psychotherapy & -0.20 & $-0.47 ; 0.07$ & 2.06 & 92.31 & 0.14 & 0.155 \\
\hline $\begin{array}{l}\text { Time -Squared x Condition } x \text { Preference } \\
\text { psychotherapy }\end{array}$ & 0.00 & $-0.00 ; 0.01$ & 2.14 & 87.17 & 0.15 & 0.148 \\
\hline Time $x$ Condition $x$ Preference ADM & 0.17 & $-0.15 ; 0.48$ & 1.11 & 87.20 & 0.11 & 0.295 \\
\hline Time -Squared $x$ Condition $x$ Preference ADM & -0.00 & $-0.01 ; 0.00$ & 0.58 & 82.39 & 0.08 & 0.449 \\
\hline \multicolumn{7}{|l|}{ HRSD } \\
\hline Intercept & 21.56 & $20.45 ; 22.67$ & 1495.24 & 103.66 & 0.96 & $<0.001$ \\
\hline Condition & -1.50 & $-3.71 ; 0.72$ & 1.80 & 105.51 & 0.12 & 0.183 \\
\hline Preference psychotherapy & 0.15 & $-0.74 ; 1.05$ & 0.12 & 85.16 & 0.03 & 0.730 \\
\hline Preference ADM & -0.93 & $-1.81 ;-0.06$ & 4.50 & 77.28 & 0.23 & 0.036 \\
\hline Time & -1.50 & $-1.61 ;-1.40$ & 774.37 & 93.94 & 0.94 & $<0.001$ \\
\hline Time-Squared & 0.03 & $0.02 ; 0.03$ & 680.76 & 90.17 & 0.93 & $<0.001$ \\
\hline Time $x$ Condition & -0.37 & $-0.57 ;-0.16$ & 12.56 & 91.66 & 0.34 & $<0.001$ \\
\hline Time-Squared $x$ Condition & 0.01 & $0.00 ; 0.01$ & 13.16 & 90.48 & 0.35 & $<0.001$ \\
\hline Condition x Preference psychotherapy & 0.59 & $-1.65 ; 2.84$ & 0.28 & 104.56 & 0.05 & 0.601 \\
\hline Condition $\mathrm{x}$ Preference ADM & 0.81 & $-0.73 ; 2.35$ & 1.09 & 77.81 & 0.11 & 0.300 \\
\hline Time $\mathrm{x}$ Preference psychotherapy & 0.01 & $-0.01 ; 0.03$ & 0.44 & 85.42 & 0.07 & 0.508 \\
\hline Time-squared $x$ Preference psychotherapy & 0.00 & $-0.00 ; 0.00$ & 0.10 & 91.03 & 0.03 & 0.749 \\
\hline Time $x$ Preference ADM & 0.00 & $7.47 ; 0.00$ & 5.54 & 73.97 & 0.26 & 0.021 \\
\hline Time-squared $\mathrm{x}$ Preference ADM & 0.00 & $3.89 ; 0.00$ & 4.75 & 74.28 & 0.24 & 0.032 \\
\hline Time $x$ Condition $x$ Preference psychotherapy & -0.23 & $-0.45 ;-0.02$ & 4.52 & 93.89 & 0.21 & 0.036 \\
\hline $\begin{array}{l}\text { Time -Squared x Condition x Preference } \\
\text { psychotherapy }\end{array}$ & 0.00 & $0.00 ; 0.01$ & 5.45 & 90.40 & 0.23 & 0.022 \\
\hline Time $\mathrm{x}$ Condition $\mathrm{x}$ Preference ADM & 0.04 & $-0.21 ; 0.28$ & 0.08 & 87.64 & 0.03 & 0.777 \\
\hline Time -Squared $x$ Condition $x$ Preference ADM & 1.70 & $-0.00 ; 0.00$ & 0.00 & 83.77 & 0 & 0.994 \\
\hline
\end{tabular}

Abbreviations: $B D I=$ Beck Depression Inventory; HRSD = Hamilton Ratings Scale for Depression; $A D M=$ antidepressant medication (Sertraline). ${ }^{1}$ Effect size $r=V(F /(F+d f))$. 
Table 2. Mixed Regression results after deleting three-way and preference $x$ time (squared) interaction

\begin{tabular}{|c|c|c|c|c|c|c|}
\hline BDI & B & $95 \% \mathrm{Cl}(\mathrm{B})$ & $\mathrm{F}$ & df & ra & $\mathrm{p}$ \\
\hline Intercept & 28.41 & $26.60 ; 30.21$ & 970.46 & 110.48 & 0.94 & $<0.001$ \\
\hline Condition & -1.77 & $-4.39 ; 0.84$ & 1.80 & 116.43 & 0.12 & 0.182 \\
\hline Time & -1.87 & $-2.06 ;-1.68$ & 392.69 & 95.20 & 0.89 & $<0.001$ \\
\hline Time-squared & 0.03 & $0.03 ; 0.04$ & 353.36 & 89.22 & 0.89 & $<0.001$ \\
\hline Condition $\mathrm{x}$ Time & -0.32 & $-0.57 ;-0.06$ & 6.00 & 91.16 & 0.24 & 0.016 \\
\hline Condition $\mathrm{x}$ Time-Squared & 0.00 & $0.00 ; 0.00$ & 4.36 & 86.31 & 0.21 & 0.040 \\
\hline Preference psychotherapy & 1.23 & $0.22 ; 2.25$ & 5.85 & 95.71 & 0.24 & 0.018 \\
\hline Preference ADM & 0.91 & $-0.06 ; 1.88$ & 3.48 & 84.00 & 0.19 & 0.066 \\
\hline Preference psychotherapy $x$ Condition & -1.09 & $-2.53 ; 0.36$ & 2.22 & 86.40 & 0.15 & 0.140 \\
\hline Preference ADM x Condition & -1.07 & $-2.86 ; 0.73$ & 1.41 & 77.10 & 0.13 & 0.239 \\
\hline \multicolumn{7}{|l|}{ HRSD } \\
\hline Intercept & 21.85 & $20.29 ; 23.42$ & 765.89 & 108.25 & 0.93 & $<0.001$ \\
\hline Condition & -0.80 & $-3.11 ; 1.49$ & 0.49 & 115.82 & 0.06 & 0.487 \\
\hline Time & -1.41 & $-1.55 ;-1.26$ & 349.91 & 95.49 & 0.88 & $<0.001$ \\
\hline Time-squared & 0.02 & $0.02 ; 0.03$ & 311.49 & 91.15 & 0.87 & $<0.001$ \\
\hline Condition x Time & -0.29 & $-0.50 ;-0.09$ & 8.14 & 90.87 & 0.28 & 0.005 \\
\hline Condition x Time-Squared & 0.01 & $0.00 ; 0.01$ & 7.30 & 87.01 & 0.27 & 0.008 \\
\hline Preference psychotherapy & 0.94 & $-0.03 ; 1.91$ & 3.74 & 89.69 & 0.20 & 0.056 \\
\hline Preference ADM & 0.39 & $-0.54 ; 1.32$ & 0.70 & 78.29 & 0.09 & 0.404 \\
\hline Preference psychotherapy $x$ Condition & -0.61 & $-0.00 ; 0.77$ & 0.79 & 78.69 & 0.09 & 0.378 \\
\hline Preference ADM x Condition & -0.36 & $-2.08 ; 1.36$ & 0.18 & 69.86 & 0.05 & 0.677 \\
\hline
\end{tabular}

Abbreviations: BDI = Beck Depression Inventory; HRSD = Hamilton Ratings Scale for Depression; $A D M=$ antidepressant medication (Sertraline)

${ }^{a}$ Effect size $r=V(F /(F+d f))$.

$B D I$. Three-way psychotherapy preference/attitude score $\mathrm{x}$ time (squared) $\mathrm{x}$ condition interactions were not significant for the BDI (Table 1). The same held for the three-way interaction of the ADM preference/attitude score (Table 1). The two-way psychological treatment preference/attitude $\mathrm{x}$ condition interaction was also nonsignificant for the BDI, as was the two-way interaction of ADM preference/attitude and condition (Table 2). These findings indicate that preferences for and attitudes towards psychotherapy or ADM did not influence the overall condition effects or the condition effects on changes in the BDI over time

HRSD. Three-way psychological treatment preference/attitude $\mathrm{x}$ time (squared) $\mathrm{x}$ condition interactions were significant for the HRSD, $F(1,93.89)=4.52, p=0.036$ and $F(1,90.40)=5.45, p=0.022$, indicating that preference/attitude for psychological treatment moderated the difference between conditions in treatment effects (Table 
1). Inspection of the difference between BA and ADM in the association between preference/attitude for psychological treatment and HRSD at the four assessments shows that the effect is caused by a temporary change in the association in the BA condition after acute phase treatment which disappears at 49 weeks (Fig. 2). Thus, BA participants, who preferred psychological treatment at baseline and received such a treatment, initially responded better to this treatment than others (see negative slope for BA at week 13), but not at one year follow-up. In other words, preference/attitude for psychotherapy did not moderate the outcome at follow-up (Fig. 2).

Three-way ADM preference/attitude $x$ time (squared) $x$ condition interactions were not significant (Table 1), as was the ADM preference/attitude $x$ condition interaction (Table 2), indicating that ADM preference/attitudes did not moderate condition differences over time or general differences between conditions.

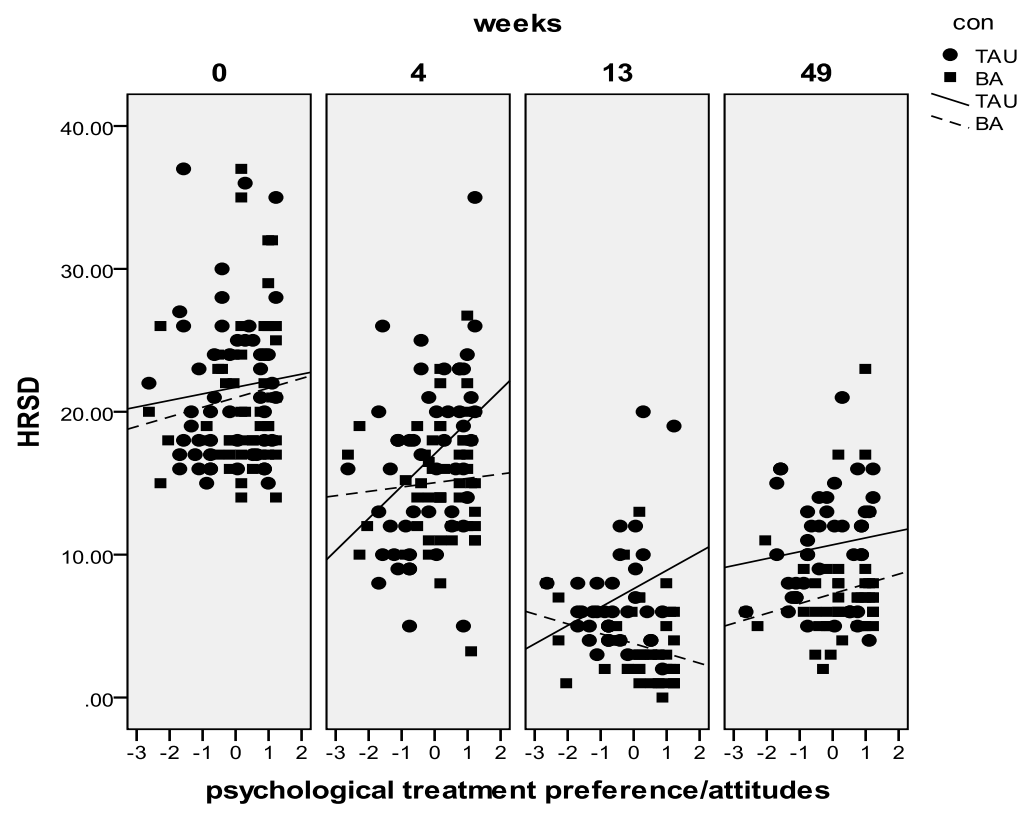

Figure 2. Mixed regression based-estimated HRSD scores at baseline ( 0 weeks), during treatment (4 weeks), post-treatment (13 weeks) and at 49 weeks follow-up for the two conditions as a function of baseline psychotherapy preference/attitude score (x-axis). The slopes depict the linear relationships between psychological preference/attitudes (z-scores) and HRSD at the four assessments. The negative slope between this preference and HRSD at 13 weeks for BA indicates superior effects of BA for those with a high psychotherapy preference/attitude. This effect disappears at week 49 (parallel slopes; the distance between the slopes depicts the superior long term effects of BA above ADM). This difference between conditions in change of the relationship between baseline psychotherapy preference/attitude scores and HRSD over time is reflected in significant time (squared) $x$ condition $x$ psychotherapy preference interactions.

Abbreviations: $B D I=$ Beck Depression Inventory; HRSD = Hamilton Ratings Scale for Depression; $A D M=$ antidepressant medication (Sertraline); BA = behavioural Activation. 


\section{Discussion}

We developed a self-report instrument to assess patients' treatment preferences for and attitudes towards either psychotherapy or pharmacological treatment for depression. Preference and attitude items related to a treatment modality loaded on the same factor, but psychological and ADM treatment preferences/attitudes could be clearly distinguished, and showed only a modest correlation (-.41, i.e. shared variance $=17 \%$ ). This indicates that a high (or a low) preference for/attitude towards one modality does not necessarily imply an opposite preference for and attitude towards the other modality. The scales turned out to be treatment-specific predictors. Firstly, dropout from ADM could be predicted by both preference/attitude scales, with the ADM preference scale being the strongest predictor. Secondly, preference for psychological treatment moderated the condition by time interaction effects on the HRSD caused by a specific effect on short-term response to BA. These findings will now be discussed in detail.

Participants with a lower ADM preference/attitude score showed more dropouts from the ADM condition. Those with a higher psychological preference/attitude score had also a higher chance of dropout from ADM. Of the two preference/attitude scales, the ADM scale was the most important, as the psychological preference/attitude scale had no additional contribution in predicting dropout from ADM. BA participants' dropout was not influenced by preference/attitude. The influence of preference/attitude on dropout was not similar in the two conditions. Whereas a mismatch between preference and treatment predicted dropout from ADM, no mismatch was associated with dropout from BA. It seems that BA has higher acceptability than ADM even for those that prefer and have positive attitudes to ADM, and for those that have a low preference for psychotherapy.

The existence of three-way preference/attitude psychological treatment $x$ time (squared) $x$ condition interactions for the HRSD indicates that preference/attitude for psychological treatment moderated the difference between treatment conditions. However, this difference disappeared after one year follow-up. This might point toward some kind of placebo effect. People who believe that the treatment they receive works also report to get better, but only as long as they also receive that treatment. However, one would then also expect such an effect after 4 weeks of treatment, but no association between high psychological treatment preference/attitude and treatment outcome was apparent in BA. Moreover, similar effects were not found on the $B D I$. Thus, we can conclude that we found some evidence for the short-term effects of preference/attitude on outcome, but in the long-run this effect disappeared.

The main outcomes of the RCT (Moradveisi et al., 2013) remained stable when controlled for treatment preference/attitudes. Dropout was higher from ADM than 
from BA, and this effect remained significant after controlling for ADM preference/attitudes and its interaction with condition $(O R=0.26$ without controlling for preference/attitudes, $\mathrm{OR}=0.21$ after controlling). BA was more effective than ADM on the HRSD and BDI, and these effects remained stable after controlling for treatment preference/attitudes: the beta coefficients of the mixed regression estimates of the time effects, and the condition by time interactions are highly comparable with and without controlling for preference scores. This indicates that the main findings of the RCT are not dependent on specific treatment preferences and attitudes, and speaks for the applicability of BA as a highly acceptable and effective treatment for many depressed patients.

Our results on the influence of preference on dropout are consistent with Van Schaik et al (2004), Schulberg et al (1996), and Raue et al (2009). Our study suggests a qualification, as the effect was only observed for pharmacological treatment, and not for psychological treatment, as dropout from BA was not influenced by preference. The finding that differences between BA and pharmacotherapy in outcome as assessed with the HRSD was moderated by preference are in line with four previous studies reporting effects of preference on outcome (Patricia et al., 2005; Steidtmann et al., 2012; Kocsis et al., 2009; Mergl et al., 2011), but in contrast to the seven studies that did not find such effects (Raue et al., 2009; Bedi et al., 2000; Ward et al., 2000; Van et al.,2009; Dunlop et al., 2012; Kwan et al., 2010; Laykin et al., 2007). It is unclear which factors might explain the different findings across studies, but these might include differences between samples (e.g., primary vs. secondary care), differences between treatments that were compared, differences in designs, and different assessment methods of preferences. It should be stressed however, that our moderation effect on outcome by preference was only temporary and only found in one of the two outcome instruments. Consequently, our moderation effect does not seem to constitute strong evidence for the effects of preference on treatment outcome.

The results suggested that the majority of our participants preferred psychological treatment above ADM. One explanation for this is that ADM is widely available in Iran, and most depressed patients have experience with ADM treatment. Thus, offering a new treatment such as BA may have attracted participants to our study, so that the sample might have been biased towards those that had positive attitudes towards psychological treatment. On the other hand, preference for psychological treatment above ADM seems a fairly general phenomenon (Van Schaik et al., 2004; Laine and davidoff, 1996; Schulberg et al., 1996; Raue et al, 2009) and perhaps not so specific for our sample.

$A D M$ is more easily available in most regions of the world than psychological treatment. The finding that dropout from ADM is influenced by preference and attitudes towards it, whereas dropout from BA was lower and not influenced by prefer- 
ence and attitudes, and had better effects than ADM, is worrisome in that context. It indicates that simple psychological treatments like BA should be made more available around the globe, or that negative attitudes towards ADM should be addressed.

\section{Limitations}

A number of limitations should be mentioned with respect to the data presented in this study. Due to the fact that in Iran most patients have only access to ADM, offering a psychological treatment for depression could attract especially those patients that prefer this newly available treatment. Our results might therefore be subjected to selection bias and only apply to Iran and the Iranian culture. Most participants with recurrent MDD have had already medication treatment. The most accessible treatment for psychological disorders in Iran is medication. Thus, those who previously sought help for depression likely received ADM from psychiatrists in the past rather than psychological treatment by clinical psychologists. Unfortunately, we did not collect data on previous treatments in our sample so that we could not look into the possible effects of this.

However, several previous studies in Western cultures have reported a general preference for psychological treatment in depressed patients (Van Schaik et al., 2004; Laine and Davidoff, 1996; Schulberg et al., 1996; Raue et al, 2009). Another limitation is that we used a newly developed instrument that was not previously used in research to assess preferences and attitudes towards depression treatments. However, the straightforwardness of the items in combination with the results from our principal component analysis suggest our newly developed scales have ecological validity. As to the moderation of effectiveness by preference and attitude, a limitation is that this was only detected on the HRSD and not on the BDI, and our findings on moderation of effects should be interpreted with some caution.

\section{Conclusion}

In conclusion, our study found that those participants who received ADM and who at the same time had a low preference for or attitude towards ADM had a higher chance to drop out of treatment than those without such a preference/attitude. The fact that dropout from BA was not affected by preferences/attitude speaks for its high acceptability. Moreover, psychotherapy preference had a positive effect on initial response to the psychological treatment. Our conclusion is therefore that taking patient preference into account may improve treatment retention and initial response. Future studies should investigate the effects of preference/attitude for BA and ADM in other clinical settings and cultures. 


\section{References}

American Psychiatric Association. (2000). Diagnostic and statistical manual of mental disorders (DSM-IV-TR.). Washington, DC: APA.

Beck, A.T., Steer, R.A., Brown, G.K. (1996). Manual for the BDI-II. San Antonio, TX: Psychological Corporation.

Bedi, N., Lee, A., Harrison, G., Chilvers, C., Dewey, M., Fielding, K., et al. (2000). Assessing effectiveness of treatment of depression in primary care: Partially randomized preference trial. British Journal of Psychiatry, 177, 312-318.

Dimidjian, S., Hollon, S.D., Dobson, K.S., Schmaling, K.B., Kohlenber,R.J., Addis, M.E., et al., (2006). Randomized trial of behavioural activation, cognitive therapy, antidepressant medication in the acute treatment of adults with major depression. Journal of Consulting and Clinical Psychology, 74, 658-670.

Dunlop, B.W., Kelly, M.E., Mletzko, T.C.,Velasquez, C.M., Craighead, W.E., Mayberg, H.S. (2012). Depression beliefs, treatment Preference, and outcomes in a randomized trial for major depressive disorder. Journal of Psychiatric Research, 46, 375-381.

First, M.B., Williams, J.B., Spitzer, R.L., Gibbon, M. (2007). Structured Clinical Interview for DSM-IV- TR Axis I Disorders, Clinical Trials Version (SCID-CT). New York: Biometrics Research, New York State Psychiatric Institute.

Fortney, J. C., Harman, J. S., \& Dong, F. (2009). Rural-urban differences in depression care. http://www.wiche.edu/info/publications/fortneyWorkingpaperYr3Proj2.pdf Assessed 17.09.13.

Hamilton, M. (1960). A rating scale for depression. Journal of Neurology Neurosurgery and Psychiatry 23, 5661.

Jacobson, N.S., Dobson, K.S., Truax, P.A., Addis, M.E., Koerner, K., Gollan, J.K., Et al. (1996). A component analysis of cognitive- behavioural treatment for depression. Journal of Consulting and Clinical Psychology 64, 295- 304.

Khalsa, S.R., McCarthy, K.S., Sharpless, B.A., Barrett, M.S., Barber, J.P. (2011). Beliefs about the causes of depression and treatment preferences. Journal of Clinical Psychology 67, 539-549.

Kwan, B.M., Dimijian, S., Rezvi, S.L. (2010). Treatment preference, engagement, and clinical improvement in pharmacotherapy versus psychotherapy for depression. Behaviour Research and Therapy 48, 799-804.

Kocsis, J.H., Leon, A.C., Marcowitz, J.C., Manber, R., Arnow, B., Klein, D.E., et al. (2009). Patient preference as moderator outcome for chronic forms of major depressive disorder treated with nefazodone, cognitive behavioural analysis systems of psychotherapy, or their combination. Journal of Clinical Psychiatry 70 (3), 354-361.

Laine, C., Davidoff, F. (1996). Patient-cantered medicine. A professional evolution. Journal of American Medical Association 275, 152-156.

Lambert, D., Agger, M., \& Hartley, D. (1999). Service use of rural and urban Medicaid beneficiaries suffering from depression: the role of supply. Journal of Rural Health, 15,344-355.

Laykin, Y., Gallop, R., Amsterdam, J.D., Shelton, R.C., Hollon, S.D. (2007). The relation of Patient's preference to outcome in randomized clinical trial. Behaviour Therapy 38, 209-217.

Mental Health atlas. (2011). World Health Organization. http://www.who.int/about/lisencing /copyrig/copyright_form/en/index.html. ISBN 9729241564359.

Mergl, R., Henkel, V., Algaier, A.K., Kramer, D., Hautzinger, M., Kohnen, R., et al. (2011). Are treatment preferences relevant in response to Serotonergic antidepressants and cognitive-behavioural therapy in Depressed primary care patients? Results from a randomized controlled trial including a patients' choice arm. Psychotherapy and Psychosomatics 80, 39-47.

Moradveisi, L., Huibers, M., Arasteh, M., Renner, F., Arntz, A. (2013). Behavioural activation v. Antidepressant Medication for depression in Iran: a Randomized trial. British Journal of Psychiatry, DOI:10.1192/bjp.bp112.113696. 
Patricia, L., Duncan, G.C., Edmund, F.C., Chuan, F.L., Patrick, H., Bradford, L.F., et al. (2005). The influence of patient preference on depression treatment in primary care. Annals of Behavioural Medicine 30, 164173.

Raue, J.R., Schulberg, H.C., Heo, M., Klimstra, S., Bruce, M.L. (2009). Patients' depression treatment preference and initiation, adherence, and outcome: A randomized care study. Psychiatric Services 60, 337343.

Schulberg, H.C., Magruder, K.M., DeGruy, F. (1996). Major depression in primary care: Research trends and future priorities. General Hospital Psychiatry 18, 395- 406.

Steidtmann, D., Manber, R., Arnow, B.A., Daniel, N.K., Markowitz, J.C., Rothbaum, B.O., et al. (2012). Patient treatment preference as predictor of response and attrition in treatment for chronic depression. Depression and Anxiety 29, 896-905.

Van, H.L., Dekker, J., Koelen, J., Kool, S., Van Aalst, G., Hendriksen, M., et al. (2009). Patient preference compared with random allocation in short-term psychodynamic supportive psychotherapy with indicated addition of pharmacotherapy for depression. Psychotherapy Research 19, 205-212.

Van Schaik, D.J.F., klijn, A.F.J., Van Hout, H.P.J.V.,Van Marwijk, H.W.J., Beekman, A.T.F., De Han, M., et al. (2004). Patients preference in the treatment of depressive disorder in primary care. General Hospital Psychiatry 26, 184-189.

Ward, E., King, M., Lioyd, M., Bower, P., Sibbald, B., Farelly, et al. (2000). Randomized controlled trial of nonDirective counselling, cognitive-behaviour therapy and usual general practitioner care for patients with depression. I: Clinical effectiveness British Medical Journal 321, 1383-1388.

WHO-AIMS Report on Mental Mealth System in the Islamic Republic of Iran. (2006). WHO and Ministry of Health and Medical Education, Tehran, the Islamic Republic of Iran. 



\section{Chapter 5}

The influence of patients' attributions of the immediate effects of treatment of depression on long-term effectiveness of behavioural activation and antidepressant medication ${ }^{7}$

7- Moradveisi, L., Huibers, M. J., \& Arntz, A. (2014). The influence of patients' attributions of the immediate effects of treatment of depression on long-term effectiveness of behavioural activation and antidepressant. Behaviour Research and Therapy, 'in revision". 


\section{Abstract}

Patients' attributions of effects of treatment are important, as these can affect longterm outcome. Most studies so far focused on the influence of attributions to medication for anxiety and depression disorders. We investigated the effects of patients' attributions made after acute treatment on the long-term outcome of antidepressant medication (ADM) and psychological treatment (behavioural activation, BA). Data are based on a randomized trial testing the effectiveness of BA vs. ADM for major depression (MDD) in Iran. Patients with MDD $(N=100)$ were randomized to BA $(N=50)$ or $\operatorname{ADM}(N=50)$. Patients' attributions were assessed at post-test (after completion of the treatments). Scores on an attribution questionnaire were factor analysed, and factor scores were retained as predictors of depressive symptoms at 1-year follow-up. Regression analysis was used to test whether attributions predicted depressive symptoms at 1-yr follow-up, controlling for symptom level, condition, and their interaction at post-test. Belief in coping was the only attribution factor significantly predicting 1year HRSD scores, controlling for condition, post-test HRSD and their interaction. It also mediated the condition differences at follow-up. Credits to self was the single attribution factor that predicted BDI follow-up scores, controlling for condition, posttest $\mathrm{BDI}$, and their interaction. It partially mediated the condition differences on the BDI at follow-up. Attribution to increased coping capacities and giving credits to the self appear essential. In the long-term (at 1 year follow-up), the difference in outcome between BA and ADM (with BA being superior to ADM) is at least partially mediated by attributions. 


\section{Introduction}

Antidepressant medication (ADM) is a standard treatment for depressed patients in current psychiatric guidelines (American Psychiatric Association, 2000; (Frank, et al. 1990) and the most recent practice guideline for the initial treatment of patients with mild to moderate major depressive disorder (MDD) is antidepressant medication and depression-focused psychotherapy. For depressed patients with severe MDD with or without psychiatric features however, ADM is the first choice (American Psychiatric Association, 2010). The short-term effectiveness of ADM is well studied and comparable to that of CBT and IPT, although dropout from ADM is higher (Cuijpers et al., 2008). Much less is known about the long-term effectiveness of ADM, and how it compares to that of psychological treatment. A recent meta-analysis reported a trend towards superiority in relapse prevention of CBT compared to maintenance of ADM over 5 studies $(O R=1.62 ; p=.07)$. The superiority of CBT over ADM became significant after exclusion of one outlier, $O R=1.77, p<.05$ (Cuijpers et al., 2013). The same meta-analysis reports clear evidence of superiority of CBT over ADM when ADM is discontinued after the acute treatment phase over eight studies, $O R=2.61, p<.001$ (see also Imel et al., 2008). Thus, when patients stop taking antidepressant medication, those who recovered from their depressive episode are at a substantial risk for recurrence, whereas CBT appears to offer a better protection for future relapse. The superior effects of CBT over ADM in relapse prevention seem to hold for both the Beckian approaches (Hollon, et al. 2002); Hollon et al., 2005; Dobson et al., 2008) and for Behavioural Activation (BA) (Dobson et al., 2008; Moradveisi et al., 2013).

The important question then arises: what explains the apparent superior longterm effects of psychological treatment over ADM? It has been argued before that where ADM only alleviates depression symptoms as long as the medication is used, patients in psychotherapy actually learn to get better and stay well (Paykel et al., 2006; Hollon et al., 2005). More specifically, it was found that the skills that patients acquire in CT actually predict the prevention of relapse after treatment (Strunk et al., 2007). From a behavioural activation point of view, a likely reason of relapse after discontinuation medication is that patients did not change their coping skills. The lack of reinforcement, patterns of avoidance and rumination might still exist, although antidepressant medication might reduce temporarily their effects on mood. In contrast, those patients treated with behavioural activation have acquired healthy behavioural skills and new coping styles that might reduce relapse (Moradveisi et al., 2013).

Another explanation is that patients' beliefs about why they recovered in therapy (attributions) impact the sustaining of gains. It has been postulated by Brewin and Antaki (1982) that patients who attribute gains to their own efforts are more likely to sustain those gains compared to those who attribute improvement to external causes 
such as a drug's activity or a therapist's charisma. A study by Basoglu et al. (1994) investigated attributions made by patients with panic disorder and agoraphobia who had participated in an RCT comparing 8 weeks of alprazolam or placebo (medication treatment) plus exposure or relaxation (psychological treatment; relaxation being the "psychological placebo"). At the end of 8 weeks of treatment, 40 patients who much/very much improved assessed how much they attributed their gains to medication or to their own efforts. At the treatment-free follow-up in week 43, those who at week 8 had attributed their gains to medication and felt less confident about coping without medication had more severe withdrawal symptoms and a higher loss of gains in comparison to those who at week 8 had attributed their gains to their own efforts during treatment. Another study by Biondi and Picardi (2003) that investigated panic disorder with agoraphobia reported similar results. They found that $60 \%$ of the patients with panic disorder who attributed improvement to medication in a combined medicationpsychotherapy treatment relapsed, whilst those who attributed improvement to the self-reported no relapse. Although similar attributional processes have been hypothesized to play a role in the differential long-term effects of CBT vs. ADM in depression treatment, no study so far assessed this to the best of the present authors' knowledge.

Behavioural activation (BA) is a relatively new treatment for patients with major depressive disorder (MDD) (Jacobson et al., 1996). Recent studies have shown that BA is an effective treatment for depression that might even be more effective than cognitive therapy in severely depressed patients (Dimijian et al., 2006). To date, no study investigated the effects of attribution to medication and attribution to the self on treatment effects of BA in comparison to antidepressant medication (ADM) for participants with MDD. The data presented in this paper are drawn from a randomized controlled trial comparing BA and antidepressant medication (Sertraline) for patients with MDD, in which BA proved to be superior to ADM (Moradveisi et al., 2013). The focus of this paper is on whether depressed patients' attributions of treatment effects (i.e. to the medication or to the self), impact the long-term effects of treatment, assessed after approximately one year. If it is true that CBT has better long-term effects than ADM because of attribution of improvement to controllable factors in the self instead of to external factors such as medication, two predictions follow.

(1) Attribution of treatment effects to the self will predict better long-term effects of treatment, even after controlling for the short-term effects. In contrast, attribution of treatment effects to medication will not be associated, or negatively associated, with long-term treatment effects.

(2) Attribution of treatment effects to the self will mediate the long-term differences between BA and ADM that were observed in our trial. 
We tested the first prediction by assessing participants' beliefs about factors explaining improvement after treatment, and testing their predictive power in explaining longterm depressive complaints, assessed at 49 weeks, whilst controlling for the level of these complaints as assessed immediately after treatment (week 13). The second prediction was tested by formal mediation tests, investigating whether attributions statistically mediated the difference between conditions in long-term effects, even when controlling for the short-term effects of treatment. Implicated in the attribution mediation hypothesis is that attributions that play a role in explaining the differences between BA and ADM on the long-term effects should differ significantly between conditions; we therefore also tested whether attributions differed between BA and ADM.

\section{Methods}

Main treatment outcome findings and the sample characteristics of the study have been reported elsewhere (Moradveisi et al., 2013). The original sample consisted of 100 depressed patients from Sanandaj, Iran, between the ages of 18 to 60 years (mean 31.37, SD 8.97), 85 women, with a primary diagnosis of MDD according to the Diagnostic and Statistical Manual of Mental Disorders DSM-IV-TR (American Psychiatric Association, 2000), confirmed by the Structured Clinical Interview for the DSM-IV-TR Axis-I Disorders Clinical Trials Version (SCID-CT) (First et al., 2007). Participants had to have a score of $\geq 19$ on the Beck Depression Inventory, second edition (BDI-II) (Beck et al., 1996) and a score of $\geq 14$ on the 17-item Hamilton Rating Scale for Depression (HRSD) (Hamilton, 1960). The present study reports on the 70 participants with complete data at the 3-months and 1-year follow-up assessments. These were all treatment completers. The study was approved by the local Committee of Medical Ethics, Second Session of Kurdistan University of Medical Sciences. All participants signed written informed consent to participate in the study.

\section{Treatments, measures and assessments}

Participants were randomized by an independent coordinator. Fifty participants were randomly assigned to each condition, behavioural activation $(\mathrm{N}=50)$ and antidepressant medication $(\mathrm{N}=50)$. Participants in the BA group received 16 sessions over 12 weeks. For the first 4 weeks they received two sessions per week, and for the following 8 weeks one session per week. No patient in the BA group took medication during the three months of the treatment phase.

Patients in the ADM group received sertraline, which is the usual treatment in Iran for depression. In week 1, participants in the ADM group started with $25 \mathrm{mg} /$ daily of sertraline, and the dosage in week 2 increased to $50 \mathrm{mg}, 75 \mathrm{mg}$ in week 4, and $100 \mathrm{mg}$ 
in week 6 up to week 12. Psychiatrists could reduce the dosage temporarily in case of side-effects and then increase the dosage to the previous level. The maximum dosage of sertraline was $100 \mathrm{mg}$ per day. After 12 weeks, antidepressant medication use was discontinued.

Depression severity was assessed with the modified 17-item version of the HRSD (Hamilton, 1960) and the BDI-II (Beck et al., 1996). Both measures were administered at baseline, 4, 13 (three months of treatment), and 49 weeks (also referred to as 1 year follow-up). HRSD assessments were done by evaluators blind to treatment conditions. Independent assessors assessed the HRSD for TAU patients and the BDI for BA patients before every treatment session and supplied results to psychiatrists and therapists.

The attribution questionnaire was constructed by two authors (L.M and A.A) on the basis of Basoglu's attribution questionnaire (Basoglu et al., 1994). We modified items to make them applicable to depression treatment, and replaced items 3, 4, 7, 9, and 14 to add more items with explicit attribution to psychological treatment. The questionnaire had 15 items (Table 1). Items were scored on 9-point Likert scales ( $0=$ not at all; 8 = very much so). Participants filled out all items, they were instructed to use their subjective belief if they had no experience with what was asked. Item 14 caused too many interpretation problems, probably because of the double negation, and was left out further analyses. It should be noted that most participants had previous experience with ADM before entering the trial.

\section{Statistical analysis}

The attribution items were subjected to a Principal Component Analyses, retrieving components with Eigenvalue $>1$, also using the scree test to decide on the number of components to extract, followed by Oblimin rotation. Attribution scores were based on factor scores from the Principal Component Analysis, which are by definition centred. Regression analyses were used to estimate the influences of attribution on depression severity at week 49, controlling for depression severity at week 13 and the interaction between condition and depression severity at week 13, if significant. We used HRSDfollow up and BDI-follow up as dependent variables, and centred predictors, by using Z-scores of BDI and HRSD at week 13, and treatment condition dummies - 0.5 (ADM) and 0.5 (BA). Predictors were centred as main effects cannot be interpreted validly when interactions are included in the model. For each dependent variable, the following predictors were forced into the model: $z$-score of the dependent variable at week 13 , condition, and their interaction (if significant); this was model 1 . Next, the 4 factor scores of the belief questionnaire were entered, as well as their interactions with condition. As none of these 


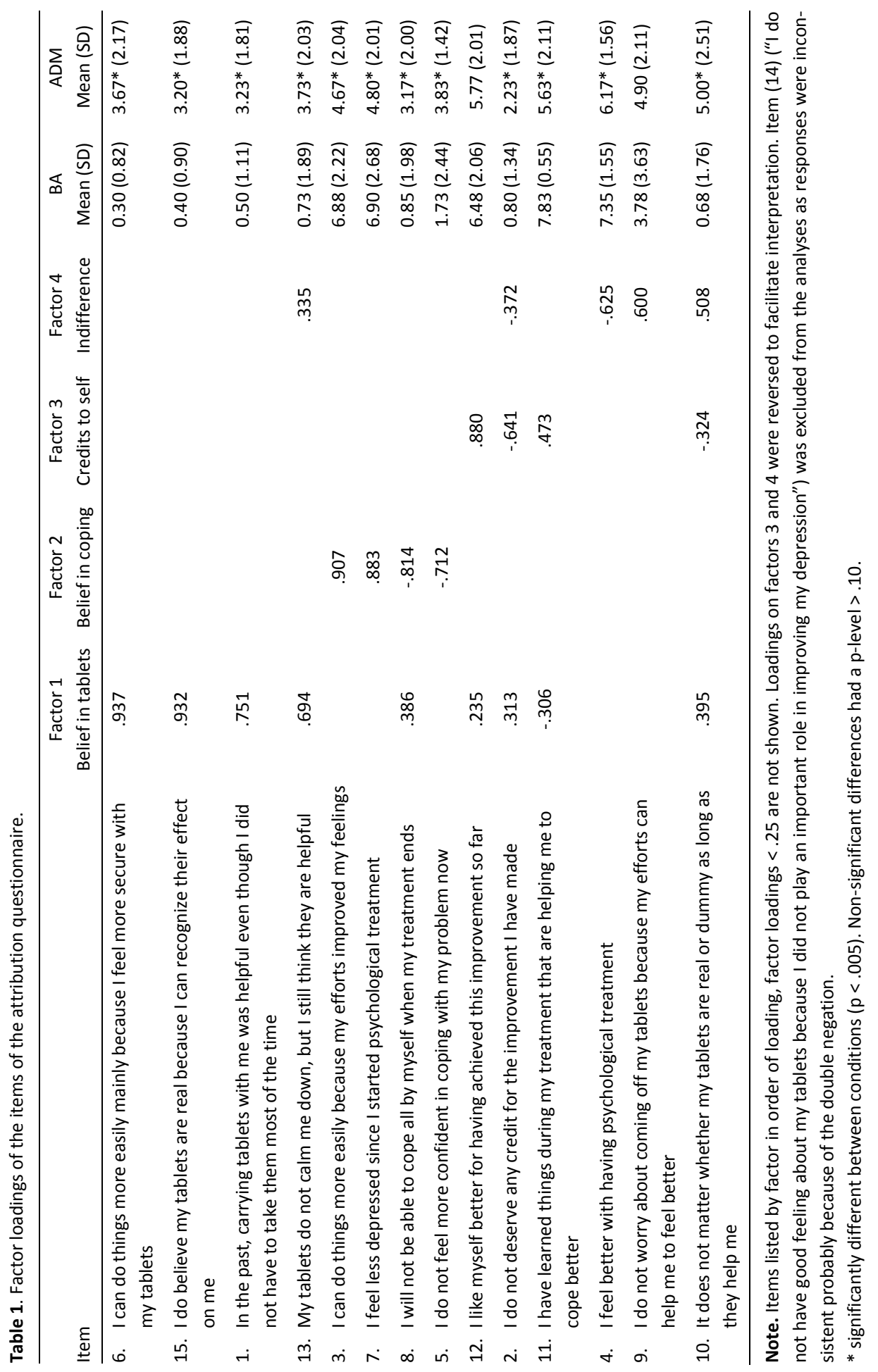


interactions was significant, we will not report them. Thus, the second model we report had all 4 factor scores as predictors in addition to the predictors of model 1 . Next, non-significant predictors involving attribution factors were deleted backwards, using $\mathrm{p}<.05$ as a criterion, leading to models 3,4 , etc., until only significant attribution predictors remained. The significant attribution factors were then tested as mediators of long-term differences between BA and ADM, controlling for post-test level of the dependent variable (HRSD, respectively $\mathrm{BDI}$ ) and its interaction with condition (if significant). The mediation tests were executed using Hayes and Preacher's (2013; see also Preacher \& Hayes, 2004) bootstrap mediation test with the SPSS Macro "Mediate" (http://www.afhayes.com/spss-sas-and-mplus-macros-and-code.html, downloaded March 9, 2013), using 50,000 replications. This test allows multiple covariates in the model. We used a high number of replications to get more precise estimates (less estimation error) as the $95 \% \mathrm{Cl}$ intervals were near zero. Statisticians have criticized the use of relatively small numbers of replications in Monte Carlo tests like the bootstrap, and the underestimation of the error resulting from relatively small numbers of replications (Koehle, Brown \& Haneuse, 2009). The higher the number of replications, the more precise the estimate becomes, and therefore practical aspects (computational time) and not statistical theory usually determines the number of replications. With the mediation test we assessed whether the difference between BA and ADM in depression severity at 1-year follow-up is statistically explained by attributions. The mediation test examines whether the direct effect of condition on 1-year depression severity is explained by an "indirect" effect through attribution, that is whether BA and ADM differ in attribution, and whether this difference accounts for the long-term differences in depression severity. Mediation is inferred when (i) attribution differs between conditions (i.e., condition predicts attribution); (ii) attribution predicts 1-year depression severity; (iii) the effect of condition becomes non-significant after controlling for attribution; (iv) the indirect path from condition to 1-year depression severity through attribution is significant. Partial mediation is concluded when all criteria are fulfilled except (iii), that is the effect of condition remains significant (despite reducing in strength). As the indirect path effect is the product of the effects of condition on the mediator (i.e., attribution) and of the mediator on 1-year depression severity, the distribution of the indirect path effect is usually not normal (but highly skewed). Testing the indirect path is therefore done in the Preacher and Hayes (2004) approach by a bootstrap test; high numbers of samples (with replacement) of the same $\mathrm{N}$ as the empirical sample are taken, the indirect path is calculated for every sample, and thereby a simulated distribution of the indirect path is created. From this simulated distribution the $95 \%$ confidence interval $(\mathrm{Cl})$ is derived and if it does not contain zero, significance at $p<.05$ of the indirect path is concluded. The mediation tests were controlled for the level of severity at 3 months as well as for the (significant) interaction of condition by 
level of severity at 3 months. Figures 1-4 illustrate the mediation models that were tested.

\section{Results}

\section{Structure of the attribution scale}

A Principal Component Analysis indicated 4 components with Eigenvalue $>1$. The four components explained $72.43 \%$ of the variance. After Oblimin rotation three of the four components could be well interpreted: (1) belief in tablets; (2) belief in coping; (3) credits to self; whereas the fourth was provisionally labeled (4) indifference (to facilitate interpretation, the original loadings of factors 3 and 4 were reversed). Table 1 presents the item's factor loadings per factor in order of size, omitting loadings with an absolute value $<.25$. The factor inter-correlations ranged from -.37 to .22 . For further computations, factor scores were retained (reversed for factors 3 and 4), with higher scores representing higher positions on the dimensions as listed above. As might be expected, BA participants scored higher on "belief in coping", $\mathrm{t}(68)=4.36, \mathrm{p}<.001$, and "credits to the self", $\mathrm{t}(68)=3.81, \mathrm{p}<.001$, compared to ADM participants. ADM participants scored higher on "belief in tablets", $\mathrm{t}(68)=11.24, \mathrm{p}<.001$, and "indifference" $, t(68)=3.02, p=.004$.

\section{Effects of attribution on BDI and HRSD}

Table 2 and 3 present the results of the regression analyses of the full model for HRSD and $\mathrm{BDI}$, respectively.

$H R S D$. The two-way condition $\times$ zHRSD post interaction was significant for the HRSD in all models and therefore included in all (Table 2). The interaction reflected a positive association between HRSD at 3 months and 1 year in ADM $(r=0.65, p<.001)$ and an absence of an association in BA ( $r=0.03$, n.s.). Condition was significant in model 1, before entering the attribution factors, reflecting lower HRSD scores at 1-year follow-up in BA than in ADM. After backward deletion of the non-significant attribution factors, belief in coping remained as the single significant attribution factor predicting 1-year HRSD scores, with higher scores predicting lower HRSD scores (Table 2, model 5 ). In model 5, condition became non-significant ( $p=.074$; Table 2$)$, suggesting that the condition effect at 1-year follow-up was mediated to a large extent by the belief in coping attribution factor.

The formal test of mediation with Hayes \& Preacher's (2013) bootstrap mediation test yielded positive evidence for mediation of the group effect on follow-up HRSD, as the direct effect of group on the mediator ("belief in coping") was significant when con- 
trolling for posttest HRSD and group by posttest HRSD as covariates (Beta $=1.04$, $\mathrm{se}=.25, \mathrm{t}(66)=4.24, \mathrm{p}=.0001$ ), and the bootstrap $95 \%$ confidence interval of the indirect effect of condition through the mediator on 1-year HRSD (-.86; SE .63) did not contain zero, $95 \% \mathrm{Cl}[-2.75 ;-0.05]$ (Figure 1).

$B D I$. The two-way condition $\times \mathrm{zBDI}$ post interaction was significant in all analyses, and therefore retained in all models (Table 3). The interaction reflected a positive association between BDI at 3 months and 1 year in ADM ( $r=0.58, p=.001)$ and an absence of an association in $B A(r=0.01$, ns). Condition was significant, reflecting superior effects of BA above ADM on BDI-scores at 1-year follow-up. After backward deletion of the non-significant attribution factors, credits to the self was found to be the single significant attribution factor predicting 1-year BDI scores, controlling for condition, posttest BDI and their interaction (model 5, Table 3 ). Credits to the self predicted lower BDI scores at 1-year follow-up. In model 5, condition remained significant, though there was a shrinkage in explanatory power, suggesting partial mediation of the condition effect by the credits to the self factor.

The formal test of mediation with Hayes \& Preacher's (2013) bootstrap mediation test yielded positive evidence for (partial) mediation of the group effect on follow-up $\mathrm{BDI}$, as the effect of group on the mediator ("credits to the self") was significant when controlling for posttest BDI and group by posttest BDI as covariates (Beta $=-.59$, $\mathrm{se}=.26, \mathrm{t}(66)=-2.26 .24, \mathrm{p}=.027)$, and the bootstrap 95\% confidence interval of the indirect effect of condition through the mediator on 1-year BDI (-.51; SE .32) did not contain zero, 95\% Cl [-1.52; -0.08] (Figure 2). 
Table 2. Results of regression analyses testing effects of attributions after 13 weeks of treatment on 49 weeks HRSD scores.

\begin{tabular}{|c|c|c|c|c|c|}
\hline \multirow[t]{2}{*}{ Predictor } & \multicolumn{2}{|c|}{ Unstandardized coefficients } & \multirow{2}{*}{$\begin{array}{l}\text { Standardized } \\
\text { Beta }\end{array}$} & \multirow[t]{2}{*}{ t-value } & \multirow[t]{2}{*}{$p$-value } \\
\hline & B & S.E & & & \\
\hline \multicolumn{6}{|l|}{ Model $1\left(R^{2}=.45\right)$} \\
\hline Constant & 7.90 & 0.37 & & 21.43 & $<0.001$ \\
\hline Condition & -2.32 & 0.74 & -0.33 & -3.15 & 0.002 \\
\hline z (HRSD Post) & 1.12 & 0.36 & 0.33 & 3.07 & 0.003 \\
\hline Condition* z (HRSD Post) & -2.04 & 0.73 & -0.27 & -2.81 & 0.007 \\
\hline \multicolumn{6}{|l|}{ Model $2\left(R^{2}=.51\right)$} \\
\hline Constant & 7.81 & 0.38 & & 20.70 & $<0.001$ \\
\hline Condition & -1.56 & 1.40 & -0.22 & -1.11 & 0.27 \\
\hline$z$ (HRSD Post) & 1.10 & 0.38 & 0.32 & 2.85 & 0.006 \\
\hline Condition* z (HRSD Post) & -2.17 & 0.76 & -0.28 & -2.87 & 0.006 \\
\hline Belief in tablets & 0.04 & 0.64 & 0.01 & 0.06 & 0.95 \\
\hline Belief in coping & -0.84 & 0.36 & -0.24 & -2.30 & 0.025 \\
\hline Credits to self & -0.27 & 0.37 & -0.08 & -0.74 & 0.46 \\
\hline Indifference & -0.43 & 0.35 & -0.12 & -1.25 & 0.22 \\
\hline \multicolumn{6}{|l|}{ Model $3\left(R^{2}=.51\right)$} \\
\hline Constant & 7.82 & 0.36 & & 21.88 & $<0.001$ \\
\hline Condition & -1.62 & 0.85 & -0.23 & -1.90 & 0.062 \\
\hline$z$ (HRSD Post) & 1.09 & 0.37 & 0.32 & 2.92 & 0.005 \\
\hline Condition* z (HRSD Post) & -2.15 & 0.71 & -0.28 & -3.06 & 0.003 \\
\hline Belief in coping & -0.84 & 0.36 & -0.24 & -2.33 & 0.023 \\
\hline Credits to self & -0.27 & 0.36 & -0.08 & -0.75 & 0.46 \\
\hline Indifference & -0.44 & 0.34 & -0.12 & -1.27 & 0.21 \\
\hline \multicolumn{6}{|l|}{ Model $4(\mathrm{R2}=.51)$} \\
\hline Constant & 7.83 & 0.36 & & 22.04 & $<0.001$ \\
\hline Condition & -1.77 & 0.83 & -0.25 & -2.15 & 0.035 \\
\hline$z$ (HRSD Post) & 1.17 & 0.35 & 0.35 & 3.34 & 0.001 \\
\hline Condition* z (HRSD Post) & -2.19 & 0.70 & -0.29 & -3.13 & 0.003 \\
\hline Belief in coping & -0.88 & 0.36 & -0.25 & -2.47 & 0.016 \\
\hline Indifference & -0.49 & 0.33 & -0.14 & -1.48 & 0.14 \\
\hline \multicolumn{6}{|l|}{ Model $5\left(R^{2}=.49\right)$} \\
\hline Constant & 7.83 & 0.36 & & 21.82 & $<0.001$ \\
\hline Condition & -1.46 & 0.81 & -0.21 & -1.82 & 0.074 \\
\hline$z$ (HRSD Post) & 1.20 & 0.35 & 0.35 & 3.38 & 0.001 \\
\hline Condition* z (HRSD Post) & -2.12 & 0.71 & -0.28 & -3.01 & 0.004 \\
\hline Belief in coping & -0.83 & 0.36 & -0.23 & -2.31 & 0.024 \\
\hline
\end{tabular}

Note. Condition was centred with BA $=.5$ and TAU (ADM) $=-.5 . z$ (HRSD Post $)=$ standardized HRSD score at post-test (13 weeks). The four factor scores (by definition centred) of the attribution questionnaire taken at post-test were labelled: (1) Belief in Tablets; (2) Belief in Coping; (3) Credits to Self; and (4) Indifference. Significant $p$-levels are printed bold. 
Table 3. Results of regression analyses testing the effects of attributions after 13 weeks of treatment on 49 weeks BDI scores.

\begin{tabular}{|c|c|c|c|c|c|}
\hline \multirow[t]{2}{*}{ Predictor } & \multicolumn{2}{|c|}{ Unstandardized coefficients } & \multirow{2}{*}{$\begin{array}{c}\text { Standardized } \\
\text { Beta }\end{array}$} & \multirow[t]{2}{*}{ t-value } & \multirow[t]{2}{*}{$\mathrm{p}$-value } \\
\hline & B & S.E & & & \\
\hline \multicolumn{6}{|l|}{ Model 1 (R2 = .56) } \\
\hline Constant & 9.76 & 0.42 & & 23.54 & $<0.001$ \\
\hline Condition & -4.29 & 0.83 & -0.49 & -5.17 & $<0.001$ \\
\hline$z$ (BDI Post) & 1.15 & 0.41 & 0.27 & 2.79 & 0.007 \\
\hline Condition* z (BDI Post) & -2.21 & 0.82 & -0.23 & -2.69 & 0.009 \\
\hline \multicolumn{6}{|l|}{ Model 2 (R2 = .62) } \\
\hline Constant & 9.79 & 0.43 & & 22.91 & $<0.001$ \\
\hline Condition & -4.73 & 1.50 & -0.54 & -3.15 & 0.003 \\
\hline z (BDI Post) & 0.96 & 0.41 & 0.23 & 2.36 & 0.021 \\
\hline Condition* z (BDI Post) & -1.97 & 0.87 & -0.20 & -2.27 & 0.027 \\
\hline Belief in tablets & -0.72 & 0.69 & -0.16 & -1.04 & 0.30 \\
\hline Belief in coping & -0.69 & 0.39 & -0.16 & -1.76 & 0.083 \\
\hline Credits to self & -0.65 & 0.39 & -0.16 & -1.66 & 0.10 \\
\hline Indifference & -0.50 & 0.38 & -0.12 & -1.32 & 0.19 \\
\hline \multicolumn{6}{|l|}{ Model $3\left(R^{2}=.61\right)$} \\
\hline Constant & 9.64 & 0.40 & & 23.96 & $<0.001$ \\
\hline Condition & -3.50 & 0.93 & -0.40 & -3.75 & $<0.001$ \\
\hline z (BDI Post) & 0.98 & 0.41 & 0.23 & 2.41 & 0.019 \\
\hline Condition* z (BDI Post) & -2.34 & 0.79 & -0.24 & -2.95 & 0.004 \\
\hline Belief in coping & -0.67 & 0.39 & -0.16 & -1.72 & 0.091 \\
\hline Credits to self & -0.71 & 0.39 & -0.17 & -1.85 & 0.069 \\
\hline Indifference & -0.43 & 0.37 & -0.10 & -1.17 & 0.25 \\
\hline \multicolumn{6}{|l|}{ Model $4(\mathrm{R} 2=.60)$} \\
\hline Constant & 9.60 & 0.40 & & 23.88 & $<0.001$ \\
\hline Condition & -3.20 & 0.90 & -0.37 & -3.56 & $<0.001$ \\
\hline z (BDI Post) & 0.93 & 0.40 & 0.22 & 2.30 & 0.025 \\
\hline Condition* z (BDI Post) & -2.37 & 0.80 & -0.25 & -2.98 & 0.004 \\
\hline Belief in coping & -0.62 & 0.39 & -0.14 & -1.59 & 0.12 \\
\hline Credits to Self & -0.81 & 0.38 & -0.20 & -2.17 & 0.034 \\
\hline \multicolumn{6}{|l|}{ Model $5(\mathrm{R2}=.59)$} \\
\hline Constant & 9.69 & 0.40 & & 24.02 & $<0.001$ \\
\hline Condition & -3.78 & 0.83 & -0.43 & -4.52 & $<0.001$ \\
\hline z (BDI Post) & 0.92 & 0.41 & 0.22 & 2.24 & 0.029 \\
\hline Condition* z (BDI Post) & -2.19 & 0.80 & -0.23 & -2.75 & 0.008 \\
\hline Credits to Self & -0.86 & 0.38 & -0.21 & -2.28 & 0.026 \\
\hline
\end{tabular}

Note. Condition was centred with $B A=.5$ and $T A U(A D M)=-.5 . z(B D I$ Post $)=$ standardized BDI score at posttest (13 weeks). The four factor scores (by definition centred) of the attribution questionnaire taken at posttest were labelled: (1) Belief in Tablets; (2) Belief in Coping; (3) Credits to Self; and (4) Indifference. Significant p-levels are printed bold. 
Table 4. Factor loadings of the 6 items of the reduced attribution questionnaire.

\begin{tabular}{lcc}
\hline Item & $\begin{array}{c}\text { Factor } 1 \\
\text { Lack of Belief in } \\
\text { Coping }\end{array}$ & $\begin{array}{c}\text { Factor } 2 \\
\text { Credits to Self }\end{array}$ \\
\hline 8. I will not be able to cope all by myself when my treatment ends & .947 & -.926 \\
3. I can do things more easily because my efforts improved my feelings \\
5. I do not feel more confident in coping with my problem now \\
$\begin{array}{l}\text { 2. I do not deserve any credit for the improvement I have made } \\
\text { 12. I like myself better for having achieved this improvement so far }\end{array}$ \\
$\begin{array}{l}\text { 11. I have learned things during my treatment that are helping me to } \\
\text { cope better }\end{array}$
\end{tabular}

Note. Factor loadings with absolute value $<.25$ are not displayed.

Table 5. Results of regression analyses testing effects of attributions from the reduced attribution questionnaire after 13 weeks of treatment on 49 weeks HRSD scores.

\begin{tabular}{|c|c|c|c|c|c|}
\hline \multirow[t]{2}{*}{ Predictor } & \multicolumn{2}{|c|}{ Unstandardized coefficients } & \multirow{2}{*}{$\begin{array}{c}\text { Standardized } \\
\text { Beta }\end{array}$} & \multirow[t]{2}{*}{ t-value } & \multirow[t]{2}{*}{$p$-value } \\
\hline & B & S.E & & & \\
\hline \multicolumn{6}{|l|}{ Model 1 (R2 = .45) } \\
\hline Constant & 7.90 & 0.37 & & 21.43 & $<0.001$ \\
\hline Condition & -2.32 & 0.74 & -0.33 & -3.15 & 0.002 \\
\hline z (HRSD Post) & 1.12 & 0.36 & 0.33 & 3.07 & 0.003 \\
\hline Condition* z (HRSD Post) & -2.04 & 0.73 & -0.27 & -2.81 & 0.007 \\
\hline \multicolumn{6}{|l|}{ Model $2(\mathrm{R2}=.51)$} \\
\hline Constant & 7.79 & 0.36 & & & \\
\hline Condition & -0.97 & 0.86 & -0.14 & -1.13 & 0.26 \\
\hline z (HRSD Post) & 1.03 & 0.37 & 0.30 & 2.79 & 0.007 \\
\hline Condition* z (HRSD Post) & -2.12 & 0.70 & -0.28 & -3.03 & 0.004 \\
\hline Lack of Belief in Coping & 0.81 & 0.38 & 0.23 & 2.13 & 0.037 \\
\hline Credits to Self & -0.58 & 0.38 & -1.54 & -1.54 & 0.13 \\
\hline \multicolumn{6}{|l|}{ Model $3($ R2 = .49) } \\
\hline Constant & 7.79 & 0.36 & & 21.62 & $<0.001$ \\
\hline Condition & -1.24 & 0.85 & -0.18 & -1.46 & 0.15 \\
\hline z (HRSD Post) & 1.21 & 0.35 & 0.36 & 3.42 & .001 \\
\hline Condition* z (HRSD Post) & -2.20 & 0.71 & -0.29 & -3.11 & .003 \\
\hline Lack of Belief in Coping & 0.89 & 0.38 & 0.25 & 2.34 & .023 \\
\hline
\end{tabular}

Note. Condition was centred with BA $=.5$ and TAU $(A D M)=-.5 . z$ (HRSD Post) $=$ standardized HRSD score at post-test (13 weeks). The two factor scores (by definition centred) of the reduced attribution questionnaire (only items that did not refer to medication or psychological treatment) taken at post-test were labelled: (1) Lack of Belief in Coping; and (2) Credits to Self. Significant p-levels are printed bold. 
Table 6. Results of regression analyses testing effects of attributions from the reduced attribution questionnaire after 13 weeks of treatment on 49 weeks BDI scores.

\begin{tabular}{|c|c|c|c|c|c|}
\hline \multirow[t]{2}{*}{ Predictor } & \multicolumn{2}{|c|}{ Unstandardized coefficients } & \multirow{2}{*}{$\begin{array}{c}\text { Standardized } \\
\text { Beta }\end{array}$} & \multirow[t]{2}{*}{ t-value } & \multirow[t]{2}{*}{ p-value } \\
\hline & B & S.E & & & \\
\hline \multicolumn{6}{|l|}{ Model $1\left(R^{2}=.56\right)$} \\
\hline Constant & 9.76 & 0.42 & & 23.54 & $<0.001$ \\
\hline Condition & -4.29 & 0.83 & -0.49 & -5.17 & $<0.001$ \\
\hline z (BDI Post) & 1.15 & 0.41 & 0.27 & 2.79 & 0.007 \\
\hline Condition* z (BDI Post) & -2.21 & 0.82 & -0.23 & -2.69 & 0.009 \\
\hline \multicolumn{6}{|l|}{ Model $2\left(R^{2}=.61\right)$} \\
\hline Constant & 9.64 & .40 & & 23.98 & $<.001$ \\
\hline Condition & -3.00 & 0.95 & -0.35 & -3.17 & 0.002 \\
\hline z (BDI Post) & 0.92 & 0.40 & 0.22 & 2.27 & 0.026 \\
\hline Condition* z (BDI Post) & -2.34 & 0.80 & -0.24 & -2.93 & 0.005 \\
\hline Lack of Belief in Coping & 0.54 & 0.42 & 0.23 & 1.30 & 0.20 \\
\hline Credits to Self & -0.99 & 0.40 & -0.23 & -2.48 & 0.016 \\
\hline \multicolumn{6}{|l|}{ Model $3\left(R^{2}=.60\right)$} \\
\hline Constant & 9.73 & 0.40 & & 24.46 & $<0.001$ \\
\hline Condition & -3.59 & 0.84 & -0.41 & -4.27 & $<0.001$ \\
\hline z (BDI Post) & 0.89 & 0.41 & 0.21 & 2.21 & 0.031 \\
\hline Condition* z (BDI Post) & -2.14 & 0.79 & -0.22 & -2.72 & 0.008 \\
\hline Credits to Self & -1.04 & 0.40 & -0.24 & -2.61 & 0.011 \\
\hline
\end{tabular}

Note. Condition was centred with BA $=.5$ and TAU $(A D M)=-.5 . z$ (HRSD Post) $=$ standardized HRSD score at post-test (13 weeks). The two factor scores (by definition centred) of the reduced attribution questionnaire (only items that did not refer to medication or psychological treatment) taken at post-test were labelled: (1) Lack of Belief in Coping; and (2) Credits to Self. Significant p-levels are printed bold. 


\section{A. Unmediated model}

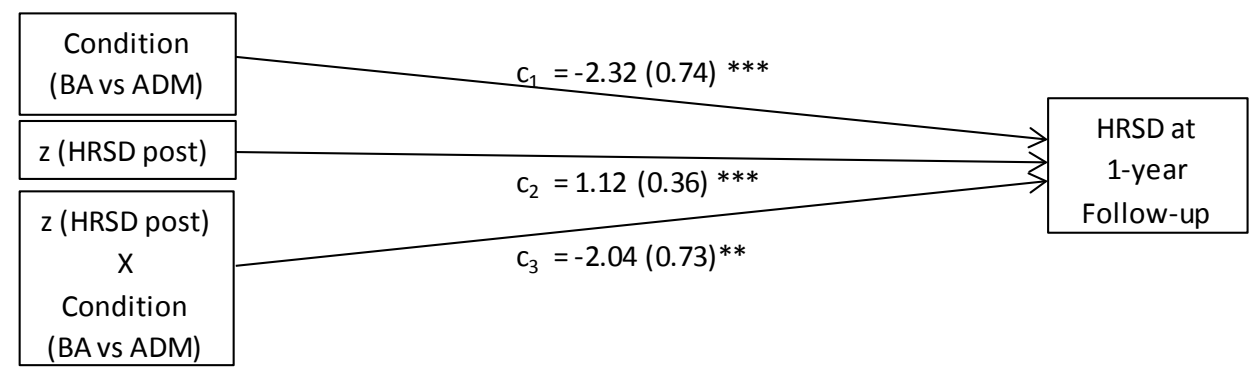

\section{B. Mediation model}

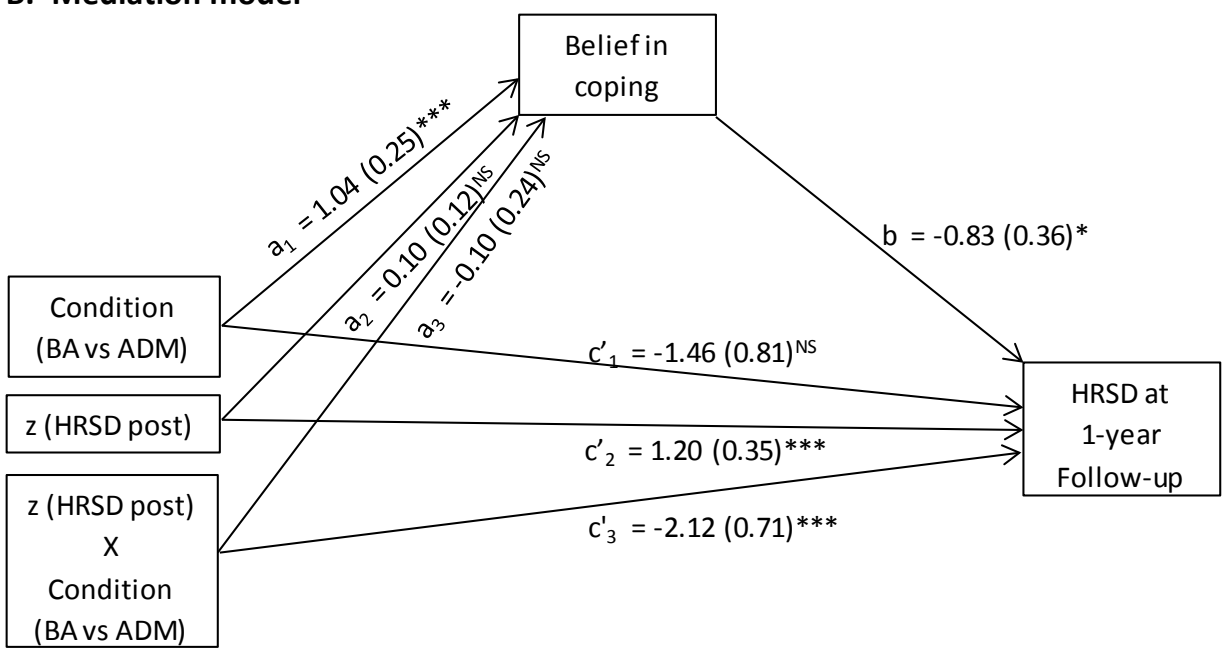

Mediation was significant:

(i) $a_{1}$ and $b$ were significant;

(ii) condition effect $\mathrm{c}_{1}{ }_{1}$ became nonsignificant ( whereas $\mathrm{c}_{1}$ was significant in model A);

(iii) bootstrap $95 \% \mathrm{Cl}$ of the indirect effect did not contain zero $[-2.75 ;-0.05]$

Figure 1. Mediation of effects of treatment condition on 1-year depression assessed with the HRSD by attribution factor "belief in coping".

Note. $B A=$ behavioural Activation; $A D M=$ Antidepressant Medication; $z($ HSRD post $)=$ standardized score of the Hamilton Rating Scale for Depression at posttest (post-treatment); HRSD = Hamilton Rating Scale for Depression; a, b, c = unstandardized regression coefficients (with SE in brackets); ${ }^{N S} \mathrm{p}>.05 ;{ }^{*} \mathrm{p}<.05 ;{ }^{* *} \mathrm{p}<$ $.01 ; * * * \mathrm{p}<.005 ; * * * * \mathrm{p}<.001$ 


\section{A. Unmediated model}

\begin{tabular}{|c|c|c|}
\hline $\begin{array}{l}\text { Condition } \\
\text { (BA vs ADM) }\end{array}$ & $\mathrm{c}_{1}=-4.29(0.83) * * * *$ & \\
\hline z (BDI post) & & $\begin{array}{l}\text { BDI at } \\
\text { 1-vear }\end{array}$ \\
\hline z (BDI post) X & $c_{2}-1 .+0.40$ & Follow-up \\
\hline $\begin{array}{l}\text { Condition } \\
\text { (BA vs ADM) }\end{array}$ & $c_{3}=-2.21(0.82)^{* *}$ & \\
\hline
\end{tabular}

\section{B. Mediation model}

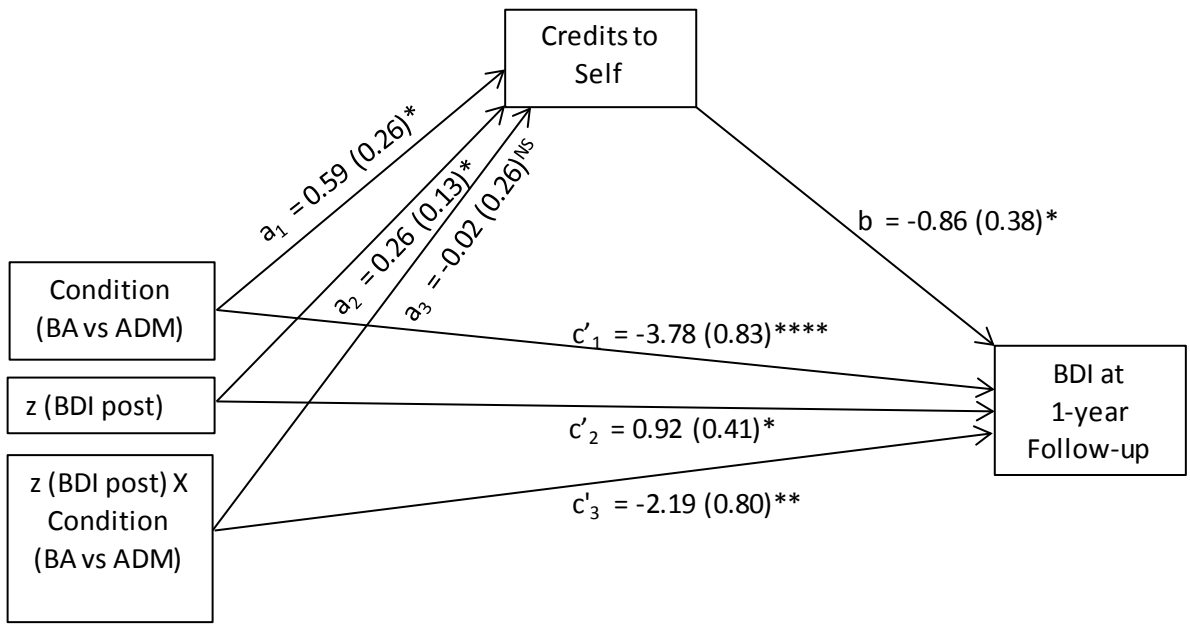

Partial mediation was significant:

(i) $\mathrm{a}_{1}$ and $\mathrm{b}$ were significant;

(ii) condition effect $c^{\prime}{ }_{1}$ remained significant $\left(c_{1}\right.$ was significant in model $A$, but reduced in strength);

(iii) bootstrap $95 \% \mathrm{Cl}$ of the indirect effect did not contain zero [-1.52; -0.08$]$

Figure 2. Partial mediation of effects of treatment condition on 1-year depression assessed with the BDI by attribution factor "credits to self".

Note. $B A=$ behavioural Activation; $A D M=$ Antidepressant Medication; $z$ (BDI post) = standardized score of the Beck Depression Inventory at posttest (post-treatment); BDI = Beck Depression Inventory; $a, b, c=u n-$ standardized regression coefficients (with SE in brackets); ${ }^{N S} \mathrm{p}>.05 ;{ }^{*} \mathrm{p}<.05 ;{ }^{* *} \mathrm{p}<.01 ;{ }^{* * *} \mathrm{p}<.005 ;{ }^{* * * *}$ $p<.001$ 


\section{A. Unmediated model}

\begin{tabular}{|c|c|c|}
\hline $\begin{array}{l}\text { Condition } \\
\text { (BA vs ADM) }\end{array}$ & $\mathrm{c}_{1}=-2.32(0.74) * * *$ & \multirow{3}{*}{$\begin{array}{c}\text { HRSD at } \\
\text { 1-year } \\
\text { Follow-up }\end{array}$} \\
\hline z (HRSD post) & \multirow{2}{*}{$c_{2}=1.12(0.36)^{* * *}$} & \\
\hline z (HRSD post) & & \\
\hline $\begin{array}{c}\mathrm{X} \\
\text { Condition } \\
\text { (BA vs ADM) }\end{array}$ & $c_{3}=-2.04(0.73)^{* *}$ & \\
\hline
\end{tabular}

\section{B. Mediation model}

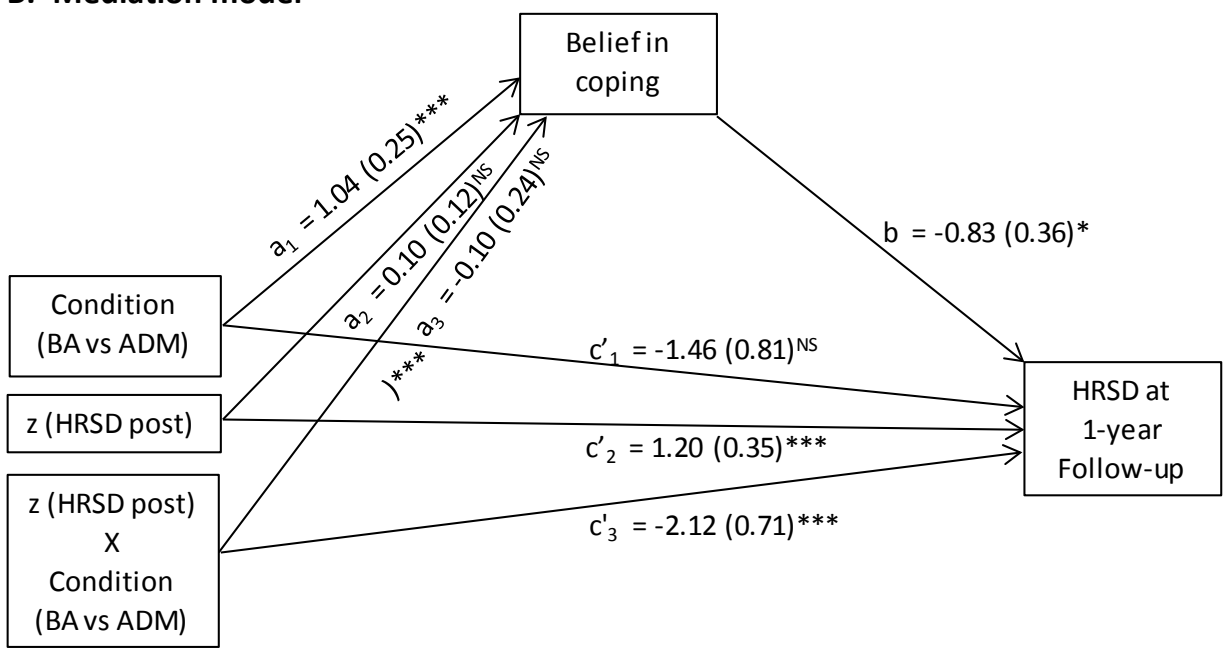

Mediation was significant:

(i) $a_{1}$ and $b$ were significant;

(ii) condition effect $\mathrm{C}_{1}{ }_{1}$ became nonsignificant in model $\mathrm{B}$ ( whereas $\mathrm{C}_{1}$ was significant in model A);

(iii) bootstrap $95 \% \mathrm{Cl}$ of the indirect effect $(-0.86)$ did not contain zero [-2.77; -0.007$]$

Figure 3. Mediation of effects of treatment condition on 1-year depression assessed with the HRSD by attribution factor "lack of belief in coping" from the reduced attribution questionnaire (additional analyses).

Note. $B A=$ behavioural Activation; $A D M=$ Antidepressant Medication; $z($ HSRD post $)=$ standardized score of the Hamilton Rating Scale for Depression at posttest (post-treatment); HRSD = Hamilton Rating Scale for Depression; a, b, c = unstandardized regression coefficients (with SE in brackets); ${ }^{\text {NS }} \mathrm{p}>.05 ;{ }^{*} \mathrm{p}<.05 ;{ }^{* *} \mathrm{p}<$ $.01 ; * * \mathrm{p}<.005 ; * * * * \mathrm{p}<.001$ 


\section{A. Unmediated model}

\begin{tabular}{|c|c|c|}
\hline $\begin{array}{l}\text { Condition } \\
\text { (BA vs ADM) }\end{array}$ & $\mathrm{c}_{1}=-4.29(0.83) * * * *$ & \\
\hline z (BDI post) & & $\begin{array}{l}\text { BDI at } \\
\text { 1-vear }\end{array}$ \\
\hline z (BDI post) X & $c_{2}-1 .+0.40$ & Follow-up \\
\hline $\begin{array}{l}\text { Condition } \\
\text { (BA vs ADM) }\end{array}$ & $c_{3}=-2.21(0.82)^{* *}$ & \\
\hline
\end{tabular}

\section{B. Mediation model}

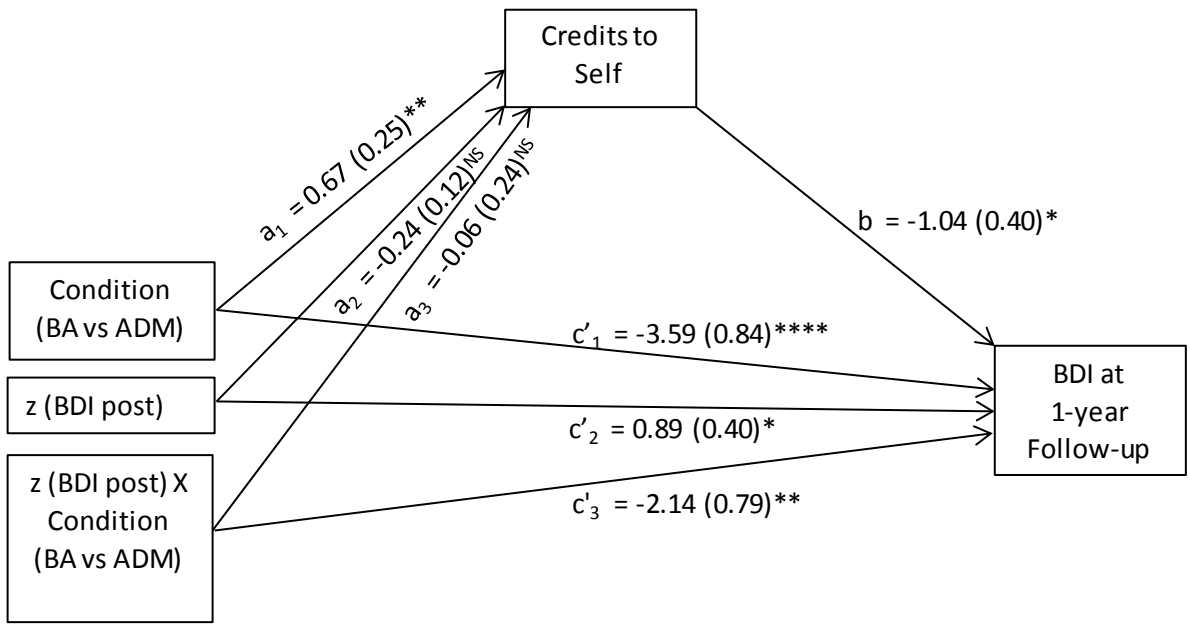

Partial mediation was significant:

(i) $\mathrm{a}_{1}$ and $\mathrm{b}$ were significant;

(ii) condition effect $c^{\prime}{ }_{1}$ remained significant $\left(c_{1}\right.$ was significant in model $A$, but reduced in strength in model B);

(iii) bootstrap $95 \% \mathrm{Cl}$ of the indirect effect $(-0.70)$ did not contain zero $[-1.73 ;-0.16]$

Figure 4. Partial mediation of effects of treatment condition on 1-year depression assessed with the BDI by attribution factor "credits to self" from the reduced attribution questionnaire (additional analyses).

Note. $B A=$ behavioural Activation; $A D M=$ Antidepressant Medication; $z$ (BDI post) = standardized score of the Beck Depression Inventory at posttest (post-treatment); BDI = Beck Depression Inventory; $a, b, c=u n-$ standardized regression coefficients (with SE in brackets); ${ }^{N S} p>.05 ; * p<.05 ; * * p<.01 ; * * * p<.005 ;{ }^{* * * *}$ $p<.001$ 


\section{Additional analyses}

The analyses so far may be criticized as the attribution questionnaire contained items that might have been difficult to rate for participants not receiving the type of treatment the items refer to. We therefore checked attributional effects within each condition by construing ad-hoc attribution scales from item subsets that did not refer to the other treatment. For ADM, items 1,2,3,5,6,8,9,10,11,12,13 and 15 were considered as none referred to psychological treatment (reversed scoring when indicated). Based on a reliability analysis, items 5, 8, and 13 were deleted. The subscale had (within the ADM subgroup) an internal consistency of .53 (Cronbach's alpha) and correlated significantly with change from 3-month to 1-year follow-up changes in HRSD ( $r=.37, p=.046)$ and BDI ( $r=.36, p=.049)$, indicating that higher attributions to medication and lower attributions to skills and the self predicted increases in depression severity from 3months to one year. Similarly, we considered items 2,3,4,5,7,8,11 and 12 for the BA condition, as none referred to medication. Based on a reliability analysis items $3,4,5,7$ and 8 were retained (Cronbach alpha $=.91)$. Correlations with changes from 3-month to 1-year follow-up failed to reach significance for HRSD $(r=-.22, p=.17)$ and BDI $(r=-$ .002, $\mathrm{p}=.99)$.

Lastly, the main analyses were repeated using only items of the attribution questionnaire that did not refer to medication or psychological treatment, that is items $2,3,5,8,11$ and 12 . A principal component analyses yielded two components with eigenvalue $>1$ (total variance explained $71.5 \%$ ), and the scree plot also supported a twofactor solution. After Oblimin rotation, the two factors were interpreted as "lack of belief in coping" and "credits to the self", see table 4 for factor loadings. The factor intercorrelation was -. 31. Factor scores were retained for further computations. The conditions differed significantly in mean factor scores; on "lack of belief in coping" means (SD) were for ADM .63 (.65) vs. for BA -.47 (.96), t(68) = 5.10, $p<.001$; and on "credits to the self" for ADM -.53 (1.02) vs. for BA .40 (.78), $t(68)=4.34, p<.001$. Using the same regression procedures as above, factor 1 scores significantly added to the prediction of HRSD scores at 1-year follow-up, controlling for condition, 3-months HRSD and their interaction (Table 5). The prediction by condition became nonsignificant, indicating mediation of the condition differences on HRSD at 1-year followup by "lack of belief in coping". This was confirmed by a formal mediation test, see figures 3 and 4 . In short, condition significantly predicted the mediator, the mediator significantly predicted the HRSD at follow-up, the direct effect of condition on 1-year follow-up HRSD became non-significant after controlling for the mediator, and the $95 \%$ $\mathrm{Cl}$ of the indirect effect of condition (beta $=-.86$ ) through the mediator did not contain zero (-2.7708; -.0067). 
Similar findings as from the primary analyses were found for the prediction of 1year BDI by the revised attribution questionnaire's factors. As is shown in Table 6, factor 2 (Credits to Self), but not factor 1, predicted 1-year BDI controlling for condition, 3-months BDI, and their interaction. Similarly as in the primary analysis, adding factor 2 reduced the contribution of condition, but did not make it non-significant. A formal mediation analysis demonstrated that the (partial) mediation of the condition effect by factor 2 was significant, as condition significantly predicted factor 2 , and the indirect effect of condition through the mediator (beta $=-0.70$ ) was significant (the $95 \% \mathrm{Cl}$ did not contain zero: $(-1.73 ;-0.16))$.

\section{Discussion}

We used a self-report instrument to assess patients' treatment attribution towards either psychotherapy or pharmacological treatment for depression. The instrument was a modification of the instrument constructed by Basoglu et al. (1994), adapted to depression and to represent not only medication but also psychological treatment. The four components of the instrument explained $72.43 \%$ of the variance, and were labelled: (1) belief in tablets; (2) belief in coping; (3) credits to self; and (4) indifference. The results of the study indicated that BA and ADM treatment conditions differentially influenced the attribution types. ADM treatment led to relatively stronger beliefs in medication and to stronger indifference compared to BA, whereas BA conduced to relatively stronger beliefs in own coping capabilities and to stronger crediting the self for improvement. It is likely that increased belief in medication was due to improvement of depression symptoms in the ADM condition attributed to the medication participants took, but the higher scores on factor 4 (labelled "indifference") are more difficult to interpret. By hindsight, the label of factor 4 might be wrong, and for instance "unconditional preference for medication above psychological treatment" is a better description. Perhaps a cognitive dissonance reduction process might have played a role here, with (some) ADM participants placing stronger trust in medication and not in psychological treatment because they were randomized to ADM. In any case, this attribution factor did not appear to be important as a mediator, and can be ignored in that sense. Stronger beliefs in coping and stronger crediting the self for improvement in $B A$ than in ADM is probably directly related to learning new strategies and skills in treatment to cope with problems, and the direct experience that one's own actions lead to overcoming problems and improvement in mood. However, we did not assess the degree of skill acquisition and actual application, so we cannot test this interpretation.

Long-term effects were predicted by attributional factors. Attribution of effects to medication does not seem to play a role, but attribution to increased coping capacities 
and giving credits to the self appear essential. The difference between BA and ADM treatment (with $B A>A D M$ ) in the long-term (at 1 year follow-up) is at least partially mediated by attributions. Thus, we have evidence that the superior long-term effects of $B A$ above $A D M$ are at least partially related to self-attributions, which are higher in BA.

The attribution questionnaire we used contained items that referred to ADM or to psychological treatment, and therefore might have been difficult to rate by participants that did not receive, or had previously received, the treatment referred to. We therefore redid the analyses after all items that either referred to ADM or psychological treatment were deleted. Although now only two factors were found, they were similar in content to the two of the four factors of the primary analysis that turned out to be mediators, and they mediated condition differences in the same way as in the primary analysis. That is, the "lack of belief in coping" factor mediated the condition differences at 1-year on the HRSD, with no mediating role for the other factor. The "credits to the self" factor partially mediated the condition differences on the BDI, with no role for the "lack of belief in coping" factor. This indicates that the main findings of the study are not caused by items that were in content condition-specific. We also explored whether a scale constructed from items that do not refer to psychological treatment related to changes from 3 months to 1-year within the ADM condition, and found evidence for a negative relationship, reflecting that stronger attributions to $A D M$ and weaker attributions to the self and to improved coping are related to poorer long-term effects in the ADM condition, replicating similar associations in the Basoglu et al. (1994) study. Remarkably, a scale constructed from items that do not refer to ADM did not significantly correlate to changes from 3 months to 1 year in the BA condition. This might reflect a restriction of range effect in BA caused by many participants in the BA condition having relatively strong beliefs in their own coping and strong attributions to the self, while at the same time having good immediate and follow-up effects. This indicates that belief in one's own coping and crediting the self for improving are factors that explain differences in long-term effects between AMD and BA, but not so much within BA.

The results of the study showed that clinician-rated depressive symptoms (HRSD) are predicted by "belief in coping", i.e. belief in the effectiveness of specific behaviours and one's capacities to use these behaviours. On the other hand, self-reported depressive symptoms (BDI) were predicted by feeling good about progress and improvement made and attributing this to the self (credits to the self). There are indications that interviews more validly assess objectifiable symptom manifestations and self-reports better capture symptom experience (Hopwood et al., 2008), and factors like severity of depression and neuroticism appear to play a role in discrepancies between the two (Carter et al., 2010; Enns et al., 2000). For example, it has been suggested that more 
severely depressed patients have difficulties in appropriately rating their symptoms (Enns et al., 2000). It is unclear what underlies the specific relationships between attribution type and method of depression severity assessment. Speculations might consider the possibility that the relationships are meaningful, in the sense that attribution to a concrete cause (i.e. skills) relates to more objectifiable depressive symptoms (those that can be rated by an assessor) whereas attribution to a subjective feeling (i.e. crediting oneself and liking oneself better for accomplishing improvement) is related to a more subjective experience of depressive symptoms. Possibly, behavioural skills specifically reduce objectifiable depression symptoms, whereas feeling emotionally good reduces specifically subjective depression symptoms. Clearly, more research is needed to disentangle the associations if they prove to be replicable.

Our results on the influence of attribution to the self and belief in own coping is consistent with Brewin and Antaki (1982) proposition that patients who attribute their improvement to their own efforts will maintain those improvements better than those who attribute gains to external attribution such as medication. Our findings are also in line with the Basoglu et al. (1994) study, in that patients who attributed their improvement to medication and felt less confident in coping without medication had more severe withdrawal symptoms and more loss of gains than those who attributed their improvement to their own efforts during treatment. Biondi and Picardi (2003) findings are also consistent with our results. They found that panic patients with agoraphobia who attributed their improvement to the self showed no relapse, whereas $60 \%$ of those who attributed their improvement to the medication relapsed.

One can speculate about the relationship between attributing progress to the self and one's own coping, and DeRubeis et al.'s (1990) explanation for the superior longterm effects of CBT over ADM treatment. They speculated that in CBT patients learn skills and strategies in coping with life problems which are not learned in ADM. These skills and new strategies may act directly to prevent relapse, but may also lead to increased attributions to own efforts and belief in coping, which might directly guard patients against relapse. To what degree attributions or skills, or both, explain the superior long-term effects of CBT over (discontinued) ADM is an important topic for further research.

A number of limitations should be mentioned with respect to the data presented in this study. Since most patients in Iran have only access to ADM, offering a relatively new psychological treatment for depression could attract especially those who prefer this new treatment available. Most participants in our sample with recurrent MDD had previously received medication treatment, due to accessibility of medication treatment for psychological disorder in Iran. Another limitation is that we used a modified version of the instrument constructed by Basoglu et al. (1994), adapted to depression and to represent not only medication but also psychological treatment, which was not 
validated in a previous study. A problem with our approach was that not all items referred to experiences that participants had in their treatment condition. Although the instruction to participants to respond in such cases by rating what they believed did not seem to have reduced reliability, and an additional analysis based on items that did not suffer from this limitation yielded the same results, future research should improve on this. Moreover, there might be other attribution dimensions that are important, but are not represented in our questionnaire. Thus, the pragmatic approach we choose by modifying Basoglu's questionnaire had its limitations. Given the positive evidence we found for attributions playing a role in long-term effects of BA vs. ADM future studies might consider to improve the assessment of attributions. Still another limitation is that we restricted the analyses to participants with complete data (who happened to be all treatment completers), and dropouts were not included. We are not aware of bootstrap mediation tests for approaches that can handle dropouts with missing data (like mixed regression), but the exclusion of dropouts limits the results to those that complete treatment, whereas attributional processes might also play a role in those who dropout from treatment and/or a treatment study. Lastly, although we speculated that the new skills acquired in BA may lead to relatively stronger beliefs in skills and stronger crediting the self for improvement, we could not test this possibility. Also, whether or not attributions are essential for the long-term effects of BA, or just a reflection (or even an "epiphenomenon") of increased and effective skill use after BA could not be tested with our data.

In conclusion, our study found that long-term effects are predicted by attributional factors. Attribution of effects to medication does not seem to play a role, but attribution to increased coping capacities and giving credits to the self appear essential. In the long-term (at 1 year follow-up), the difference between BA and ADM (with BA > $A D M)$ is at least partially mediated by attributions. Moreover, we have evidence that the superior long-term effects of BA over ADM at least related to self-attributions, which are higher in BA. One interpretation waiting for further study is that offering BA to depressed patients help them learn new skills and strategies in coping with problematic life events, that lead to increased attribution to skills and higher credits to the self, that in turn guard them against a relapse into the difficult condition in their life. Future studies should investigate the effects of attributions for BA and ADM in other clinical settings and cultures. 


\section{References}

American Psychiatric Association. Diagnostic and statistical manual of mental disorders: DSM- IV-TR. American Psychiatric Publishing, Inc., 2000.

American Psychiatric Association. Practice guideline for the treatment of patients with major depressive disorder, third edition. American Psychiatric Publishing, Inc., 2010. Available at: http://www.psych.org/guidelines/mdd2010.

Basoglu M., Marks I.M., Klic C., Brewin C.R., swinson R.P. (1994). Alprazolam and exposure for panic disorder with agoraphobia. Attribution of improvement to medication predicts subsequent relapse. The British Journal of Psychiatry 164(5):652-659.

Biondi, M., \& Picardi, A. (2003). Attribution of improvement to medication and increased risk of relapse of panic disorder with agoraphobia. Psychotherapy and Psychosomatics, 72(2), 110-111.

Brewin, C.R., Antaki, C., (1982). The role of attributions in psychological treatment. In Attributions and Psychological Change (eds C. Antaki \& C. Brewin). London: Academic Press.

Carter, J.D., Frampton, C.M., Mulder, R.T., Luty, S.E. \& Joyce, P.R. (2009). The relationship of demographic, clinical, cognitive and personality variables to the discrepancy between self and clinician rated depression. Journal of Affective Disorders, 124, 202-206.

Cuijpers, P., Straten, A. van, Oppen, P. van, \& Andersson, G., (2008). Are psychological and pharmacologic interventions equally effective in the treatment of adult depressive disorders? A meta-analysis of comparative studies. Journal of Clinical Psychiatry, 69, 1675-1685.

Cuijpers, P., Hollon, S.D., Straten, A. van, Bockting, C., Berking, M., Andersson, G., (2013). Does cognitive behaviour therapy have an enduring effect that is superior to keeping patients on continuation pharmacotherapy? A meta-analysis. BMJ Open 2013;3:e002542. doi:10.1136/bmjopen-2012-002542

DeRubeis, R. J., Evans, M. D., Hollon, S. D., Garvey, M. J., Grove, W. M., \& Tuason, V. B. (1990). How does cognitive therapy work? Cognitive change and symptom change in cognitive therapy and pharmacotherapy for depression. Journal of Consulting and Clinical Psychology, 58(6), 862.

Dobson, K. S., Hollon, S. D., Dimidjian, S., Schmaling, K. B., Kohlenberg, R. J., Gallop, R. J., \& Jacobson, N. S. (2008). Randomized trial of behavioural activation, cognitive therapy, and antidepressant medication in the prevention of relapse and recurrence in major depression. Journal of Consulting and Clinical Psychology, 76(3), 468.

Enns, M.W., Larsen, D.K., Cox, B.J. (2000). Discrepancies between self and observer ratings of depression: the relationship to demographic, clinical and personality variables. Journal of Affective Disorders, 60, 3341.

Frank, E., Kupfer, D.J., Perel, J.M., cornes, C., Jarrett, D.B., Mallinger,A. G., \&Grochocinski, V. J. (1990). Threeyear outcomes for maintenance therapies in recurrent depression. Archives of General Psychiatry, 47 (12) 1093.

Hayes, A. F., \& Preacher, K. J. (2013). Statistical mediation analysis with a multicategorical independent variable. British Journal of Mathematical and Statistical Psychology, in press.

Hollon, S.D., DeRubeis, R.J., Shelton, R.C., et al. (2005). Prevention of relapse following cognitive therapy versus medication in moderate to severe depression. Archives of General Psychiatry, 62, 417-422.

Hollon, S. D., Thase, M. E., \& Markowitz, J. C. (2002). Treatment and prevention of depression. Psychological Science in the Public Interest, 3(2), 39-77.

Hollon, S. D., DeRubeis, R. J., Shelton, R. C., Amsterdam, J. D., Salomon, R. M., O’Reardon, J. P., Lovett, M. L., Young, P.R., Haman, K. L., Freeman, B.R., \& Gallop, R. (2005). Prevention of relapse following cognitive therapy vs medications in moderate to severe depression. Archives of General Psychiatry, 62 (4), 417422 . 
Hopwood, C.J., Morey, L.C., Edelen, M.O., Shea, M.T., Grilo, C.M., Sanislow, C.A., McGlashan, T.H., Daversa, M.T., Gunderson, J.G., Zanarini, M.C., Markowitz, J.C., Skodol, A.E. (2008). A comparison of interview and selfreport methods for the assessment of borderline personality disorder criteria. Psychological Assessment, 20, 81-85.

Imel, Z.E., Malterer, M.B., McKay, K.M. et al. (2008). A meta-analysis of psychotherapy and medication in unipolar depression and dysthymia. Journal of Affective Disorders, 110, 197-206.

Kessler, R. C., Berglund, P., Demler, O., Jin, R., Koretz, D., Merikangas, K. R., . . Wang, P. S. (2003). Lifetime prevalence and ago of onset distribution of DSM-IV disorders in the National Comorbidity Survey Replication (NCS-R). Journal of the American Medical Association, 289, 3095-3105. doi:10.1001/jama.289.23.3095

Koehle, E., Brown, E. \& Haneuse, S.J.P.A (2009). On the assessment of Monte Carlo erro in simulation-based statistical analyses. The American Statistician, 63, 155-162. doi:10.1198/tast.2009.0030.

Moradveisi, L., Huibers, M.J.H., Renner, F., Arasteh, M. \& Arntz, A. (2013). Behavioural Activation and Antidepressant Medication for depression in Iran: a Randomized Trial. British Journal of Psychiatry, 202 (3), 204-211.

Scott, J. A. N., Paykel, E., Morriss, R., Bentall, R., Kinderman, P., Johnson, T., Rosemary, A., \& Hayhurst, H. (2006). Cognitive-behavioural therapy for severe and recurrent bipolar disorders Randomised controlled trial. The British Journal of Psychiatry, 188(4), 313-320.

Strunk, D. R., DeRubeis, R. J., Chiu, A. W., \& Alvarez, J. (2007). Patients' competence in and performance of cognitive therapy skills: relation to the reduction of relapse risk following treatment for depression. Journal of Consulting and Clinical Psychology, 75 (4), 523.

Paykel, E.S., Scott, J., Cornwall, P.L., Abbott, R., Crane, C., Pope, M., Johnson, A.L. (2005). Duration of relapse prevention after cognitive therapy in residual depression: follow-up of controlled trial. Psychological Medicine, 35(1), 59-68.

Preacher, K. J., \& Hayes, A. F. (2004). SPSS and SAS procedures for estimating indirect effects in multiple mediator models. Behaviour Research Methods, Instruments, and Computers, 37, 717-731. 

Chapter 6

General Discussion 

The current dissertation aimed to compare the effectiveness of behavioural activation (BA) and treatment as usual (antidepressant medication (ADM)) for Major Depressive Disorder (MDD) in routine clinical practice in Iran. Depression relates to an extensive domain of mental health problems specified by the lack of a positive affect (a loss of interest and enjoyment in ordinary things and experiences), low mood and a range of related emotional, cognitive, physical and behavioural symptoms (Lewinsohn et al., 2000). In addition to the subjective suffering experienced by those who are depressed, the influence on social and occupational functioning, physical health and mortality is large. Depressive disorders bring about a greater decrease in health state than major chronic physical illnesses like angina, arthritis, asthma, and diabetes (Moussavi et al., 2007).

BA treatment is based on the behavioural component of cognitive behavioural therapy (CBT) for treating major depression (Beck et al., 1979). In BA treatment, interventions are strictly behavioural and specific cognitive techniques are prohibited. BA therapists focus on participants' behaviours and the environmental context in which these behaviours occur. Using activity charts to schedule participant's activities, acting according to goals and not to feelings, and monitoring the relationship between activity and mood are some important techniques in BA treatment. Finding and breaking down the pattern of avoidance is vital in BA. BA therapists consider rumination as behaviour and address it with behavioural techniques rather than exploring or challenging the contents of ruminative thoughts.

Jacobson et al. (1996) conducted the first RCT on BA, and found that BA was as effective as a full CBT package in treating depression. In the subsequent study by the same research group, Dimidjian et al. (2006) compared BA with CBT and ADM. The results showed that $B A$ was as effective as $A D M$, and even outperformed $C B T$ in participants with severe depression. A study by Ekers et al. (2011) compared BA (delivered by nurse practitioners) with treatment as usual in a routine clinical setting and found BA to be superior to treatment as usual.

The studies in the current dissertation focused on the effectiveness of BA compared to ADM, the effects of comorbidity of personality disorder on depression treatment, the effects of patients' preference/attitudes towards psychotherapy and ADM, and the influence of patients' attributions of the immediate effects of depression treatment on long-term effectiveness of BA and ADM. The main study examined whether BA is more effective than ADM in the treatment of MDD (chapter 2). The second study concerned the influence of comorbid personality disorder on the effects of $B A$ vs. ADM for MDD (chapter 3). Chapter 4 tested the influence of patients' preference/attitude towards psychotherapy and ADM on the treatment of MDD. The fourth and the final study was about the influence of patients' attributions of the immediate effects of depression treatment on long-term effectiveness of BA and ADM (chapter 5). 
This discussion section is organized as follows. The first subsection revolves around the question how BA compares to ADM as treatment for depressed people, and in which treatment dropout of the patients is less. The second subsection presents the influence of comorbid personality disorder on the effects of BA and ADM as treatments for MDD. We also discuss whether depressed patients comorbid with personality disorder respond to $B A$ and $A D M$ similarly to those without comorbid personality disorder. The third subsection describes the results of the influence of patients' preference/attitude towards psychotherapy and ADM on the treatment of MDD. This subsection also reviews whether those patients who received $A D M$ and who at the same time had a low preference for or negative attitude towards ADM had a higher chance to drop out of treatment than those without such a preference/attitude. The fourth subsection presents the findings of the influence of patients' attributions of the immediate effects of depression treatment on long-term effectiveness of BA and ADM. We discuss whether attribution of treatment effects to the self predicts long-term effects of depression treatment and whether attribution of treatment effects to the self mediates the longterm differences between BA and ADM. Following discussion of the four main issues addressed in this thesis, the general conclusions are presented, followed by a discussion of the limitations of the studies. Next, the Iranian context in which the study took place, and what it means for the study, and for the effectiveness and suitability of BA in particular, is discussed. After that implementation possibilities in Iran are discussed. Lastly, future prospects, as well as general clinical and societal implications are discussed.

\section{Effectiveness of behavioural activation or antidepressant medication for depressed people}

Our study compared BA to ADM and the results showed that BA was superior to ADM and even more so in the more severely depressed patients. BA targets the avoidance patterns and rumination in depressed people and may have led to the reduction of depressive symptoms. The lower treatment dropout from BA than from ADM suggests that BA was more acceptable for participants than ADM. The reason for this perhaps was that seeing a psychologist is more acceptable than seeing a psychiatrist, which in Iran is viewed as indicative of mental illness. Among those who completed the study at week 13, remission and response rates for BA were higher than for ADM. After 1-year (at 49 weeks) follow-up, 87 out of 100 participants completed assessment and remission and response rates were higher for BA than for ADM as well.

From a BA viewpoint, the likely reason for relapsing after discontinuation of medication is that depressed patients who are treated with antidepressant and then relapsed, did not change their coping skills. Patterns of avoidance, environmental pun- 
ishment, lack of reinforcement, and depressive rumination might still exist, although their effects on mood might have been temporarily reduced by using antidepressants. In contrast, BA equips individuals with healthy behavioural skills and thus the probability of relapse is reduced. As BA had less dropouts and was also more effective than medication, it might offer a viable alternative to medication, especially for those participants who prefer non-pharmacological treatment. In a country like Iran, accessible treatment for most of the depressed patients is medication. Offering psychological treatment like BA attracted more people and it should be considered as a limitation of our study. Our results are in line with the findings of three earlier trials (Jacobson et al., 1996; Dimidjian et al., 2006; Ekers et al., 2011).

BA's relatively simple techniques and strategies can be learned by non-expert mental health professionals (Ekers, 2011) and conducted in all clinical settings. The finding of our study suggests that other mental health professionals with minimum training could disseminate BA techniques. Taken together with the superior effects in the subgroup of patients with more severe depression, it pleads for dissemination in other routine clinical setting around the globe.

\section{The influence of comorbid personality disorder on the effects of behavioural activation vs. antidepressant medication for major depressive disorder}

Our second study investigated the influence of comorbid personality disorder on the effects of BA vs. ADM for MDD. The findings of the study showed that participants with comorbid PD had higher scores on BDI and HRSD at baseline and throughout the study than participants without comorbid PD. In the acute phase of treatment, both groups responded equally well to the short treatment ( 3 months treatment). After one-year follow-up, this parallel development over time was still apparent. Non-significant three-way interactions indicate that PD did not moderate the difference between treatment conditions. We also repeated the analyses for PD-trait sum score and the findings were the same: PD-traits were associated with higher depressive symptom scores from baseline on throughout the study, but not with a reduced treatment effect. However, those participants with comorbid PD had higher dropout of the treatment than those without PD.

From the exploration of the effects of the three cluster scores (A-B-C cluster), we did not find evidence for moderating effects of cluster scores on treatment differences. Furthermore, we found that cluster-C PD-traits were associated with generally higher levels of depression over the trial, whereas cluster-A and $B$ traits did not have this association. For the BDI, we found that cluster-A PD-traits were associated with a poorer treatment response over time, for both BA and ADM. These results should be interpreted with caution because they were not found on the HRSD. Our results devi- 
ate from those found by Fournier et al. (2008) that Cluster-B PD-pathology was responsible for the moderation of treatment effects.

The findings are consistent with Mulder (2002), Kool et al. (2005), and De Bolle et al. (2010). They concluded that the general PD pathology does not have an effect on treatment outcome. The results are in contrast to Newton-Howes's review (2006). However, baseline severity was not taken into account in this meta-analysis, so it cannot be excluded that that the PD effects on depression scores found at follow-up in fact reflect differences already present at baseline (Dreessen \& Arntz, 1998).

\section{The influence of patients' preference/attitude towards psychotherapy and antidepressant medication on the treatment of major depressive disorder}

Our third study investigated the influence of patients' preference/attitude towards psychotherapy and ADM on the treatment of MDD. More studies were conducted about the influence of patients' preferences on outcome and dropout for ADM but less for psychological treatment. The results of our study showed that participants with a lower ADM preference/attitude score had a higher chance to drop out from the ADM treatment condition. Those participants with a higher psychological preference/attitude score had also a higher chance to drop out from ADM condition. Dropout from BA condition was not affected by preference/attitude. Thus, those who preferred psychological treatment but received ADM had a higher chance to drop out from treatment, but the equivalent mismatch was not associated with dropout from BA. Three-way preference/attitude psychological treatment $\times$ time (squared) $\times$ condition interactions for HRSD showed that preference/attitude psychological treatment moderated the difference between treatment conditions after three-months acute treatment but this difference disappeared after one-year follow-up.

When controlled for treatment preference/attitude, the main outcomes of our RCT maintained stable. Dropout from ADM was higher than in the BA condition and after controlling for ADM preference/attitude this effect remained significant. Our findings on the influence of preference on dropout are in line with Van Schaik et al. (2004), Schulberg et al. (1996), and Raue et al. (2009). Our study found that the differences between BA and ADM in outcome as assessed with the HRSD was moderated by preference are consistent with four previous studies reporting the influence of preference on outcome (Kocsis et al., 2009; Mergl et al., 2011; Patricia et al., 2005; Steidtmann et al., 2012), but in contrast to the seven studies that did not find such influences (Bedi et al., 2000; Dunlop et al., 2012; Kwan et al., 2010; Laykin et al., 2007; Raue et al., 2009; Van et al., 2009; Ward et al., 2000).

In this study, most participants preferred psychological treatment over ADM. One explanation for this preference is having had a disappointing previous experience with 
ADM before entering the study. Another explanation is that providing the relatively new psychological treatment attracted more participants with low ADM preference and/or high BA preference to the study.

In conclusion, our study found that those participants who received ADM and at the same time had a low preference for or negative attitude towards ADM had a higher chance to drop out of than those participants without such a preference/attitude. The fact that dropout from BA was not influenced by preference/attitude pleads for its high acceptability. Overall, taking into account participants' preference/attitude might improve treatment retention and initial response. Investigating the effect of preference/attitude for BA and ADM in other clinical settings is recommended for future studies.

\section{The influence of patients' attributions of the immediate effects of depression} treatment on long-term effectiveness of behavioural activation and antidepressant medication

Previous studies so far concentrated on the influence of attributions to medication for anxiety disorders. Our study investigated the effects of patients' attributions after acute treatment on the long-term outcome of antidepressants and psychological treatment (BA). The findings of the study showed that BA and ADM treatment conditions affected attribution types differentially. Participants in ADM condition indicated relatively stronger belief in medication and to stronger indifference compared to BA, while those in BA condition displayed relatively stronger belief in own coping capabilities and stronger crediting the self for reducing depression symptoms. Participants in BA learnt strategies and skills that helped them to cope with problems and the direct experience that one's own actions lead to overcoming problems and consequential improvement in mood probably resulted in a stronger belief in coping and stronger crediting the self for improvement.

The findings of the study indicated that objectifiable depressive symptoms (HRSD) were predicted by "belief in coping", that is, belief in the effectiveness of given behaviours and one's capabilities to use these behaviours. Therefore, this belief was associated with a more objective variable (behaviour). However, subjective symptoms (BDI) were predicted by feeling good for the improvement made and attributing this gain to the self (credits to the self). Perhaps then the results of the study indicate that behavioural skills specifically reduce objective depressive symptoms, while feeling emotionally good lessen subjective depression symptoms.

Long-term effects are predicted by attributional factors. In the study, attribution of effects to medication does not appear to have a role, but attribution to coping ca- 
pabilities and giving credits to the self seems fundamental. In the long term (at 1 year follow-up), the difference between BA and ADM treatment conditions is at least partially mediated by attributions. Therefore, we can infer that the superior long-term effects of BA over ADM are at least partially associated with self-attributions, which are higher in BA.

Our findings on the influence of attribution to the self and belief in one's own coping is in line with Brewin and Antaki (1982) suggestion that participants who attribute their gains to their own efforts will maintain those gains better than those who attribute improvement to external attribution such as medication. The results of the study is also consistent with Basoglu et al. (1994) study, in that participants who attributed their improvement to medication and felt less confident in coping without medication had more severe withdrawal symptoms than those who attributed their gains to their own efforts.

In conclusion, our study found that attribution to increased coping capabilities and giving credits to the self seem essential, while attribution of effects to medication does not appear to have such a role. The difference between BA and ADM treatment conditions in the long run (at 1 year follow-up) is at least partially mediated by attributions (BA > ADM).

\section{General conclusion}

Overall, from the findings of the four studies in this dissertation we conclude that BA treatment could be conducted in clinical settings for those diagnosed with MDD. Our study was conducted in a setting where ADM was the standard treatment for MDD and most participants had been treated with ADM previously before entering to the study. The results confirmed that BA is a viable alternative for ADM. Most participants were satisfied with results of the BA treatment. With regard to participating of patients comorbid with personality disorder in the study, BA was better in improving symptoms in patients but this effect was not influenced for those with comorbid PD. The general conclusion is that comorbid PD pathology is related to higher depression severity, especially for cluster-C PD, but not with less response to treatment. Concerning the patients' preference/attitude towards depression treatment, we conclude that patients' preference/attitude influenced dropout from ADM and moderated the short-term difference in effectiveness between BA and ADM. Concerning the influence of patients' attributions of the immediate effects of depression treatment on long-term effectiveness of behavioural activation and antidepressant medication, the general conclusion is that attribution to increased coping capacities and giving credits to the self appear highly important for the long-term effects. The difference between BA and ADM in the long-term (after 1-year follow-up) is at least partially mediated by attributions. 


\section{Limitation of the studies}

A number of limitations should be considered for the studies in this dissertation. First, BA therapists were not trained by behavioural activation experts and this might have led to suboptimal application of the behavioural activation techniques. The dropout rate in ADM treatment condition was relatively high and this could have influenced the results. Third, participants in ADM condition after three month of treatment had to pay for ADM which might have contributed to discontinuation. Fourth, our prescribed medication for ADM participants was sertraline and in the case of non-response, we did not change it. However, this was the same for the BA. Fifth, due to financial constraint, we did not independently assess treatment integrity and reliability checks of the HRSD interviews. Seventh, BA treatment was a relatively new treatment and actually attracted more participants than ADM which might have biased the sample selection. Eight, the absence of a control group or placebo condition is another limitation. Finally, the majority of our sample was female and although this reflects clinical practice in Iran, it limits generalizability to male patients. Further studies into non-Western male samples are suggested.

\section{Reflections on the influence of the context of Iranian culture}

As we discussed in chapter 2, most Iranian MDD patients are referred to psychiatrists for treatment. Antidepressant medication is the first choice of psychiatrists for treating patients with MDD. Most of the patients who entered into our study had previously undergone medication treatment. Due to the limited number of psychologists in Iran, the most accessible choice for treating psychological disorders is medication. The new (at least in Iran) psychological treatment for MDD led to more participants with positive results than medication. However, this result should be interpreted in the Iranian context. Most of the participants had severe avoidance behaviours and the techniques and skills taught in BA seemed highly suitable to help these avoidant patients solve their problems and equip themselves for the future difficulties. This may be the main reason that our BA treatment displayed good results, and why BA did better than ADM. Why is avoidance such a prominent problem in Iranian culture? In the view of the present author, the traditional culture of Iran teaches children at home or at school up to university to be polite and silent in any situation because it is sign of maturation. Iranian children are taught that they do not have the right to protest against older people, even in a polite way, or ask others that they change actions or behaviours that bother them. As they grow up, Iranian people learn to avoid assertive behaviours even though they know that are useful for their life. Thereby Iran people do not learn how to cope with situations that call for assertiveness. As a psychologist who 
conducted this study, I learned that most avoidance behaviours of depressed people trace back to childhood learning. BA treatment however can detect deficit behavioural repertoires, and teach and equip patients with new adaptive behaviours. Thus, the results of the present project should especially encourage mental health policy makers and mental health professionals in Iran and other similar cultures to consider nonpharmaceutical treatments for psychological disorders and train more counsellors, psychologists and nurses in treatments like BA. Future research can clarify to what degree the results of our study depend on the specific Iranian context.

\section{Dissemination possibilities in Iran}

When I came back to Iran, I presented the results of my study to graduate students of the Faculty of Psychology, Science and Research Branch, Azad University, Kurdistan. Most of these students expressed their interest in behavioural activation treatment for treating MDD. They asked me to teach BA to them. Subsequently, I taught BA to twenty-two M.A graduate students during four days consecutively. All participants in the group expressed their interest and willingness to do BA with their MDD patients. The likely reason for their interest in BA treatment is the familiarity of the group with cognitive therapy and interpersonal therapy in treatment of depression. Before I taught BA skills and techniques, most of them had already discussed the possibility that changing beliefs and thoughts is for some depressed patients more difficult than changing behaviours. BA treatment was positively received as it matched the idea that behavioural change would fit the needs and possibilities of many Iranian patients better than cognitive or interpersonal change. The other reason for the positive response to $B A$ is that offering $B A$ is simple and doable for inexperienced counsellors and psychologists.

After six months, I had a final review session with 18 of the graduate students. Approximately 13 of them worked in mental health clinics in several cities in the province. They reported that the new BA treatment for MDD patients displayed promising results with their patients. In my personal opinion, BA can become a widely accepted treatment approach for depression in Iranian mental health care. Learning and implementing BA skills and techniques is for most mental health professionals in Iran (including psychologists and counsellors) simpler than cognitive therapy, which is the widely accepted treatment for depression. However, more studies are needed to see whether BA can be implemented on a larger scale in Iran. The important challenge that lies ahead is teaching and training mental health professionals in the skills and techniques of BA. 


\section{Future prospects}

Our results in this dissertation that BA was superior to ADM and more effective in the more severely depressed participants, should be replicated by other groups and in other settings. The effectiveness and cost-effectiveness of BA, ADM, and other psychological treatments such as cognitive therapy, in subsequent trials would be recommended. The other important issue is related to mechanisms of change that are responsible for the superior effects of BA which needs further investigation to understand the causal pathways that lead to recovery with BA and ADM.

As to the second study in this dissertation, it is recommended that further studies include more depressed patients comorbid with PD to investigate the effects of specific PDs on effects of BA or other psychological treatments, since our study had a small number of PD patients. As for the third study future studies might use the preference/attitude questionnaire in other patients and in different clinical settings. Our study was one of the first psychotherapy studies conducted in Iran, and offered a relatively new treatment (BA) that probably attracted more patients with a specific preference, which might have created a selection bias. For the fourth study, we used a modified version of the instrument constructed by Basoglu et al. (1994), adapted to depression and to not only represent medication but also psychological treatment, which was not validated in a previous study. It is likely that there are other important attribution dimensions that were not represented in our questionnaire. Future research is needed to investigate this questionnaire in other clinical settings.

\section{Clinical and societal implications}

The results of our study suggest that Behavioural Activation is a simple and effective treatment for depression that can be easily disseminated to routine clinical settings. Therapists with a minimum of training and supervision delivered BA and it is encouraging for all mental health professionals in the field that results were so positive. BA treatment showed superior effects in the subgroup of participants with more severe depression, which pleads for its dissemination also in clinical settings where more severely depressed patients are seen. Various mental health professionals, including counsellors, psychologists and psychiatric nurses, can deliver this relatively simple treatment. Most patients diagnosed with MDD in Iran will receive antidepressant medications after their first referral to a general practitioner or psychiatrist. The findings of our study demonstrated that BA treatment is at least as effective as ADM and acceptable for depressed patients, even for those that are severely depressed. As to the cost-effectiveness of BA over ADM, we did not do a formal economic evaluation in the 
study, but we calculated the total direct costs for BA and ADM. The results favoured BA.

The results of this dissertation are interested not only for academic community but also for all mental health professionals that help depressed patients regularly. The skills and techniques taught in BA treatment can be learned and practiced in the short term.

The findings of this dissertation are relatively new and promising. As it was the second study around the world other than Washington University that developed BA treatment assessed the effectiveness of BA treatment for depressed patients and displayed good results.

In sum, we conclude that BA treatment can be one of the most effective and costeffective treatments for MDD, relatively easy to disseminate, and with a potentially great societal impact. 


\section{References}

American Psychiatric Association. Practice guidelines for the treatment of patients with major depressive disorder (revision). American Journal of Psychiatry 2000; 157: 1-45.

Basoglu M., Marks I.M., Klic C., Brewin C.R., swinson R.P. (1994). Alprazolam and exposure for panic disorder with agoraphobia. Attribution of improvement to medication predicts subsequent relapse. The British Journal of Psychiatry 164(5):652-659.

Beck, A. T., Rush, A. J., Shaw, B. F., \& Emery, G. (1979). Cognitive Therapy of Depression. New York. Guilford Press.

Bedi, N., LEE, A., HARRISON, G., CHILVERS, C., DEWEY, M., Fielding, K., Miller, P., Gretton, V., Williams,l., Churchil, R., \& DUGGAN, C. (2000). Assessing effectiveness of treatment of depression in primary care Partially randomised preference trial. The British Journal of Psychiatry, 177 (4), 312-318.

Brewin, C.R., Antaki, C., (1982). The role of attributions in psychological treatment. In Attributions and Psychological Change (eds C. Antaki \& C. Brewin). London: Academic Press.

De Bolle, M., De Fruyt, F.,C., Quilty, L., Rolland, J. P., Decuyper, M., Bagby, R. M. (2011). Does personality disorder co-morbidity impact treatment outcome for patients with major depression? a multi-level analysis. Journal of Personality Disorders, 25(1), 15.

Dimidjian, S., Hollon, S. D., Dobson, K. S., Schmaling, K. B., Kohlenberg, R. J., Addis, M. E.,\& Jacobson, N. S. (2006). Randomized trial of behavioural activation, cognitive therapy, and antidepressant medication in the acute treatment of adults with major depression. Journal of Consulting and Clinical Psychology, 74 (4), 658.

Dobson, K. S., Hollon, S. D., Dimidjian, S., Schmaling, K. B., Kohlenberg, R. J., Gallop, R. J., Rizvi, S. L., Gollan, J. K., Dunner, D. L., \& Jacobson, N. S. (2008). Randomized trial of behavioural activation, cognitive therapy, and antidepressant medication in the prevention of relapse and recurrence in major depression. Journal of Consulting and Clinical Psychology, 76 (3), 468.

Dunlop, B. W., Kelley, M. E., Mletzko, T. C., Velasquez, C. M., Craighead, W. E., \& Mayberg, H. S. (2012). Depression beliefs, treatment preference, and outcomes in a randomized trial for major depressive disorder. Journal of Psychiatric Research, 46 (3), 375-381.

Ekers, D., Richards, D., McMillan, D., Bland, J. M., \& Gilbody, S. (2011) Behavioural activation delivered by the non-specialist: phase II randomised controlled trial. British Journal of Psychiatry, 198: 66-72.

Fournier, J. C., DeRubeis, R. J., Shelton, R. C., Gallop, R., Amsterdam, J. D., \& Hollon, S. D. (2008). Antidepressant medications $v$. cognitive therapy in people with depression with or without personality disorder. The British Journal of Psychiatry, 192 (2), 124-129.

Gloaguen, V., Cottraux, J., Cucherat, M., \& Blackburn, I. M. (1998). A meta-analysis of the effects of cognitive therapy in depressed patients. Journal of Affective Disorders, 49 (1), 59-72.

Hollon, S. D., \& Shelton, R. C. (2001). Treatment guidelines for major depressive disorder. Behaviour Therapy, $32(2), 235-258$

Jacobson, N. S., Dobson, K. S., Truax, P. A., Addis, M. E., Koerner, K., Gollan, J. K., Gortner, E., \& Prince, S. E. (1996). A component analysis of cognitive-behavioural treatment for depression. Journal of Consulting and Clinical Psychology, 64(2), 295.

Kocsis, J. H., Leon, A. C., Markowitz, J. C., Manber, R., Arnow, B., Klein, D. N., \& Thase, M. E. (2009). Patient preference as a moderator of outcome for chronic forms of major depressive disorder treated with nefazodone, a cognitive behavioural analysis system of psychotherapy, or there combination. Journal of Clinical Psychiatry, 70 (3), 354-361.

Kool, S., Schoevers, R., de Maat, S., Van, R., Molenaar, P., Vink, A., \& Dekker, J. (2005). Efficacy of pharmacotherapy in depressed patients with and without personality disorders: a systematic review and metaanalysis. Journal of Affective Disorders, 88 (3), 269-278. 
Kwan, B. M., Dimidjian, S., \& Rizvi, S. L. (2010). Treatment preference, engagement, and clinical improvement in pharmacotherapy versus psychotherapy for depression. Behaviour Research and Therapy, 48 (8), 799-804.

Laykin, Y., Gallop, R., Amsterdam, J. D., Shelton, R. C., \& Hollon, S. D. (2007). The relation of patient's preference to outcome in randomized clinical trial. Behaviour Therapy, 38, $209 e 217$.

Lewinsohn, P. M., Rohde, P., Seeley, J. R., Klein, D. N., \& Gotlib, I. H. (2000). Natural course of adolescent major depressive disorder in a community sample: predictors of recurrence in young adults. American Journal of Psychiatry,157(10), 1584-1591.

Lin, P., Campbell, D. G., Chaney, E. F., Liu, C. F., Heagerty, P., Felker, B. L., \& Hedrick, S. C. (2005). The influence of patient preference on depression treatment in primary care. Annals of Behavioral Medicine, 30 (2), 164-173.

Mergl, R., Henkel, V., Algaier, A. K., Kramer, D., Hautzinger, M., Kohnen, R., Hautzinger, M., Kohnen, R., Coyne, J., \& Hegerl, U.,(2011). Are treatment preferences relevant in response to serotonergic antidepressants and cognitive behavioural therapy in depressed primary care patients? Results from a randomized controlled trial including a patients' choice arm. Psychotherapy and Psychosomatics, 80, 39-47.

Moussavi, S., Chatterji, S., Verdes, E., Tandon, A., Patel, V., \& Ustun, B. (2007). Depression, chronic diseases, and decrements in health: results from the World Health Surveys. The Lancet, 370(9590), 851-858.

Mulder, R. T. (2002). Personality pathology and treatment outcome in major depression: a review. American Journal of Psychiatry, 159 (3), 359-371.

Newton-Howes, G., Tyrer, P., \& Johnson, T. (2006). Personality disorder and the outcome of depression: meta-analysis of published studies. British Journal of Psychiatry, 188, 13e20.

Olfson, M., Marcus, S. C., Druss, B., \& Pincus, H. A. (2002). National trends in the use of outpatient psychotherapy. American Journal of Psychiatry, 159 (11), 1914-1920.

Raue, P. J., Schulberg, H. C., Heo, M., Klimstra, S., \& Bruce, M. L. (2009). Patients' depression treatment preferences and initiation, adherence, and outcome: a randomized primary care study. Psychiatric Services (Washington, DC), 60 (3), 337.

Schulberg, H. C., Magruder, K. M., \& deGruy, F. (1996). Major depression in primary medical care practice: Research trends and future priorities. General Hospital Psychiatry, 18(6), 395-406.

Steidtmann, D., Manber, R., Arnow, B. A., Klein, D. N., Markowitz, J. C., Rothbaum, B. O., Michael, E, T., \&Kocsis, J. H. (2012). Patient treatment preference as a predictor of response and attrition in treatment for chronic depression. Depression and Anxiety, 29 (10), 896-905.

Van Schaik, D. J., Klijn, A. F., van Hout, H. P., van Marwijk, H. W., Beekman, A. T., de Haan, M., \& van Dyck, R. (2004). Patients' preferences in the treatment of depressive disorder in primary care. General Hospital Psychiatry,26(3), 184-189.

Van, H. L., Dekker, J., Koelen, J., Kool, S., van Aalst, G., Hendriksen, M., Peen, J., \& Schoevers, R. (2009). Patient preference compared with random allocation in short-term psychodynamic supportive psychotherapy with indicated addition of pharmacotherapy for depression. Psychotherapy Research, 19(2), 205-212.

Ward, E., King, M., Lloyd, M., Bower, P., Sibbald, B., Farrelly, S., Gabbay, M., tarrier, N., \& Addington-Hall, J. (2000). Randomised controlled trial of non-directive counselling, cognitive-behaviour therapy, and usual general practitioner care for patients with depression. I: Clinical effectiveness. British Medical Journal, 321(7273), 1383-1388. 
Valorisation addendum 



\section{Impact of depression on quality of life, health, and society}

Depression is considered by the World Health Organization (WHO) to be the second greatest cause of disability in the world (Murray and Lopez, 1997; Mathers CD, Stein C, Ma Fat D, et al, 2002; WHO, 2004). Depression is described as a chronic disorder and follows a pattern of relapse and remission that is related to illness burdens that falls into two broad categories (Klerman and Weissman, 1992). The first is the burden of illness experienced by the depressed patients, including discomfort, pain or distress, or problems in conducting the activities of daily life. The second is the extensive economic burden that consists of the costs of providing social and health care, loss of productivity and time off work, the burden on caregivers, and loss of wages. Moreover, depression has been regarded as a condition that is "chronic and recurrent in nature, impairs family life, reduces social adjustment, and is a burden on the community" (Klerman and Weissman, 1992).

Depression is associated with an extensive domain of mental health problems and interferes with the experience of positive well-being. Various components of quality of life are influenced by depression. It is quite clear that depression is related to impairment and disabilities in role functioning. Depression can impair social functioning and thereby have a negative influence on patients' life. Thus, by reducing psychological well-being, impairing role functioning and depriving patients of social support, depression may lead to a reduced overall quality of life.

In addition to the subjective suffering experienced by those who are depressed, the impact on social and occupational functioning, physical health and mortality is quite evident. Depressive disorders bring about a greater decrease in health state than major chronic physical illnesses like angina, arthritis, asthma, and diabetes (Moussavi et al, 2007).

Therefore, effective treatment (s) for depression that can be conducted by many mental health professionals around the globe that is cost-effective and has enduring effects for patients is necessary. Moreover, easy implementation and dissemination of the treatment for depression is another issue to be considered. Most patients with MDD in Iran will have access to antidepressants (ADM) when they see a general practitioner or a psychiatrist for their first visit. Thus, ADM are commonly prescribed for depressed patients. The results of our study indicated that BA treatment is at least as effective as ADM and acceptable for depressed patients, even for those patients that are severely depressed. However, the most available treatment for depression is still ADM, although psychological treatments often have higher acceptability and better long-term effects than ADM. 


\section{Access to treatment in various countries in the world and specifically in Iran}

Antidepressant medications are often prescribed for patients with depression. Because of the unavailability of psychotherapies, psychological treatments are not offered in primary care (Van Schaik et al., 2004). There is a lack of specialist mental health care for depression in rural areas, compared to urban areas (Lambert, Agger, \& Hartley, 1999), and especially the availability of psychotherapy is low in rural areas (Fortney, Harman, Xu, \& Dong, 2009). There are vast differences in availability of psychological treatment for mental disorders when Western countries are compared to nonWestern countries. The median rate of psychologists per 100,000 population working in the mental health sector by WHO region is 0.04 for Africa, 1.29 for the Americas, 0.48 for the Eastern Mediterranean, 2.58 for Europe, 0.03 for South East Asia, and 0.00 for the Western Pacific (WHO Mental Health Atlas, 2011).

In Iran, for instance, the usual treatment for depression is ADM and because of the lack of enough mental health professionals, psychological treatments are not available for most patients. In rural area and even in urban areas in Iran the provision of psychological treatments is very limited (WHO-AIMS Report, 2006). Sanandaj for example, where the present study was conducted, has a population of more than 500.000 , but there are only five psychologists available for mental health care. In sum, equipment of mental health professionals with a relatively simple treatment like BA could be beneficial for the improvement of depression and decrease of mental disorders in society.

\section{What are the results of our study for patients and societies worldwide and specifically in Iran?}

The findings of our study indicated that BA is an effective psychological treatment for major depressive disorder. The simplicity to implement BA in clinical settings in comparison to the complexity of the implementation of cognitive behaviour therapy should appeal to the majority of mental health professionals. In our study, BA therapists had a minimum of training and supervision in BA and the results of BA were nevertheless very positive. After the short-term treatment (three months) BA was more effective than antidepressant medication (Sertraline). Moreover, BA treatment had superior effects for the subgroup of patients with more severe symptoms of depression, which calls for its dissemination in clinical settings where more severely patients are seen by clinicians.

The results of our study showed that depressed patients with comorbid personality disorders (PDs) had a higher dropout rate from treatment, even though the superior effect of BA was not influenced by comorbid PD. Among patients who preferred psy- 
chotherapy, but received ADM, dropout from treatment was higher compared to those who preferred ADM. Thus, preference influenced treatment completion in case of ADM. Interestingly, no association between dropout and preference was found in BA. This indicates that BA is a highly acceptable treatment, even for those that initially preferred ADM. Lastly, patients who attributed their improvement more to factors associated with themselves better maintained effects on the long-term. BA was associated with higher attribution of improvement to the self, which helps to prevent relapse. These three additional findings: (1) BA is not less effective in patients with comorbid PDs; (2) preference for ADM does not influence dropout and effectiveness of BA; and (3) BA has a positive effect on attribution of improvement to the self (which is a factor in maintenance of success and prevention of relapse); further plead for implementation of BA around the world.

The findings of BA treatment were positive and promising in the treatment of major depressive disorder in Iranian context and could be disseminated in other clinical settings in Iran and also around the world. BA treatment could be learned and practiced by a majority of psychologists, counsellors, psychiatrists and psychiatric nurses.

\section{Health care costs of depression and cost-effectiveness of BA vs ADM}

In Iran, little research about the social and economic burden of depression has been conducted. However, behavioural activation treatment might be a very cost-effective intervention for depression. Although our study did not include a formal economic evaluation, we calculated that the total direct treatment costs for behavioural activation amounted to $€ 128$ per patient, while the whole direct treatment costs for patients treated with antidepressant medication were $€ 198$ per patient on average, depending on the number of follow-up consultations. A simple index shows the difference between average costs of BA and ADM per patient, and divides this difference by the long-term difference (after 1-year follow-up) in recovery rates. This is the incremental cost-effectiveness ratio (ICER). With the cost difference estimated as $€ 128-€ 198=€-$ 70 per patient, and difference at 1 year in remission rates is .66-.28 $=.38$, the ICER is $70 / .38=-184$. This means that for every extra remitted patient at 1 year, Iranian health care wins $€ 184$ when BA treatment is provided instead of ADM. A full economic analysis would involve estimates of all depression related costs that patients make, whether health care related or not. For instance, health care costs outside the depression treatment (e.g., depressed patients going more often to the GP because of psychosomatic complaints; absence of study and work; alcohol use; etc.) should also be assessed and compared between treatments. Thus, the present ICER estimate is a very simple one, but given the positive clinical effects of BA on short and long term, lower costs in BA compared to ADM treatment in other relevant sectors can be estimated. In 
short, our study indicates that BA, compared to the standard treatment with Sertraline, is a cost-effective treatment, being not only more effective and acceptable to depressed patients, but probably also less costly for health care and society as a whole.

\section{General conclusion}

The current dissertation aimed to compare the effectiveness of behavioural activation and antidepressant medication for Major Depressive Disorder in routine clinical practice in Iran. The findings of our study suggest that behavioural activation is a simple and effective treatment for depression that can be easily disseminated to routine practice settings, similar to what has been demonstrated in Western countries. The fact that the behavioural activation was delivered effectively by therapists with a minimum of training and supervision is very encouraging, and taken together with the superior effects in the subgroup of participants with more severe depression, it speaks for its timely dissemination to other routine practice settings as well. Depressed patients comorbid with PDs were associated with higher dropout. BA was more effective in reducing symptoms in patients, but this effect was not influenced by comorbid PD. Those patients who preferred psychotherapy, but who received ADM treatment were more likely to drop out from ADM. At the same time, no association between dropout and preference was found in BA. Those patients who attributed their improvement more to factors associated with themselves did better in the long-term, also in terms of relapse prevention. Moreover, behavioural activation might be a very cost-effective intervention that could be delivered after a short-term training by psychiatrists, psychologists, counsellors and nurses around the world. 


\section{References}

Fortney, J. C., Harman, J. S., Xu, S., \& Dong, F. (2009). Rural-urban differences in depression care. http://www.wiche.edu/info/publications/FortneyWorking PaperYr3Proj2.pdf. Assessed 17.09.13.

Klerman, G. L., \& Weissman, M. M. (1992). The course, morbidity, and costs of depression. Archives of General Psychiatry, 49 (10), 831-834

Lambert, D., Agger, M., \& Hartley, D. (1999). Service use of rural and urban Medicaid beneficiaries suffering from depression: the role of supply. Journal of Rural Health, 15, 344-355.

Mathers, C. D., Stein, C., Ma Fat, D., Rao, C., Inoue, M., Tomijima, N., Bernard, C., Lopez, A. D., \& Murray, C. J. (2002). Global Burden of Disease 2000: Version 2 methods and results.

Mental Health Atlas. (2011). World Health Organization. http://www.who.int/ about/licensing/copyrig/copyright-form/en/index.html. ISBN 9799241564359.

Moussavi, S., Chatterji, S., Verdes, E., Tandon, A., Patel, V., \& Ustun, B. (2007). Depression, chronic diseases, and decrements in health: results from the World Health Surveys. The Lancet, 370 (9590), 851-858.

Murray, C. J., \& Lopez, A. D. (1997). Alternative projections of mortality and disability by cause 1990-2020: Global Burden of Disease Study. The Lancet, 349 (9064), 1498-1504.

Van Schaik, D. J. F., klijn, A. F. J., Van Hout, H. P. J. V., Van Marwijk, H. W. J., Beekman, A. T. F., De Han, M., Van Dyck, R. (2004). Patients' preference in the treatment of depressive disorder in primary care. General Hospital Psychiatry, 26, 184e189.

WHO. The global burden of disease: 2004 update. Geneva: World Health Organization, 2008.

WHO-AIMS Report on Mental Health System of the Islamic Republic of Iran. (2006). WHO and Ministry of Health and Medical Education, Tehran, the Islamic Republic of Iran. 

Summary 

Depression is associated with an extensive domain of mental health problems such as the lack of positive affect (a loss of interest and enjoyment in ordinary things and experiences), low mood, and a range of related emotional, cognitive, physical and behavioural symptoms. Depressed patients not only experience subjective suffering, but also encounter physical health, social, and occupational functioning problems. Depression causes a greater decrease in health state than chronic physical illnesses like arthritis, asthma, and diabetes.

The studies in this dissertation focused on the effectiveness of behavioural activation (BA) and antidepressant medication (ADM) as treatments for Major Depressive Disorder (MDD); the effects of comorbidity of personality disorder on depression treatment; the effects of patients' preference/attitudes towards psychotherapy and antidepressant medication; and the influence of patients' attributions of the immediate effects of depression treatment on long-term effectiveness of behavioural activation and antidepressant medication.

The main study of the dissertation investigated whether behavioural activation is more effective than antidepressant medication. The second study examined the influence of comorbid personality disorder on the effects of behavioural activation and antidepressant medication for major depressive disorder. The third study tested the influence of patients' preference/attitude towards psychotherapy and antidepressant medication on the treatment of major depressive disorder. The fourth study investigated the influence of patients' attributions of the immediate effects of depression treatment on long-term effectiveness of behavioural and antidepressant medication. Attributions are patients' beliefs about why they improved in therapy. It has been postulated that patients who attribute gains to their own efforts are more likely to sustain those gains compared to those who attribute improvement to external causes such as a drug's activity or a therapist's charisma.

The results of the main study of the dissertation showed that behavioural activation was superior to antidepressant medication (Sertraline), especially for patients with severe depression. Dropout from treatment was lower in behavioural activation compared to antidepressant medication and this pleads for the acceptability of behavioural activation above antidepressant medication among depressed patients. After three months of treatment and at 1-year follow-up, the remission and response rates for the behavioural activation group were higher compared to the antidepressant medication group.

The findings of the second study, the influence of comorbid personality disorder on the effects of behavioural activation vs. antidepressant medication for major depression disorder, indicated that patients with comorbid personality disorder had higher scores on the Beck Depression Inventory and the Hamilton Rating Scale for Depression at baseline and throughout the study compared to participants without 
comorbid personality disorder. After three months of treatment, both treatment groups responded equally well to the treatments and after one-year follow-up, this parallel development over time was still apparent. However, participants with comorbid personality disorder showed higher treatment dropout compared to those without personality disorder.

The findings of the third study on the influence of patients' preference/attitude towards psychotherapy and antidepressant medication on the treatment of major depressive disorder showed that participants who received antidepressant medication and at the same time had a low preference for or a negative attitude towards antidepressant medication had a higher chance to drop out compared to those participants without such a preference/attitude. The fact that dropout from behavioural activation was not influenced by preference/attitude pleads for its high acceptability.

The results of the study on the influence of patients' attributions of the immediate effects of depression treatment on long-term effectiveness of behavioural activation and antidepressant medication showed that behavioural activation and antidepressant medication affected attribution types differentially. Participants in the behavioural activation group showed stronger beliefs in their own capabilities to improve their symptoms of depression. More specifically, those who attributed their improvement to factors associated with themselves, showed less relapse.

\section{General Conclusion}

This dissertation aimed to compare the effectiveness of behavioural activation and antidepressant medication for major depressive disorder in routine clinical settings in Iran. The findings of our study indicated that behavioural activation is an effective treatment for major depressive disorder and can be disseminated in routine clinical settings. The fact that behavioural activation can be easily taught to mental health professionals and the superior effects in the subgroup of people with more severe depression, plead for timely dissemination to other routine clinical settings as well. Depressed participants with comorbid personality pathology had higher treatment dropout. With regard to reducing symptoms in participants, behavioural activation was more effective, but this effect was not influenced by comorbid personality disorder. Those participants who preferred psychosocial treatment, but who received at the same time antidepressant medication treatment were more likely to drop out from the antidepressant medication group. However, no association between dropout and preference was found in the behavioural activation group. Those participants who attributed their improvement to factors associated with themselves did better in the long-term, suggesting that these attributions prevent relapse. Importantly, behavioural activation leads to stronger attributions of this kind than medication. Lastly, behavioural treatment 
might turn out to be a very cost-effective intervention that can be delivered by psychiatrists, psychologist, and other health professionals after a short-term training. 

Acknowledgements 

I would like to express my special appreciation and thanks to my advisors, Professor Dr. Arnoud Arntz and Professor Dr. Marcus Huibers.

Arnoud: you have been a tremendous mentor for me. I would like to thank you for encouraging my research and for allowing me to grow as a researcher. Your advice on both research as well as on my writing have been priceless.

Marcus: you have inspired and encouraging for me all the time. I would like to thank you for helping me to renew my writing style and instilling hope for the future. I would also like to thank my committee members, Prof. Dr. P.E.H.M. Muris (Maastricht University, chairman), Prof. Dr. F.Peeters (Maastricht University, MUMC+), Prof. Dr. A.T. Jansen (Maastricht University), Prof. Dr. C.L.H. Bockting (University of Groningen), and Prof. Dr. W.J.M.J. Cuijpers (VU University) for serving as my committee members.

I would especially like to thank my colleagues in Iran for their contribution to this study. Azad Maroufi, Farzin Rezaei, Marzia Moghadam and Modabber Arasteh for providing antidepressant medication treatment; Farhad Asghari and Reza Mozhdehi for providing behavioural activation; Yahya Yarahmadi for conducting baseline diagnostic interviews; Farshid Rastgari and Ebrahim Hosseini for conducting HRSD interviews; Pedram Andalibi provided Sertraline in his drugstore free of charge. Jafar Mirzaei and Mohsen Ghadermarzi coordinated the preparation of the treatment settings and Fardin Gharibi supported and coordinated the study. Ahmad Sohrabi instructed the authors how to use the Iranian SCID-I

I would especially like to thank all the staff at the Kurdistan University of Medical Sciences, Ghods Psychiatric Hospital and Students' Mental Health Clinic in Sanandaj and all the patients participated in this study. All of you have been there to support me when I recruited patients and collected data for my Ph.D. thesis.

My special thanks to Fritz Renner, who helped me analyse the data and encouraged me during my thesis. I would like to express my deepest appreciation to all my colleagues at the Faculty of Psychology and Neuroscience at Maastricht University who provided me support during my stay at the faculty, Glynis, Lieke, Melanie, Delena, Manuela, Linda, and Jessica.

I would like also thank Angela Verweij and Lindy Dullens for helping me during my stay in Maastricht.

A special thanks to my family. Words cannot express how grateful I am to my mother and father for all of the sacrifices that you have made on my behalf. I would also like to thank all of my friends who supported me in writing, and motivated me to strive to- 
wards my goal. At the end, I would like to express appreciation to my beloved Boshiakam who was always my support in the moments when there was no one to answer my queries. 
Curriculum vitae 



\section{Biography}

Latif Moradveisi was born June 22, 1977 in Marivan, Kurdistan, Iran. After completing high school in 1995, he studied psychology at Beheshti University in Tehran. He obtained his master's diploma in psychology in June 2001. Between October 2001 to October 2008 he worked as a psychologist in a mental health clinic in Sanandaj, Iran. From November 2008 to 2014, he was an off-campus PhD student at the department of Clinical Psychological Science, Maastricht University, the Netherlands. From November 2009 to September 2011 he conducted a randomized clinical trial comparing behavioural activation and treatment as usual in the acute treatment of major depressive disorder in Sanandaj, in collaboration with Ghods Psychiatric Hospital and the Mental Health Clinic in Sanandaj. The studies that were conducted during this period are presented in this dissertation.

\section{Publications}

Moradveisi, L., Huibers, M. J., \& Arntz, A. (2014). The influence of patients' attributions of the immediate effects of depression treatment on long term effectiveness of behavioural activation and antidepressant medication. Journal of Behavior Research and Therapy, in revision.

Moradveisi, L., Huibers, M., Renner, F., \& Arntz, A. (2014). The influence of patients' preference/attitude towards psychotherapy and antidepressant medication on the treatment of major depressive disorder. Journal of Behaviour Therapy and Experimental Psychiatry, 45(1), 170-177.

Moradveisi, L., Huibers, M. J., Renner, F., Arasteh, M., \& Arntz, A. (2013). The influence of comorbid personality disorder on the effects of behavioural activation vs. antidepressant medication for major depressive disorder: results from a randomized trial in Iran. Behaviour Research and Therapy, 51, 499-506.

Moradveisi, L., Huibers, M. J., Renner, F., Arasteh, M., \& Arntz, A. (2013). Behavioural activation v. antidepressant medication for treating depression in Iran: randomised trial. The British Journal of Psychiatry, 202(3), 204-211. 


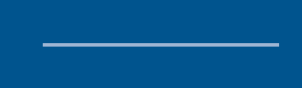

